ADVANCED STEEL CONSTRUCTION

An International Journal

Volume 9 Number 1

March 2013

CONTENTS

Technical Papers

Stability Behavior of Lightweight Aggregate Concrete Filled Steel Tubular Columns under Axial Compression

Bohai Ji, Zhongqiu Fu, Tao Qu and Manman Wang

Behaviour of SFRC Filled Steel Tube Columns under Axial Load

Soner Guler, Erol Lale and Metin Aydogan

Behaviour Factor Evaluation of Sheathed Cold-Formed Steel Structures

Luigi Fiorino, Ornella Iuorio and Raffaele Landolfo

Investigation on Temperature Distribution and Thermal Behavior of

Large Span Steel Structures Considering Solar Radiation

Hongbo Liu, Zhihua Chen and Ting Zhou

Evaluation of Welded Flange Plate Connections between Steel Beams and Box Columns M. Gholami, M. Tehranizadeh and A. Deylami

System Reliability Assessment of 3D Steel Frames Designed per AISC LRFD Specification S. Zhang and $W$. Zhou

Copyright $\odot 2013$ by

The Hong Kong Institute of Steel Construction

Website: http://www.hkisc.org

ISSN 1816-112X

Science Citation Index Expanded, Materials Science Citation Index and ISI Alerting

Cover: The Tamar Headquarters of Hong Kong SAR Government

Top five floors spanning over the two mega cores are made of composite trusses with concrete infilled

rectangular sections and designed by second-order direct analysis

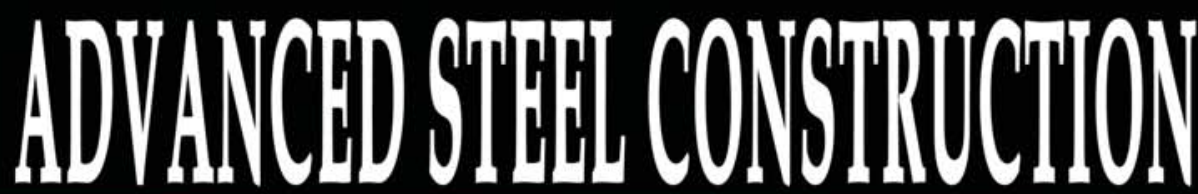

an International ]ounal ISSN 1816-112X

Volume 9 Number 1

March 2013

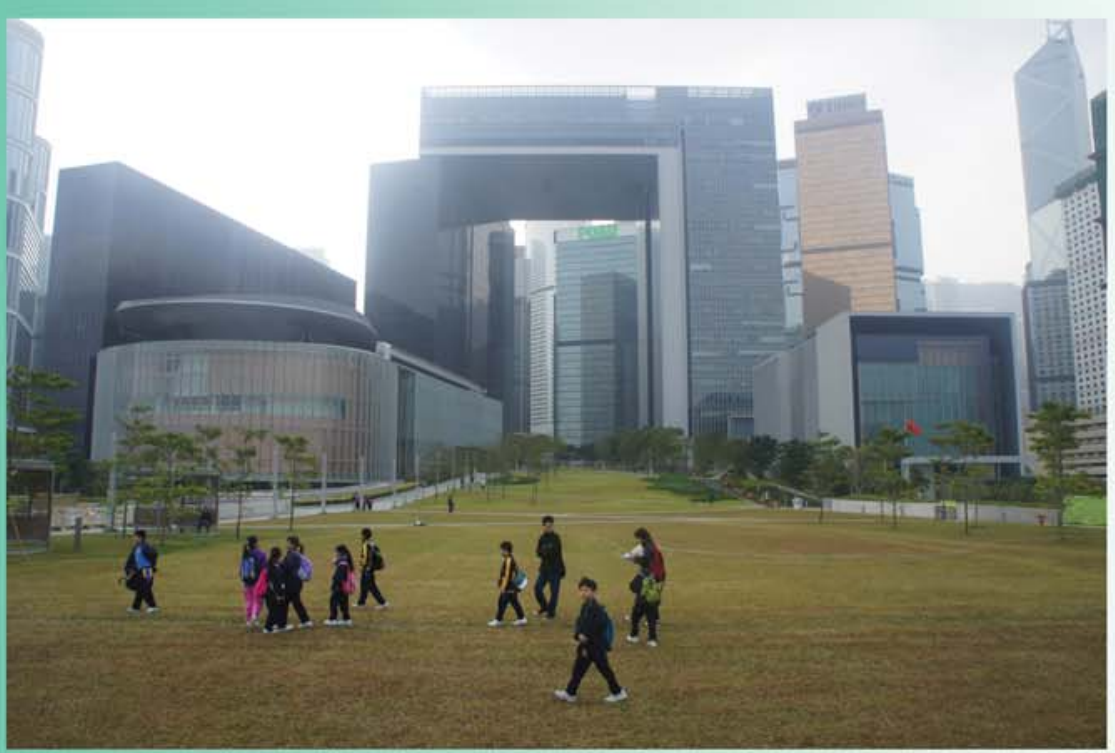

Editors-in-Chief

S.L. Chan, The Hong Kong Polytechnic University, Hong Kong

W.F. Chen, University of Hawaii at Manoa, USA

R. Zandonini, Trento University, Italy 


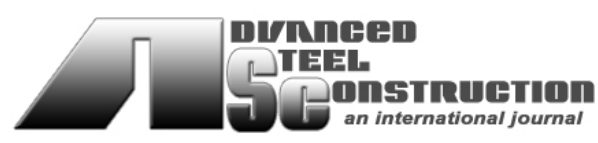

ISSN 1816-112X

Science Citation Index Expanded, Materials Science Citation Index and ISI Alerting

\section{EDITORS-IN-CHIEF}

Asian Pacific, African and organizing Editor

S.L. Chan

The Hong Kong Polyt. Univ., Hong Kong

American Editor
W.F. Chen
Univ. of Hawaii at Manoa, USA

\section{European Editor}

R. Zandonini

Trento Univ., Italy

\section{INTERNATIONAL EDITORIAL BOARD}

F.G. Albermani

The Univ. of Queensland, Australia

I. Burgess

Univ. of Sheffield, UK

F.S.K. Bijlaard

Delft Univ. of Technology, The Netherlands

R. Bjorhovde

The Bjorhovde Group, USA

M.A. Bradford

The Univ. of New South Wales, Australia

D. Camotim

Technical Univ. of Lisbon, Portugal

C.M. Chan

Hong Kong Univ. of Science \& Technology, Hong Kong

T.H.T. Chan

Queensland Univ. of Technology, Australia

S.P. Chiew

Nanyang Technological Univ., Singapore

W.K. Chow

The Hong Kong Polyt. Univ., Hong Kong

K.F. Chung

The Hong Kong Polyt. Univ., Hong Kong

G.G. Deierlein

Stanford Univ., California, USA

L. Dezi

Univ. of Ancona, Italy

D. Dubina

The Politehnica Univ. of Timosoara, Romania

\section{Advanced Steel \\ Construction an international journal}

R. Greine

Technical Univ. of Graz, Austria

L. Gardner

Imperial College of Science, Technology and

Medicine, UK

L.H. Han

Tsinghua Univ. China

S. Herion

University of Karlsruhe, Germany

G.W.M. Ho

Ove Arup \& Partners Hong Kong Ltd., Hong Kong

B.A. Izzuddin

Imperial College of Science, Technology and

Medicine, UK

J.P. Jaspart

Univ. of Liege, Belgium

S. A. Jayachandran

IIT Madras, Chennai, India

S.E. Kim

Sejong University, South Korea

S. Kitipornchai

City Univ. of Hong Kong, Hong Kong

D. Lam

Univ. of Bradford, UK

G.Q. Li

Tongji Univ., China

J.Y.R. Liew

National Univ. of Singapore, Singapore

E.M. Lui

Syracuse Univ., USA

Y.L. Mo

Univ. of Houston, USA

J.P. Muzeau

CUST, Clermont Ferrand, France

D.A. Nethercot

Imperial College of Science, Technology and

Medicine, UK

Y.Q. Ni

The Hong Kong Polyt. Univ., Hong Kong

D.J. Oehlers

The Univ. of Adelaide, Australia

K. Rasmussen

The Univ. of Sydney, Australia

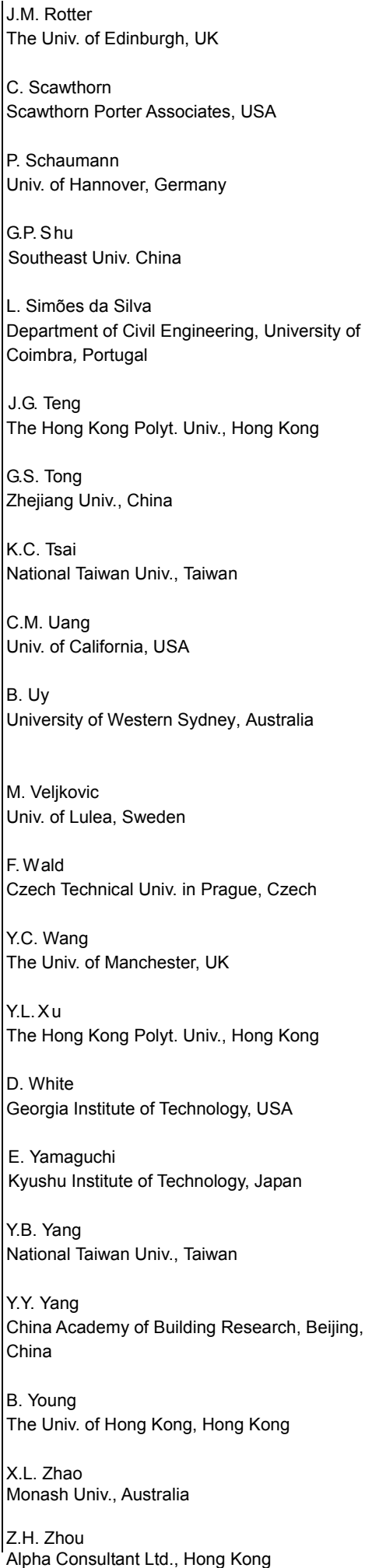




\begin{tabular}{ll}
\hline \hline & General Information \\
& Advanced Steel Construction, an international journal \\
\hline \hline Aims and scope
\end{tabular}

\section{Aims and scope}

The International Journal of Advanced Steel Construction provides a platform for the publication and rapid dissemination of ori ginal and up-to-date research and tec hnological developments in steel c onstruction, design and anal ysis. Scope of research $p$ apers published in this journal includes but is not limite $d$ to theor etical and expe rimental research on elements, assemblages, sy stems, material, design philosophy and codification, standards, fabrication, projects of innov ative nature an d computer tech niques. The journal is specifically $t$ ailored to channel the e xchange of tec hnological know-ho $w$ bet ween $r$ esearchers an d practitioners. Contributions from all aspects related to the recent developments of advanced steel construction are welcome.

\section{Instructions to authors}

Submission of the manuscript. Authors may submit double-spaced manuscripts preferably in MS Word by emailing to one of the chief editors as follows for arrangement of review. Alternatively papers can be submitted on a diskette to one of the chief editors.

Asian Pacific, African and organizing editor: Professor S.L. Chan, Email: ceslchan@polyu.edu.hk

American editor :

European editor:

Professor S.L. Chan, Email: ceslchan@polyu.edu

Professor R. Zandonini, Email: riccardo_zandonini@ing.unitn.it

All manuscripts submitted to the journal are recommended to accompany with a li st of four potential reviewers suggested by the author(s). This list should include the complete name, add ress, telephone and fax num bers, em ail address, and at least five keywords that identify the expertise of each reviewer. This scheme will improve the process of review.

Style of manuscript

General. Author(s) should provide full postal and email addresses and fax number for correspondence. The manuscript including abstract, keywords, references, figures and tables should be in English with pages numbered and typed with double line spacing on single side of A4 or letter-sized paper. The front page of the article should contain:

a) a short title (reflecting the content of the paper);

b) all the name(s) and postal and email addresses of author(s) specifying the author to whom correspondence and proofs should be sent;

c) an abstract of $100-200$ words; and

d) 5 to 8 keywords.

The paper must contain an introduction and a conclusion. The length of paper should not exceed 25 journal pages (approximately 15,000 words equivalents).

Tables and figures. Tables and figures including photographs should be typed, numbered consecutively in Arabic numerals and with short titles. They should be referred in the text as Figure 1, Table 2, etc. Originally drawn figures and photographs should be provided in a form suitable for photographic reproduction and reduction in the journal.

Mathematical expressions and units. The Systeme Internationale (SI) should be followed whenever possible. The numbers identifying the displayed mathematical expression should be referred to in the text as Eq. (1), Eq. (2).

References. References to published literature should be referred in the text, in the order of citation with Arabic numerals, by the last name(s) of the author(s) (e.g. Zandonini and Zanon [3]) or if more than three authors (e.g. Zandonini et al. [4]). References should be in English $w$ ith occasional allow ance of 1-2 e xceptional referenc es in local lang uages and $r$ eflect the curren $t$ state-of-technology. Journal titles should be abbreviated in the style of the Word List of Scientific Periodicals. References should be cited in the following style $[1,2,3]$.

Journal: [1] Chen, W.F. and Kishi, N., "Semi- rigid Steel Beam-to-column Connections, Data Base and Modellin g", Journal of Structural Engineering, ASCE, 1989, Vol. 115, No. 1, pp. 105-119.

Book: [2] Chan, S.L. and Chui, P.P.T., "Non-linear Static and Cyclic Analysis of Semi-rigid Steel Frames", Elsevier Science, 2000 .

Proceedings: [3] Zandonini, R. a nd Zanon, P., "Experimental Analy sis of S teel Beams with Semi -rigid Joint s", Proceedings of International Conference on Advances in Steel Structures, Hong Kong, 1996, Vol. 1, pp. 356-364.

Proofs. Proof will be sent to the c orresponding author to correct an y typesetting errors. Alternations to the original manuscript at this stage will not be accepted. Proofs should be returned within 48 hours of receipt by Express Mail, Fax or Email.

Copyright. Submission of an article to "Advanced Steel Construction" implies that it presents the original and unpublished work, and not under consideration for publication nor published elsewhere. On acceptance of a manuscript submitted, the copyright thereof is transferred to the publisher $b y$ the Transfer of $C$ opyright Agreement and upon the acceptance of publication for the $p$ apers, the corresponding author must sign the form for Transfer of Copyright.

Permission. Quoting from this journal is granted provided that the customary acknowledgement is given to the source.

Page charge and Reprints. There will be no page charges if the length of paper is within the limit of 25 journal pages. A total of 30 free offprints will be supplied free of charge to the corresponding author. Purchasing orders for additional offprints can be made on order forms which will be sent to the authors. These instructions can be obtained at the Hong Kong Institute of Steel Construction, Journal website: http://www.hkisc.org

The International Journal of Advanced Steel Construction is published quarterly by non-profit making learnt society, The Hong Kong Institute of Steel Construction, c/o Department of Civil \& Structural Engineering, The Hong Kong Polytechnic University, Hung Hom, Kowloon, Hong Kong.

Disclaimer. No responsibility is assumed for a ny injury and / or damage to per sons or property as a matter of products liability, negligence or otherwise, or from any use or operation of any methods, products, instructions or ideas contained in the material herein.

Subscription inquiries and change of address. Address all subscription inquiries and correspondence to Member Records, IJASC. Notify an address change as soon as possible. All communications should include both old and new addresses with zip codes and be accompanied by a mailing label from a recent issue. Allow six weeks for all changes to become effective.

The Hong Kong Institute of Steel Construction

HKISC

c/o Department of Civil and Structural Engineering,

The Hong Kong Polytechnic University,

Hunghom, Kowloon, Hong Kong, China.

Tel: 852- 27666047 Fax: 852- 23346389

Email: ces/chan@polyu.edu.hk Website: http://www.hkisc.org/

ISSN 1816-112X

Science Citation Index Expanded, Materials Science Citation Index and ISI Alerting

Copyright $\odot 2013$ by:

The Hong Kong Institute of Steel Construction. 


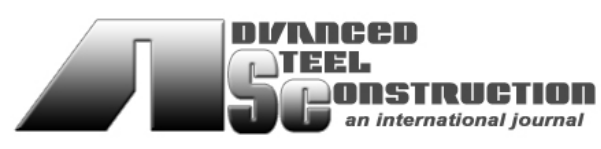

ISSN 1816-112X

Science Citation Index Expanded, Materials Science Citation Index and ISI Alerting

\section{EDITORS-IN-CHIEF}

Asian Pacific, African and organizing Editor

S.L. Chan

The Hong Kong Polyt. Univ., Hong Kong

Email: ceslchan@polyu.edu.hk

\section{American Editor}

W.F. Chen

Univ. of Hawaii at Manoa, USA

Email:waifah@hawaii.edu

\section{European Editor}

R. Zandonini

Trento Univ., Italy

Email: riccardo.zandonini@ing.unitn.it

\section{Advanced Steel Construction an international journal}

VOLUME 9 NUMBER 1

MARCH 2013

Technical Papers

Stability Behavior of Lightweight Aggregate Concrete Filled Steel 1

Tubular Columns under Axial Compression

Bohai Ji, Zhongqiu Fu, Tao Qu and Manman Wang

Behaviour of SFRC Filled Steel Tube Columns under Axial Load

Soner Guler, Erol Lale and Metin Aydogan

Behaviour Factor Evaluation of Sheathed Cold-Formed Steel

Structures

Luigi Fiorino, Ornella Iuorio and Raffaele Landolfo

Investigation on Temperature Distribution and Thermal Behavior of Large Span Steel Structures Considering Solar Radiation Hongbo Liu, Zhihua Chen and Ting Zhou

Evaluation of Welded Flange Plate Connections between Steel Beams and Box Columns

M. Gholami, M. Tehranizadeh and A. Deylami

System Reliability Assessment of 3D Steel Frames Designed per AISC LRFD Specifications

S. Zhang and W. Zhou 



\title{
STABILITY BEHAVIOR OF LIGHTWEIGHT AGGREGATE CONCRETE FILLED STEEL TUBULAR COLUMNS UNDER AXIAL COMPRESSION
}

\author{
Bohai Ji*, Zhongqiu Fu, Tao Qu and Manman Wang \\ College of Civil and Transportation Engineering, Hohai University, Nanjing 210098, China \\ *(Corresponding author: E-mail: hhbhji@163.com)
}

Received: 10 August 2011; Revised: 26 October 2011; Accepted: 14 November 2011

\begin{abstract}
Based on the previous study of the lightweight aggregate concrete filled steel tube (LACFST) slender columns, LACFST specimens with larger slenderness ratio from 64 to 96 were tested. According to the test results, the stability behavior was studied and its influence factors were analyzed. The bound slenderness ratio value was judged and the calculation method was studied. The test results demonstrated that LACFST slender columns under axial compression were damaged instability, and the value of bearing capacity and stability factor decrease as the slenderness ratio increases. Based on the test results analysis, the bound slenderness ratio of LACFST is 80 in this test. A method based on the Euler formula to calculate bound slenderness ratio is provided, and the calculation results are consistent with test ones. By comparison, it is found that the bound slenderness ratio of LACFST is smaller than that of normal CFST. The calculation results using Euler formula indicates that the bearing capacity can be calculated using Euler formula when the LACFST slender columns slenderness ratio is larger than the bound value.
\end{abstract}

Keywords: Lightweight aggregate concrete filled steel tube, Axial compression, Stable, Bound slenderness ratio, Euler formula

\section{INTRODUCTION}

Concrete filled steel tube (CFST) has the excellence of high bearing capacity, good seismic performance, small cross-sectional area and convenient construction. It has been widely studied and used in projects $[1,2,3,4,5]$. Lightweight aggregate concrete (LAC) can be produced from solid waste, and is about $20 \%$ to $30 \%$ lighter than normal concrete. Therefore, LAC is an environmental material which can be used in engineering to reduce the self weight $[6,7,8]$. If LAC is filled into steel tube, it forms lightweight aggregate concrete filled steel tube (LACFST). Similar to normal CFST, the buckling of steel pipe is delayed by LAC, and the LAC compressive strength is increased by the confinement of steel pipe. At the same time, the lower elastic modulus and higher brittleness of LAC are also improved. Because of the lightweight characteristic and good performance, LACFST has good application prospect. Especially in the long span bridge and high-rise building structures, the crossover ability will be increased and the foundation cost will be reduced.

Compared to normal CFST and LAC, the studies and applications about LACFST are less according to the literature number. In recent years, more and more scholars start to study the behavior of LACFST. The test by Assi and Qudeimat showed that LAC can enlarge the bearing capacity of steel pipe [9]. The study by Ghannam and Jawad indicated that LAC can replace normal concrete to fill in the steel tube in composite structural [10]. From the test result, Mouli found that LAC offered higher bond strength than normal concrete and contribution of LAC to the squash load were shown to be considerable [11]. Japan had used LACFST in "Shinkansen" project (high-speed railway bridge) [12]. In China, Li tested a lot of self stress lightweight concrete and gangue concrete filled steel tubular specimens $[13,14]$. Ding and Yu analyzed the Nonlinear Properties of LACFST [15]. He tested 16 square thin-walled stub LACFST columns and proposed mechanical model [16]. Gao and Li studied the seismic behavior of LACFST frame in experimental way [17]. 
In spite of that, the study about the performance of LACFST is still in a primary stage. The author has studied the behavior of LACFST stub columns and slender columns whose slenderness ratio is from 12 to $56[18,19]$. The influence of different parameters was surveyed, including steel and LAC strength, steel ratio, slenderness ratio, and so on. It was found that slenderness ratio impacts on the behavior more and more obvious as the LACFST column length increases. As a further study on the behavior of slender column, the stability of LACFST with the larger slenderness ratio from 64 to 96 was studied in this paper.

\section{EXPERIMENTAL INVESTIGATIONS}

\section{$2.1 \quad$ Materials}

The coarse aggregate of lightweight aggregate concrete is shale ceramic. The physical and mechanical properties are as following: lightweight aggregate bulk density is $814 \mathrm{~kg} / \mathrm{m}^{3}$, cylindrical compression strength is $8.5 \mathrm{MPa}$, the ratio of water absorption ratio is $6 \%$ per hour. Ordinary Portland cement is used in this test. Materials are mixed by concrete mixer. According to the relevant Chinese standards, compression tests were carried out on a number of Standard cubes $([150 \times 150 \times 150] \mathrm{mm})$ to determine the concrete grade, and prisms $([150 \times 150 \times 300] \mathrm{mm})$ in order to determine the 28-days compressive strength $\left(f_{c k}\right)$ and elastic modulus $\left(E_{c}\right)$ of the unconfined concrete. The cubes and prisms were conditioned at room temperature. The concrete mixture is shown in Table 1 and the material properties are shown in Table 2.

Table 1. Mixture Mass for per Cubic Meter LAC Concrete

\begin{tabular}{cccc}
\hline Cement $(\mathrm{kg})$ & Haydite $(\mathrm{kg})$ & Sand $(\mathrm{kg})$ & Water $(\mathrm{kg})$ \\
\hline 460 & 670 & 650 & 170 \\
\hline
\end{tabular}

Table 2. Properties of LAC Concrete

\begin{tabular}{cccc}
\hline $\begin{array}{c}\text { Cubic strength } \\
f_{c u}(\mathrm{MPa})\end{array}$ & $\begin{array}{c}\text { Prism strength } \\
f_{c k}(\mathrm{MPa})\end{array}$ & $\begin{array}{c}\text { Elastic Modulus } \\
E_{c}(\mathrm{GPa})\end{array}$ & $\begin{array}{c}\text { Bulk density } \\
\left(\mathrm{kg} / \mathrm{m}^{3}\right)\end{array}$ \\
\hline 44.7 & 35.2 & 26.2 & 1810 \\
\hline
\end{tabular}

Straight welded steel tube Q235 was used in the test. A group of three standard specimens which were cut from each thickness of steel tube were tested to determine the tensile strength of the steel. Test method followed the regulations of Chinese standard "Metallic materials at ambient temperature tensile test method" (GB/T228, 2002). The data was collected by TS3890 pseudo-dynamic strain instrument in the whole process. Two kinds of steel tubes with thicknesses of $2.9 \mathrm{~mm}$ and $3.5 \mathrm{~mm}$ respectively were tested. Because the tested results are very close, Yield strength $274.7 \mathrm{MPa}$ was used for convenience. The stress and strain relationship of specimen is shown in Figure 1.

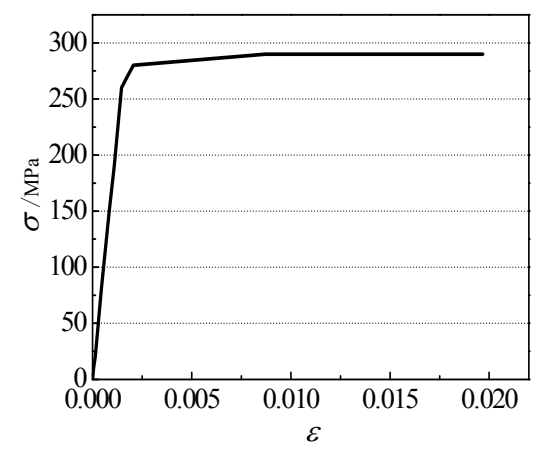

Figure 1. Stress Versus Strain Curve of Steel 


\section{$2.2 \quad$ Specimens}

Steel tubes were processed according to the required length, and the two ends were polished flat. Each column was welded with a $10 \mathrm{~mm}$ thick circular endplate on one end before pouring concrete. The LAC was filled into steel tube with $500 \mathrm{~mm}$ thickness for each layer. A $50 \mathrm{~mm}$ diameter vibrating rod was used to vibrate concrete to ensure its density after pouring work finished. The specimens were maintained in natural conditions. After 10 days conservation, another end was smoothed with cement mortar, and welded with a $10 \mathrm{~mm}$ thick circular endplate. The parameters of LACFST specimens are given in Tables 3 together with the results which will be discussed later.

Table 3. Detail of the Test Specimens

\begin{tabular}{|c|c|c|c|c|c|c|c|c|}
\hline \multirow{2}{*}{ Specimens } & \multicolumn{3}{|c|}{ Pipe size (mm) } & \multirow{2}{*}{$\lambda$} & \multirow{2}{*}{$\alpha(\%)$} & \multirow{2}{*}{$N_{u}(\mathrm{kN})$} & \multirow{2}{*}{$\overline{N_{u}}(\mathrm{kN})$} & \multirow{2}{*}{$\varphi=N_{u} / N_{o}$} \\
\hline & $D$ & $t$ & $L$ & & & & & \\
\hline A-3-a & 114 & 2.9 & 342 & 12 & 11.00 & 814.76 & \multirow{3}{*}{813.02} & 1.002 \\
\hline$A-3-b$ & 114 & 2.9 & 342 & 12 & 11.00 & 850.87 & & 1.046 \\
\hline A-3-c & 114 & 2.9 & 342 & 12 & 11.00 & 773.44 & & 0.951 \\
\hline A-16-a & 114 & 2.9 & 1824 & 64 & 11.00 & 739.50 & \multirow{3}{*}{743.95} & 0.910 \\
\hline A-16-b & 114 & 2.9 & 1824 & 64 & 11.00 & 780.56 & & 0.960 \\
\hline A-16-c & 114 & 2.9 & 1824 & 64 & 11.00 & 711.81 & & 0.876 \\
\hline A-20-a & 114 & 2.9 & 2280 & 80 & 11.00 & 648.00 & \multirow{3}{*}{692.00} & 0.797 \\
\hline A-20-b & 114 & 2.9 & 2280 & 80 & 11.00 & 728.00 & & 0.895 \\
\hline A-20-c & 114 & 2.9 & 2280 & 80 & 11.00 & 700.00 & & 0.861 \\
\hline A-24-a & 114 & 2.9 & 2736 & 96 & 11.00 & 548.50 & \multirow{3}{*}{501.17} & 0.675 \\
\hline A-24-b & 114 & 2.9 & 2736 & 96 & 11.00 & 448.00 & & 0.551 \\
\hline A-24-c & 114 & 2.9 & 2736 & 96 & 11.00 & 507.00 & & 0.624 \\
\hline B-3-a & 114 & 3.5 & 342 & 12 & 13.51 & 865.28 & \multirow{3}{*}{883.16} & 0.980 \\
\hline B-3-b & 114 & 3.5 & 342 & 12 & 13.51 & 863.72 & & 0.979 \\
\hline B-3-c & 114 & 3.5 & 342 & 12 & 13.51 & 920.50 & & 1.042 \\
\hline B-16-a & 114 & 3.5 & 1824 & 64 & 13.51 & 773.00 & \multirow{3}{*}{753.38} & 0.875 \\
\hline B-16-b & 114 & 3.5 & 1824 & 64 & 13.51 & 747.05 & & 0.846 \\
\hline B-16-c & 114 & 3.5 & 1824 & 64 & 13.51 & 740.10 & & 0.838 \\
\hline B-20-a & 114 & 3.5 & 2280 & 80 & 13.51 & - & \multirow{3}{*}{703.00} & - \\
\hline B-20-b & 114 & 3.5 & 2280 & 80 & 13.51 & 701.01 & & 0.794 \\
\hline B-20-c & 114 & 3.5 & 2280 & 80 & 13.51 & 705.00 & & 0.798 \\
\hline B-24-a & 114 & 3.5 & 2736 & 96 & 13.51 & 615.03 & \multirow{3}{*}{592.50} & 0.696 \\
\hline B-24-b & 114 & 3.5 & 2736 & 96 & 13.51 & 558.01 & & 0.632 \\
\hline B-24-c & 114 & 3.5 & 2736 & 96 & 13.51 & 604.46 & & 0.684 \\
\hline
\end{tabular}

Note: $1 . \quad D$ is the external diameter, $t$ is the thickness, $L$ is the length of specimen,

2. $f_{y}$ is the yield strength of steel, $\lambda$ is the slenderness ratio, $\lambda=4 L / D$;

3. $\alpha$ is steel ratio, $\alpha=A_{s} / A_{c}$, here $A_{s}$ is the area of steel, $A_{c}$ is the area of concrete;

4. $\quad N_{u}$ is test ultimate load, $\overline{N_{u}}$ is the average value of test ultimate load for each group;

5. $\varphi$ is stability factor, $\varphi=N_{u} / N_{o}$, here $N_{o}$ is test ultimate load of short column $(L / D=3)$.

\subsection{Test Instruments and Procedure}

Figure 2 shows the details of the test instruments. The experiment was performed in the structural engineering laboratory of Hohai University. Hydraulic jack was implemented to apply load on the specimen, and pressure sensor was used to measure load value. At the two ends of the specimen, column, support plate were utilized to simulate the hinged boundary condition. 
In order to reduce the adverse effect of initial imperfection, several methods were adopted. They were as follows: (1) Steel pipe surface were examined carefully; (2) two ends of the steel pipe were polished flat; (3) the end was smoothed with cement mortar before the second endplate wedded; (4) a bolt was inserted in the holes which were set on the center of the endplate and support plate (Figure 2); (5) a plumb line was used as reference at the side of the specimen when loading (Figure 2). In these ways, it can ensure the specimen was vertical and the load was added axially as much as possible.

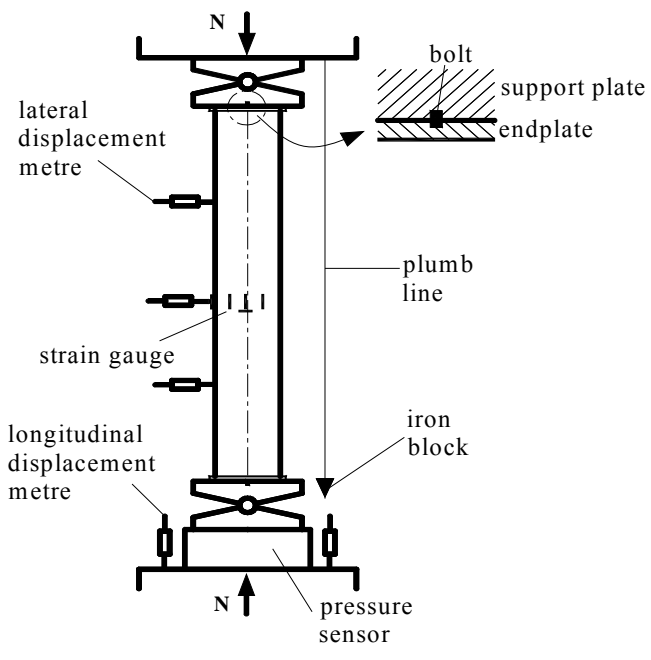

Figure 2. Loading and Measurement System

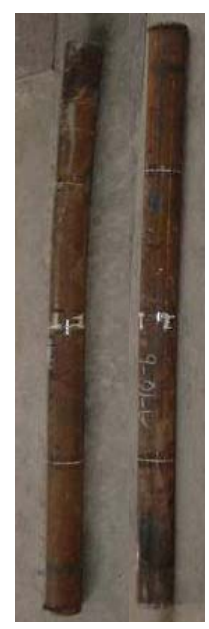

(a) $\mathrm{A}-16$

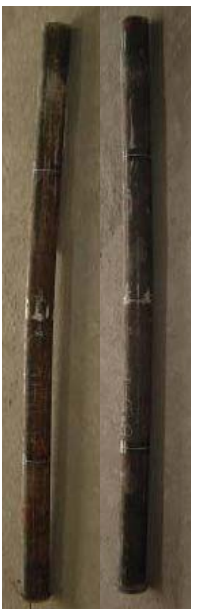

(b) B-20

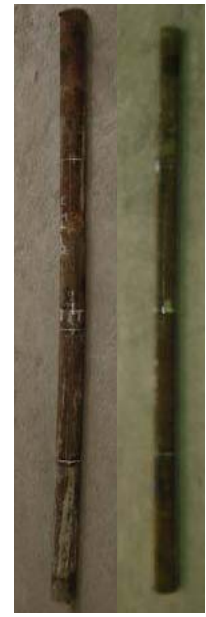

(c) A-24

Figure 3. Failure specimens

For the accuracy of the specimen's deformation measurement, strain gauges were set at the mid-length of the column to record longitudinal strain and transverse strain. On the reaction frame, three lateral displacement meters were set to measure the deflection at quadrant point along the length of the column. And two longitudinal displacement meters were set to measure the longitudinal deformation. All data was recorded by computer data acquisition system in the whole test phase. The specimen was loaded at rate of $1 / 10$ of the predicted ultimate load in the elastic phase and at loading rate of $1 / 15$ of the predicted ultimate load in the column yielding phase. Each load was maintained for 2-3 minutes to enable the full deformation development. When approaching the predicted ultimate capacity, the load was added slowly.

\section{DISCUSSIONS OF TEST RESULTS}

\subsection{Test Phenomenon}

Figure 3 shows some typical failure specimens. No local buckling phenomenon was observed. All slender columns specimens failed because of excessive lateral deformation, and damaged instability under axial compression. When jack was loaded off after the experiment, majority bending deformation of slender columns could be resumed, which meant the majority of the deflection was elastic deformation when the specimen was damaged under loading.

Deflection distribution along the length under different load is shown in figure 4. For most specimens, as the load increased, deflection increased gradually with the largest value at middle point and symmetrical growth at two sides (Figure 4a). The curves shape is similar with the sine half-wave. However, due to initial defects containing material discontinuity and load eccentricity and so on, the deflection developed asymmetry for some specimens as shown in Figure 4(b). However, the deflection was rectified as the load increasing. The deflection distribution tended to 
symmetry. The largest deflection value appeared at the middle point when the specimen was destroyed finally.

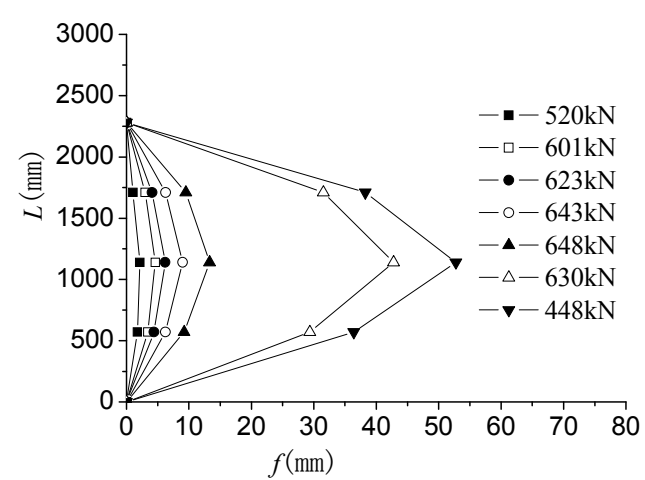

(a) A-20-a

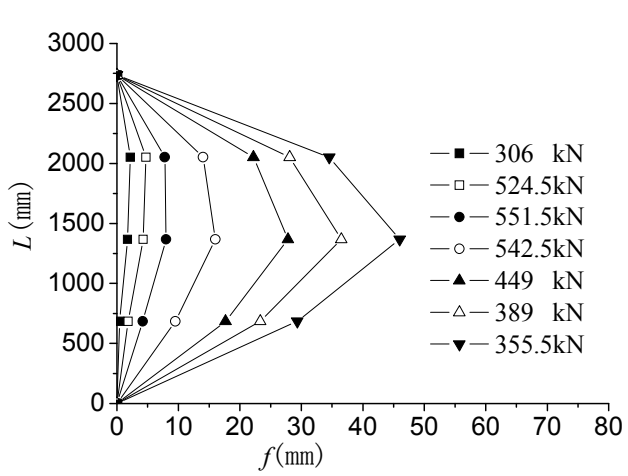

(b) B-24-b

Figure 4. Deflection Distribution Along the Length as the Load Increasing

\subsection{Failure Process}

Figure 5 is load $N$ - midpoint deflection $f$ curves. Because of initial defects, the deflection of some specimens developed at the beginning of test. At the loading initial stage, the deflection increased slowly. When the load was about $60 \%$ to $70 \%$ of ultimate load, lateral deflection and vertical displacement increased rapidly. When reaching the ultimate load, deflection increased more quickly, and the load became coming down. The larger slenderness ratio led to the more quickly deflection increased. This is because larger slenderness ratio has smaller bending stiffness, and will produce larger additional bending moment.

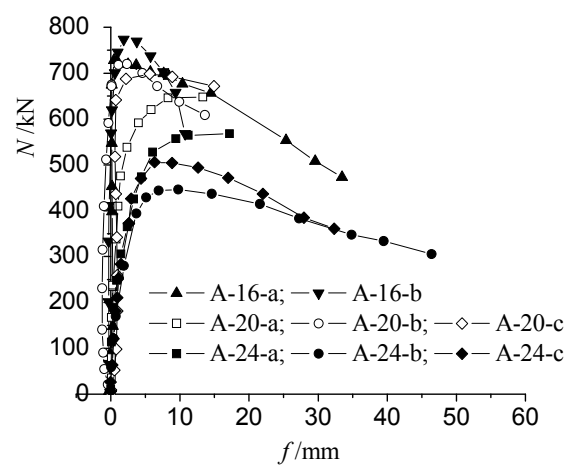

(a)

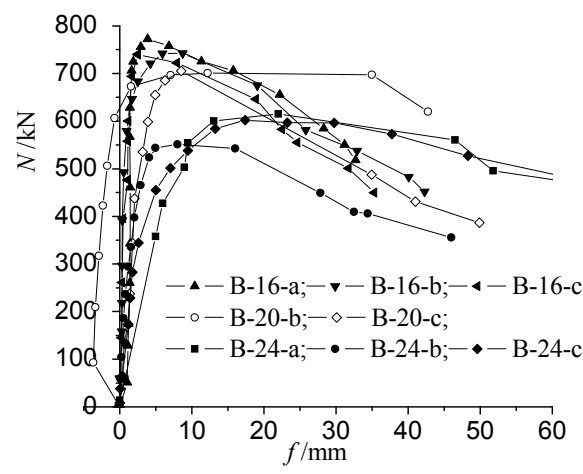

(b)

Figure 5. Load $(N)$ - Midpoint Displacement $(f)$ Curves

\subsection{Strain analysis}

Figure 6 is the load $(N)$ - strain $(\varepsilon)$ curves at middle partial. It reflects the development of longitudinal and hoop stain of the steel which were obtained by strain gauge set on the steel pipe. Point $a$ and $b$ represent the specimen on two sides divided by roll shaft. Point $a$ is the middle side of flexural specimen, and point $b$ is the lateral side of flexural specimen. 


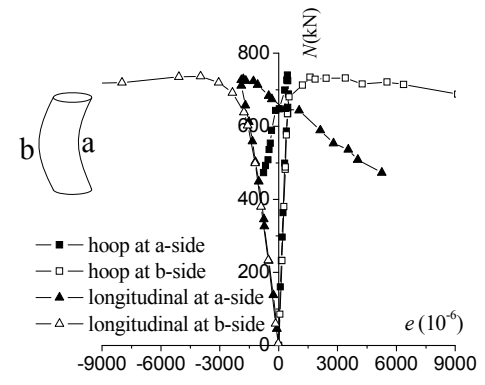

(b)A-16-a

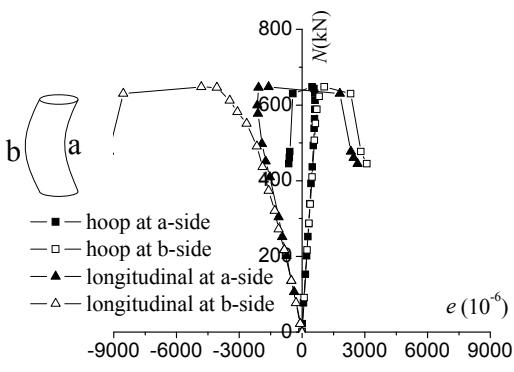

(c)A-20-a

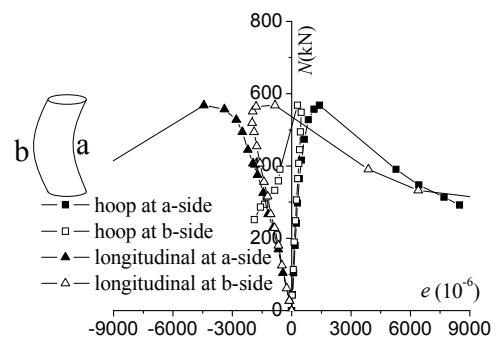

(d)A-24-a

Figure 6. Load $(N)$ - Strain $(\varepsilon)$ Curves at Middle Partial

From the figures, it can be seen that, at the beginning of load application, the whole cross-section of specimen was under pressure. The differences of longitudinal strain at two sides were not obvious. Achieved about $70 \%$ of the ultimate load, longitudinal strain at a-side became growing slower than b-side. After reaching the ultimate load, longitudinal strain in a-side reduced and became to be tensile strain finally. At the same time, the opposite situation occurred for hoop strain at a-side. This is because the deflection produced additional bending moment, and this made the specimen under the situation that one side was bearing tension and another side was bearing compression.

The lateral deformation coefficient $\mu$ is defined similar as Poisson's ratio in order to reflect whether the material has yielded or not. In general, Poisson's ratio of steel is $0.25 \sim 0.3$. If the lateral deformation coefficient is less than 0.3 , the steel is in elastic stage. The lateral deformation coefficient can be calculated by equation (1). In the equation, $\varepsilon_{s h}$ is the hoop strain and $\varepsilon_{s l}$ is the longitudinal strain of the steel at middle point. They were measured by the strain gauges on the steel tube.

$$
\mu=\varepsilon_{s h} / \varepsilon_{s l}
$$

Figure 7 is the lateral deformation coefficient variation curves of specimen. Positive and negative values are used to distinguish the two side. One group of same section specimens is selected to prove that the curves of specimens with same parameter are similar. Therefore, one of them can represent a group. Based on this, one of each group specimens with different slenderness ratio is selected to compare with each other.

It can be found that the lateral deformation coefficient of specimen is close to Poisson's ratio of steel in the initial loading state. It indicates that the steel are at the elastic stage, and there is no obvious constraining stress between concrete and steel. At the beginning, variation trend of stub column and slender column is the same. When it reached to $70 \%$ of ultimate load for stub column $(L / D=3)$, the lateral deformation coefficient became increscent and exceeded Poisson's ratio of steel. This produced constraining stress between concrete and steel. It made the strength of materials used fully. While for the slender column, the lateral deformation coefficient became increscent when it reached to the ultimate load. At this moment, the specimen had already been damaged. This indicates that strength of the material is not fully used when the slender column is damaged. 


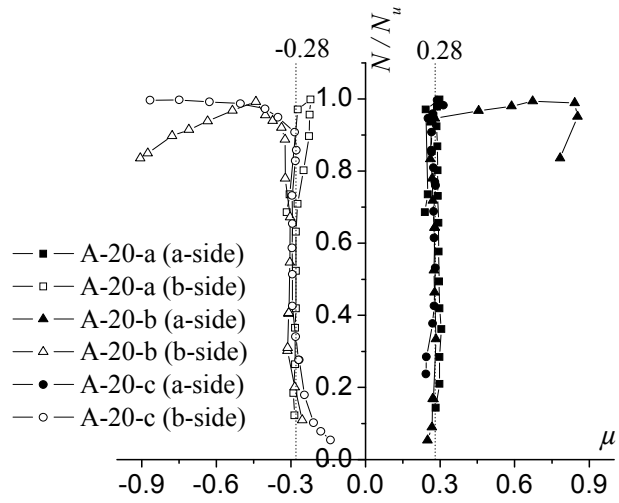

(a) One group specimens

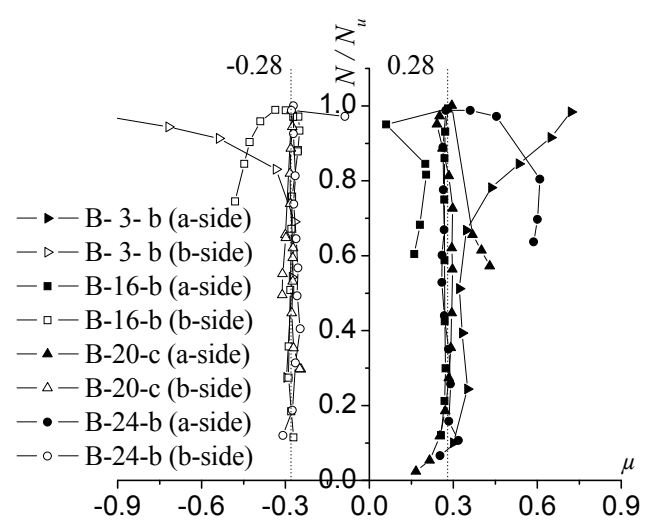

(b) Different slenderness ratio specimens

Figure 7. Lateral Deformation Coefficient Variation Curves of Specimens

\subsection{Influence of Slenderness Ratio}

The behavior of LACFST slender column had been studied by 11 group specimen tests in author's previous study [19]. And group SC2 in previous test has the same section parameter with group B in this test. The stub column bearing capacity of group SC2-3 is $887.5 \mathrm{kN}$ and group B-3 is $883.2 \mathrm{kN}$. They are very close to each other. Therefore, these two groups can be compared together.

Figure 8 shows the deflection development as load increasing with the $L / D$ from 7 to 24 . From the figure, deflection of specimen with larger slenderness ratio increased more quickly as the loading increases. After ultimate load, the specimen curve which has larger slenderness ratio develops more gently. This is because the initial defects impact more obviously when the specimen has a larger slenderness ratio.

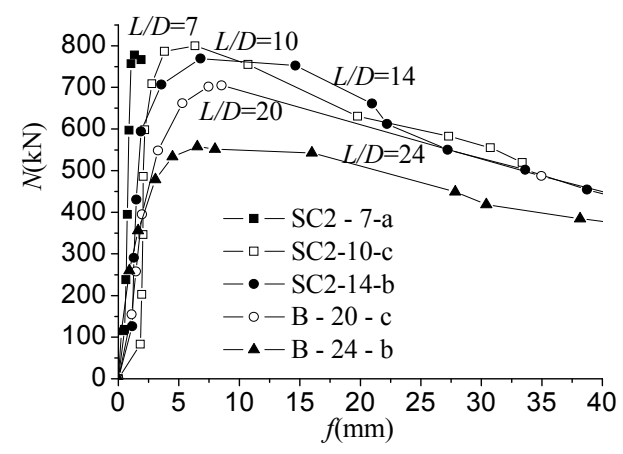

Figure 8. $N-f$ curves of Different $L / D$

Figures 9 and 10 show the development of bearing capacity $\left(N_{u}\right)$ and stability factor $(\varphi)$ as the $L / D$ increases. The average value is used in the figures. It indicates that the bearing capacity and stability factor decrease as the slenderness ratio increases. This is the same conclusion with the result studied before which $L / D$ is from 3 to 14 . 


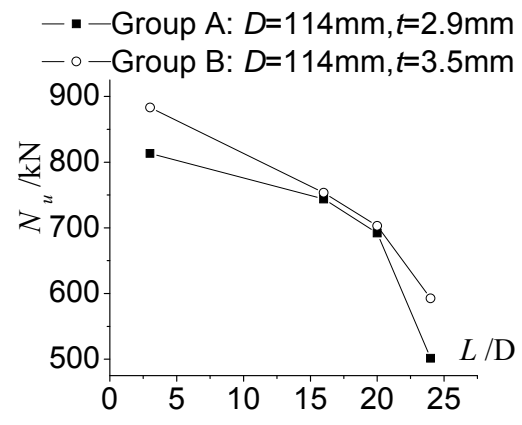

Figure 9. $N_{u}-L / D$ Curves

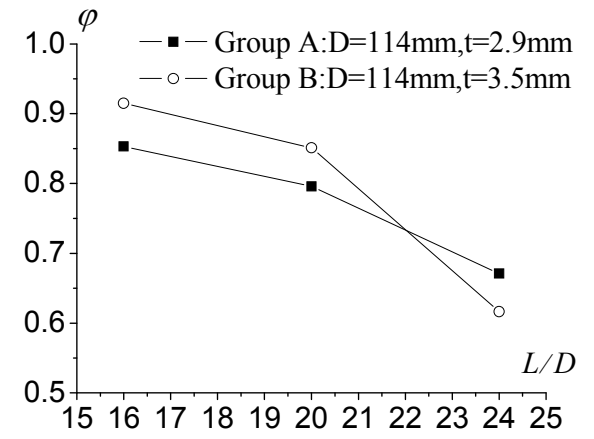

Figure 10. $\varphi-L / D$ Curves

\section{BOUND SLENDERNESS RATIO ANALYSIS}

\subsection{Bound Slenderness Ratio Judgment}

The longitudinal strain $\varepsilon_{c}$ of specimen can be obtained from expression (2). In the expression, $\Delta$ is the longitudinal compression displacement measured by displacement meters, $L$ is the length of the specimen.

$\varepsilon_{c}=\Delta / L$

As stated above, group SC2 studied before and group B studied in this test can be compared together. Figure 11 shows the longitudinal strain development with the load increases. From the figure, the specimen with smaller slenderness ratio has larger bearing capacity and longitudinal strain. The smaller the slenderness ratio, the more significant plastic deformation and the material strength played more fully. When $\lambda \geq 80$ (group B-20 and B-24 specimens), curves change from upward trend to downward trend directly without transition process. The specimen is in the elastic state when it reaches ultimate load.

Lateral deformation coefficient $\mu$ corresponding with ultimate load is analyzed to study whether the material has yielded or not. The lateral deformation coefficient was defined in equation (1) above. Its development as the slenderness ratio increases is shown in Figure 12.

The larger the slenderness ratio is, the smaller the lateral deformation coefficient is. When it reaches ultimate load, specimen bend to lateral side (b-side). It causes the longitudinal strain to change from compression to tension. Therefore, $\mu$ corresponding with ultimate load is larger at medial side (a-side) than that at lateral side (b-side). Compared to Poisson's ratio of steel, considering experimental error, it can be deemed that steel is in the elastic stage when $\mu \leq 0.3$. From figure 12 , with slenderness ratio $\lambda \geq 80$, lateral deformation coefficient $\mu \leq 0.3$ when it is ultimate load. Therefore, from the test results it can be concluded that specimen is elastic failure when it reaches to ultimate load with $\lambda \geq 80$ in the parameter range of this test. 


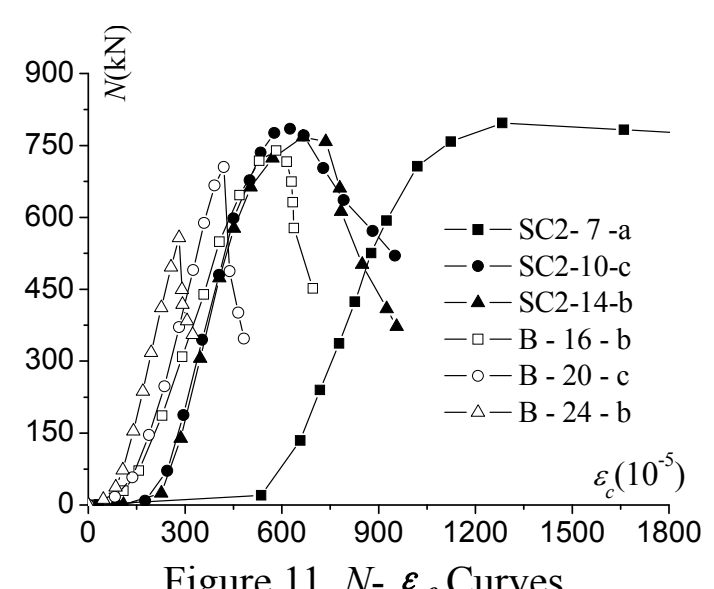

Figure 11. $N-\varepsilon_{c}$ Curves

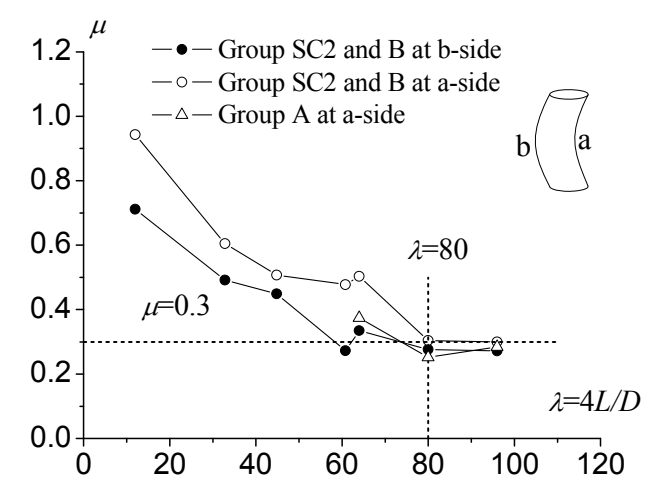

Figure 12. $\mu-\lambda$ Curves when Ultimate Load

\subsection{Bound Slenderness Ratio Calculation}

For the slender column, if its slenderness ratio is large enough, the column is damaged abruptly because of excessive deflection with the material also in elastic stage. This is elastic failure. If the material is in elastic-plastic stage when column damaged, it is elastic-plastic failure. The bound slenderness ratio $\lambda_{p}$ is the boundary between the two failure modes. When slenderness ratio of columns is less than $\lambda_{p}$, it will be elastic-plastic failure. Otherwise, it will be elastic failure. According to stability theory, Euler formula can be used to calculate the bearing capacity of slender column when it is elastic failure. And the critical stress $\sigma_{c r}$ can be got from equation (3). $E_{s c}$ is the elastic modulus of LACFST specimen.

$$
\sigma_{c r}=\pi^{2} E_{s c} / \lambda^{2}
$$

If the column is elastic failure, its limit of proportionality $f_{s c}^{p}$ will larger than or equal to critical stress $\sigma_{c r}$. In order to know the bound slenderness ratio $\lambda_{p}$, the value of $\sigma_{c r}$ can be taken as $f_{s c}^{p}$. Equation (4) can be used to calculate $\lambda_{p}$. Based on the study of LACFST stub column, $f_{s c}^{p}$ takes the sectional stress which corresponds to $85 \%$ bearing capacity of stub column [18].

$$
\lambda_{p}=\sqrt{\pi^{2} E_{s c} / f_{s c}^{p}}
$$

According to the study of LACFST stub column, the LACFST elastic modulus $E_{s c}$ can be got as equation (5). $E_{s c}, E_{s}, E_{c}$ is elastic modulus of LACFST, steel, LAC; $A_{s c}, A_{s,} A_{c}$ is sectional area of LACFST, steel, LAC.

$$
E_{s c} A_{s c}=E_{s} A_{s}+E_{c} A_{c}
$$

Equation (4) is used to calculate the bound slenderness ratio of specimens in this test. The results are listed in Table 4. 
Table 4. Calculation Results of Bound Slendemess Ratio

\begin{tabular}{|c|c|c|c|c|c|c|}
\hline \multirow{2}{*}{$\begin{array}{l}\text { Specimen } \\
\text { group }\end{array}$} & \multirow{2}{*}{$\begin{array}{c}E_{s c} \\
(\mathrm{MPa})\end{array}$} & \multirow{2}{*}{$\begin{array}{c}N_{u} \\
(\mathrm{kN})\end{array}$} & \multirow{2}{*}{$\begin{array}{c}f_{s c}^{p} \\
(\mathrm{MPa})\end{array}$} & \multicolumn{3}{|c|}{ Calculation results of $\lambda_{p}$} \\
\hline & & & & Equation (4) & Equation (6) & Equation (7) \\
\hline SC1 & $30.63 \times 10^{3}$ & 927.30 & 36.88 & 90.49 & 101 & 95.2 \\
\hline $\mathrm{SC} 2$ & $50.60 \times 10^{3}$ & 887.60 & 73.95 & 82.13 & 98 & 89.2 \\
\hline $\mathrm{SC} 3$ & $41.70 \times 10^{3}$ & 742.54 & 61.87 & 81.52 & 98 & 93.6 \\
\hline A & $44.21 \times 10^{3}$ & 813.02 & 67.74 & 80.22 & 105 & 96.4 \\
\hline B & $47.78 \times 10^{3}$ & 883.16 & 73.58 & 80.01 & 105 & 96.8 \\
\hline
\end{tabular}

Two formulas of normal CFST are also used to calculate $\lambda_{p}$, the results of which are also listed in Table 4. The calculation formulas are described with following equations. Equation (6) is a simple empirical formula [20]. Equation (7) is deduced through modifying the formulas by tangent modulus method [15].

$\lambda_{p}=1743 / \sqrt{f_{s}}$

$\lambda_{p}=\pi \eta \sqrt{\gamma E_{s} /\left(\theta f_{s}\right)}$

Coefficient $\eta, \gamma, \theta$ can be got by equations (8) to (10). In the equations, $f_{s}$ and $f_{c}$ is the strength of steel and concrete.

$$
\begin{aligned}
& \eta=\frac{0.73 f_{s} / f_{c}-1.7}{f_{s} / f_{c}-31} \leq 1 \\
& \gamma=\frac{2 n \rho+1-2 \rho}{n \rho+1-\rho}>1 \\
& \theta=f(\rho)+\frac{1-f(\rho)}{5.5 \times 10^{-3}\left(f_{s} / f_{c}\right)^{2.6}+1} \\
& f(\rho)=0.48+3.19 \rho^{1.62}, \rho=A_{s} / A_{s c}, n=E_{s} / E_{c}
\end{aligned}
$$

From Table 4, the bound slenderness ratio of specimen in this test is about 80 . It is the same conclusion as the judgment from the strain analysis of test results. Therefore, the following conclusion can be got that bound slenderness ratio of specimens is 80 in this test. And the method provided in this paper is reasonable for calculating bound slenderness ratio of LACFST. With the comparison among three equations, the results of equation (4) are smaller than the other two. It indicates that the bound slenderness ratio of LACFST is less than the one of normal CFST. The calculation method for normal CFST can not be used directly to LACFST.

\subsection{Failure Mode Judgment}

According to stability theory, the bearing capacity of slender columns can be calculated using Euler formula. The value of Elastic modulus takes into Euler formula, the ultimate bearing capacity $P_{c r}$ can be got. Figure 13 is the comparison between Euler formula and test result. When the specimens are elastic failure $(\lambda \geq 80)$, test result has the same development trend with Euler formula calculation line. The largest deviation between the two is less than $15 \%$. Therefore, it can be taken that the Euler formula result is tally with the test result well. 


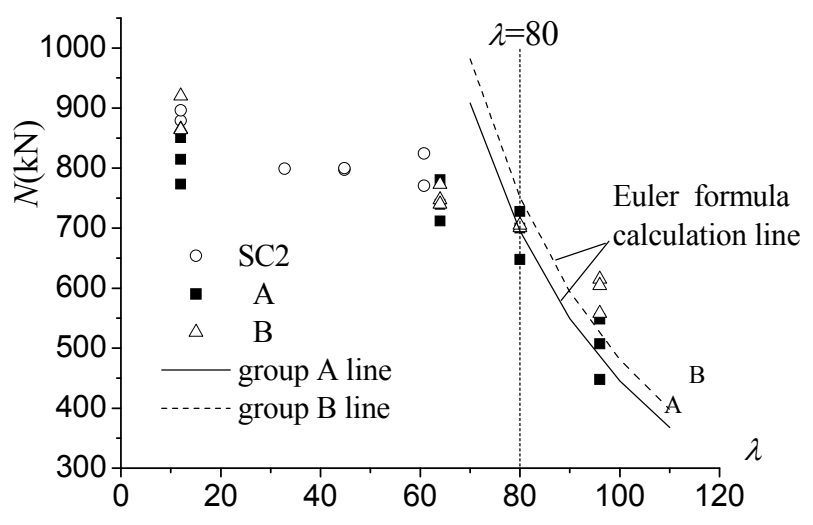

Figure 13. Comparison between Euler Formula and Test

The test and Euler formula calculation values of bearing capacity are listed in Table 5. Because Euler formula applies for the columns with $\lambda \geq \lambda_{p}$, the calculation value using Euler formula will obviously larger than the actual value when $\lambda \leq \lambda_{\mathrm{p}}$. As the same mean, it is elastic-plastic failure when the calculation value using Euler formula is obviously larger than the actual value. Otherwise, it is elastic failure. From Table 5, it has an obvious deviationt between the two bearing capacity of specimen with $\lambda=64$. While the two bearing capacity values of specimen with $\lambda=80$ and $\lambda=96$ are close to each other. This indicates that it is elastic-plastic failure when $\lambda=64$, and it is elastic failure $\lambda=80$ and $\lambda=96$. This proves that the bound slenderness ratio of LACFST specimen in this test is 80 which was obtained above.

Table 5. Test and Calculated Bearing Capacity Results Comparison

\begin{tabular}{cccccccc}
\hline \multirow{2}{*}{ Specimen } & Group name & A-16 & A-20 & A-24 & B-16 & B-20 & B-24 \\
\cline { 2 - 7 } & $\lambda=4 L / D$ & 64 & 80 & 96 & 64 & 80 & 96 \\
\hline Calculation $P_{c r}(\mathrm{kN})$ & 1075.93 & 688.59 & 478.19 & 1161.15 & 743.14 & 516.07 \\
Test $P(\mathrm{kN})$ & 743.95 & 692.00 & 501.17 & 753.38 & 703.00 & 592.50 \\
$P_{c r} / P$ & 1.4462 & 0.9951 & 0.9541 & 1.5413 & 1.0571 & 0.8710 \\
\hline
\end{tabular}

\section{CONCLUSIONS}

With larger slenderness ratio, the LACFST column under axial compression is easer to be failed by instability. And the bearing capacity and stability factor decrease as the slenderness ratio increases

Based on the test result analysis, the bound slenderness ratio of LACFST is 80 in the parameter range of this test. When the slenderness ratio is larger than 80 , the failure mode of specimen is elastic failure. Otherwise, it is elastic-plastic failure.

According to stability theory, a method based on the Euler formula to calculate bound slenderness ratio is provided, and the calculated outcome is consistent well with test result. The bound slenderness ratio of LACFST is smaller than the value calculated using experimental formula of normal CFST.

For the LACFST column with larger slenderness ratio than the bound one, the bearing capacity can be calculated using Euler formula approximately. 


\section{ACKNOWLEDGMENTS}

The authors appreciate the support of China Postdoctoral Science Foundation (2012M511187), The Fundamental Research Funds for the Central Universities (2012B02914), and Jiangsu Civil Engineering Graduate Center for Innovation and Academic Communication foundation (2010).

\section{REFERENCES}

[1] Ge, H.B., Susantha, K.A.S., Satake, Y., et al., "Seismic Demand Predictions of Concrete-filled Steel Box Columns", Engineering Structures, 2003, Vol. 25, No. 3, pp. 337-345.

[2] Gao, S.B. and Ge, H.B., "Numerical Simulation of Hollow and Concrete-filled Steel Columns", Int. J. of Advanced Steel Construction, 2007,Vol. 3, No. 3, pp. 668-678.

[3] Yang, Y.F., Han L.H. and Zhu L.T., "Experimental Performance of Recycled Aggregate Concrete-Filled Circular Steel Tubular Columns Subjected to Cyclic Flexural Loadings", Advances in Structural Engineering, 2009, Vol. 12, No. 2, pp. 183-194.

[4] Dabaon, M.A., El-Boghdadi, M.H. and Hassanein, M.F., "Experimental Investigation on Concrete-filled Stainless Steel Stiffened Tubular Stub Columns", Engineering Structures, 2009, Vol. 31, No. 2, pp. 300-307.

[5] Nakamura, S. Tanaka, H, and Kato, K., "Static Analysis of Cable-stayed Bridge with CFT Arch Ribs", Journal of Constructional Steel Research, 2009, Vol. 65, No. 4, pp. 776-783.

[6] Alengaram, U.J., Mahmud, H. and Jumaat, M.Z., "Comparison of Mechanical and Bond Properties of Oil Palm Kernel Shell Concrete with Normal Weight Concrete", International Journal of The Physical Sciences, 2010, Vol. 5, No. 8, pp. 1231-1239.

[7] Haque, M.N., Al-Khaiat, H. and Kayali, O., "Strength and Durability of Lightweight Concrete", Cement and Concrete Composites, 2004, Vol. 26, No. 4, pp. 307-314.

[8] Schaumann, E., Vallee, T. and Keller, T., "Modeling of Direct Load Transmission in Lightweight-Concrete-Core Sandwich Beams", ACI Structural Journal, 2009, Vol. 106, No. 4, pp. 435-444.

[9] Assi, I.M., Qudeimat, E.M. and Hunaiti, Y., "Ultimate Moment Capacity of Foamed and Lightweight Aggregate Concrete-filled Steel Tubes", Steel and Composite Structures, 2003, Vol. 3, No. 3, pp. 199-212.

[10] Ghannam, S., Jawad, Y.A. and Hunaiti, Y., "Failure of Lightweight Aggregate Concrete-filled Steel Tubular Columns", Steel and Composite Structures, 2004, Vol. 4, No. 1, pp. 1-8.

[11] Mouli, M. and Khelafi, H., "Strength of Short Composite Rectangular Hollow Section Columns Filled with Lightweight Aggregate Concrete", Engineering Structures, 2007, Vol. 29, No. 8, pp. 1791-1797.

[12] Nakamura, S., Momiyama, Y., Hosaka, T., et al., "New Technologies of Steel/Concrete Composite Bridges", Journal of Constructional Steel Research, 2002, Vol. 58, No. 1, pp. 99-130.

[13] Li, G.C., Liu, Z.Y., Feng, G.H., et al., "Bearing Capacity Calculation of Self Stress Lightweight Concrete Filled Steel Tubular Short Columns under Axial Compressive Loading”, Journal of Northeastern University (Natural Science), 1997, Vol. 18, No. 6, pp. 636-639. (in Chinese)

[14] Li, G.C., Long, H.B., and Wang Z.Q., "Inelastic Yield Load of Gangue Concrete Filled Steel Tubular Middle Long Columns under Axial Compression", Journal of Shenyang Architecture and Civil Engineering University, 2004, Vol.20, No.4, pp. 291-293. (in Chinese) 
[15] Ding F.X., Yu Z.W. and Jiang, L.Z. "Bearing Capacity of Middle Long Concrete filled Circular Steel Tubular Columns under Axial Compression”, China Journal of Highway and Transport, 2007, Vol. 20, No. 4, pp. 65-70. (in Chinese)

[16] He, M.S., and Liu, X.Y., "Study on Behavior of Lightweight Aggregate Concrete Filled Square Thin-walled Steel Tubes under Axial Load", Journal of Harbin Institute of Technology, 2007, Vol. 39, No. supplement 2, pp. 78-81. (in Chinese)

[17] Gao, C.Y. and Li, B., "Experimental Research on Seismic Behavior for Lightweight Aggregate Concrete-filled Steel Tubular Frame", Advanced Materials Research(Volumes 163-167), 2011, Vol. Advances in Structures, pp. 2194-2198.

[18] Fu, Z.Q., Ji, B.H., Zhou Y. and Wang X.L. "An Experimental Behavior of Lightweight Aggregate Concrete Filled Steel Tubular Stub under Axial Compression", ASCE Geotechnical Special Publication, 2011, Vol. 219, pp. 24-32.

[19] Fu, Z.Q., Ji, B.H., Lv, L. and Zhou, W.J. "The Behavior of Lightweight Aggregate Concrete Filled Steel Tube Slender Columns under Axial Compression", Advanced Steel Construction, 2011,Vol. 7, No. 2, pp. 144-156.

[20] Han, L.H. "Concrete Filled Steel Tube Structure: Theory and Practice”, Science Press, 2004 (in Chinese). 


\title{
BEHAVIOUR OF SFRC FILLED STEEL TUBE COLUMNS UNDER AXIAL LOAD
}

\author{
Soner Guler *, Erol Lale and Metin Aydogan \\ Faculty of Civil Engineering, Istanbul Technical University, Istanbul, Turkey \\ *(Corresponding author: E-mail: gulersoner@hotmail.com)
}

Received: 29 August 2011; Revised: 26 September 2011; Accepted: 14 November 2011

\begin{abstract}
This paper presents an experimental study of square high strength steel fiber reinforced concrete (SFRC) filled steel tube columns under axial load. A series of tests are performed to investigate the effects of $\mathrm{D} / \mathrm{t}$ ratio, the bond strength between concrete and the steel tube on behavior and axial load capacity of the high strength SFRC filled steel tube columns. The specimens are separated as greased and non-greased to investigate the bond effect on the axial load capacity. A total of 13 specimens are tested and compared to Eurocode 4, ACI, AS and AISC Codes. The results show that the difference of the axial load capacity between the greased and the non-greased square high strength SFRC filled tube columns is notable. The all design codes overestimate the axial load capacity for the specimens with thinner (D/t ratio is 33.3) steel tube thickness.
\end{abstract}

Keywords: Axial load capacity, Steel fiber reinforced concrete, Design codes, Bond effect, D/t ratio

\section{INTRODUCTION}

In high-rise buildings, the use of the high-strength concrete at structural members is quite widespread today. The structural members have to resist axial load and bending moment because of vertical and lateral loads. Therefore, the structural members such as columns have to be designed to sustain all kinds of effects which stem from those forces. The main aim of the concrete filled steel tube columns is to withstand against those forces by combining steel and concrete.

There have been many studies about the normal and the high strength concrete filled steel tube columns. Furlong [1] investigates 13 specimens with D/t ratios from 29 to 98 . The results show that there is no increase in the load carrying capacity if the steel tube and the concrete resist the load individually. Schneider [2] performs a comprehensive study about axially loaded concrete filled steel tubes. The total 14 specimens are tested under the axial load, and experimental results are compared to numerical solutions. As conclusions states, the circular concrete filled steel tube columns show more ductility and strength compared to square and rectangular ones.

One of the most important parameters in this study is the bond effect. Due to the mechanical properties of the high strength concrete such as Poisson ratio and the amount of shrinkage differ from the low or medium strength concrete, the bond strength between the steel tube and the concrete core is critical on the axial load capacity for high strength concrete filled steel tube columns. There have been many studies to investigate the bond effect for the concrete filled tube columns by various researchers. Roeder et.al [3] studies the composite action in concrete filled tubes and emphasizes the importance of the bond stress between the concrete core and the steel tube. The results show that the bond capacity becomes smaller as the diameter and $\mathrm{D} / \mathrm{t}$ ratios of tubes increase. They develop a formulation that estimates the bond stress capacity. Giakoumelis and Lam [4] investigate 15 circular columns with 30,60 and $85 \mathrm{MPa}$ concrete strength, and D/t ratio between 22.9 and 30.5. The specimens are separated as greased and non-greased specimens to investigate the bond effect. The results show that the difference of the axial load capacity of greased and non-greased specimens is very small for 30 and $50 \mathrm{MPa}$ concrete. The bonding of the steel and the concrete seem to be effective for $85 \mathrm{MPa}$ concrete while the percentage of difference between greased and non-greased specimens of axial load capacity is $14 \%$. The bond capacity between the steel tube and the concrete core is investigated by Morishita and Tomii [5], Virdi and Dowling [6]. 
With the development of concrete technology, there has been a remarkable advancement in developing higher performance concrete possessing high strength, toughness, energy absorption, fracture of energy, durability, etc. Steel fiber reinforced concrete (SFRC) may be defined as a composite material made with Portland cement, aggregate and incorporating discrete discontinuous fibers. 1. Swamy RN. High-strength concrete-material properties and structural behaviors. ACI SP-87, Detroit: American Concrete Institute; 1987. p. 110-146 Thus, a concrete mix possessing the higher axial ductility, bending or tensile strength as well as the high compressive strength can be obtained.

Although there have been many studies on CFT columns with low, normal and high strength concrete, there has been relatively little research on steel fiber reinforced concrete (SFRC) filled concrete filled tube columns.

Campiogne et al. [7] conduct a series of tests on the circular SFRC filled steel tube columns under axial load. The column lengths are $400 \mathrm{~mm}, 1500 \mathrm{~mm}$ and $2000 \mathrm{~mm}$. The steel fiber volume ratio is $1 \%$. They compare SFRC filled steel tube columns to plain concrete filled tube columns having compressive strength of $24 \mathrm{MPa}$. The aim of the study is to investigate the ductile post-peak behavior of these two types of concrete filled steel tube columns and to compare the axial load capacity of the test results with the design codes. The results show that the SFRC filled steel tube columns show more ductile behavior than the plain concrete filled steel tube columns. Tests of concrete-filled steel tube columns to investigate these effects are conducted by Uy [8]; Han [9]; $\mathrm{Hu}$ [10]; Young and Ellobody [11]; Teng et al. [12]; Zhong [13]; Liang [14]; Zhao et.al. [15] and many other researchers.

This paper reports an experimental study that is performed to analyze the behavior of square high strength SFRC filled steel tube columns under axial load. The first aim of this study is to report a series of new tests on square high strength SFRC filled steel tube columns under axial load. Second, the difference of the axial load capacity due to the bond effect is examined for high strength square SFRC filled steel tube columns depending on the different $\mathrm{D} / \mathrm{t}$ ratio of the specimens. Third, some important parameters such as ductility index (DI) and the strength enhancement index (SI) are investigated for the high strength SFRC filled steel tube columns. Fourth, the axial load capacity of the high strength SFRC filled steel tube columns are compared to the predicted ultimate strengths using the present design codes such as Eurocode 4, ACI and AS, AISC-LRFD 1999.

\section{EXPERIMENTAL PROGRAM}

A total of 13 square specimens are tested under axial load. The inside of the some steel tubes are greased to provide a weak interaction between the steel tube and the concrete core and to investigate the bond effect on the axial load capacity of high strength SFRC filled steel tube columns.

The wall thickness of the steel tubes is 3,4 and $5 \mathrm{~mm}$. The dimension of the square section is 100 $\mathrm{mm} \times 100 \mathrm{~mm}$. The $\mathrm{D} / \mathrm{t}$ ratio varies from 20 and 33.3. All specimens are $400 \mathrm{~mm}$ in length to prevent the slenderness effect and to ensure that the specimens behave as stub columns. The square column specimens before and after concrete is poured are shown in Figure 1. All the tests are performed at the Istanbul Technical University, Civil Engineering Department in Structural Laboratory. Testing of the high strength concrete filled steel tube columns are performed using a $5000 \mathrm{kN}$ capacity INSTRON testing machine. 

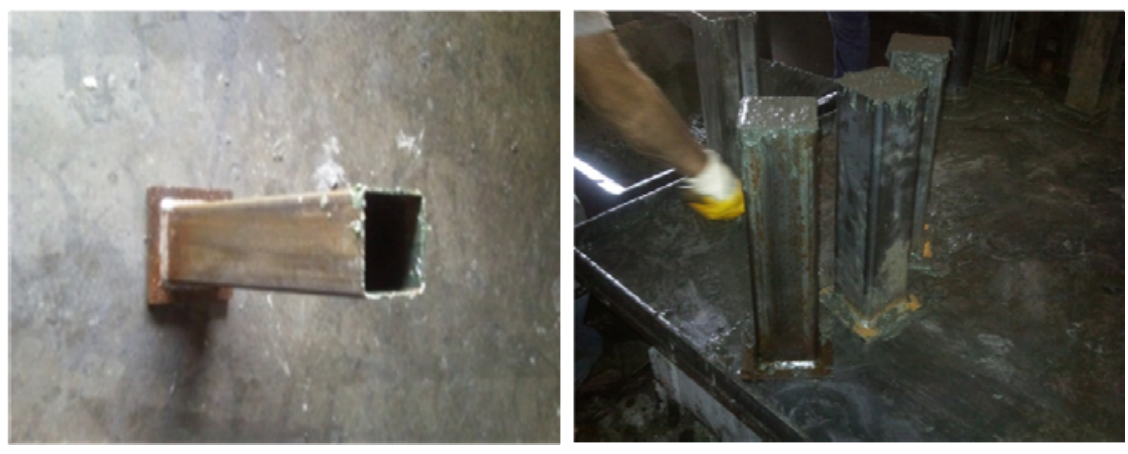

Figure 1. The Square Column Specimens before and after Concrete Filled

\subsection{Concrete Properties}

Steel fiber reinforced concrete (SFRC) is produced to enhance the mechanical properties of concrete such as the compressive strength and ductility. The high strength SFRC for the composite columns is mixed in one batch. Dramix ZP 305 steel fibers are used in the mix at two percent (2\%) by volume. The fibers in the mix have a diameter of $0.55 \mathrm{~mm}$, a length $30 \mathrm{~mm}$, tensile strength of $1100 \mathrm{MPa}$. The type of cement CEM I PÇ 42.5R is used as cement material in the mix. A super plasticizer is used for mix, the amount being varied to maintain approximately the same workability. The mixture proportions of the matrix are as follows; cement: silica fume: water: siliceous sand $(0.5-2 \mathrm{~mm})$ : siliceous powder $(0-0.5 \mathrm{~mm})$ : super plasticizer $=1: 0.250: 0.12: 0.325: 0.5: 0.13$. Water-binder ratio is kept constant at 0.13 . The typical mix composition of the high strength SFRC used in this study is shown in Table 1.

Table 1. Steel Fiber Reinforced Concrete Mix Design

\begin{tabular}{|l|l|}
\hline & $\begin{array}{l}\text { Mix proportions } \mathrm{kg} \\
\text { (for 1 m3 concrete) }\end{array}$ \\
\hline Cement & 1000 \\
\hline Siliceous sand $(0.5-2 \mathrm{~mm})$ & 325 \\
\hline Siliceous powder $(0-0.5 \mathrm{~mm})$ & 500 \\
\hline Silica fume & 250 \\
\hline Super plasticizer & 130 \\
\hline Water & 165 \\
\hline ZP 305 Dramix steel fiber & 160 \\
\hline Total & 2530 \\
\hline
\end{tabular}

The target concrete compressive cylinder strength $\left(f_{c y l, 150}\right)$ at 28 days approximately is $100 \mathrm{MPa}$. Standard cylinder $(150 \mathrm{~mm} \times 300 \mathrm{~mm})$ tests are carried out in accordance to Turkish Standard TS EN 206 to determine the compressive strength. The concrete cylinder specimens are tested at a loading rate of 300 and $250 \mathrm{kN} / \mathrm{min}$. Cylinders size are $150 \mathrm{~mm}$ diameter and $300 \mathrm{~mm}$ length. The average compressive strength $\left(f_{c k}\right)$ at the time of test is $115 \mathrm{MPa}$. Each layer of concrete is compacted using a poker vibrator. The modulus of elasticity of concrete is the tangent modulus at one-third the ultimate strength and measured in accordance with Turkish standards (TS EN 206-1). The average modulus of elasticity value is $42579 \mathrm{MPa}$. 


\section{$2.2 \quad$ Steel Properties}

The tubes are all manufactured from mild steel by the steel company. In order to determine the actual material properties, three coupons are cut from each steel tube having different steel tube according to Turkish Standard TS 138 EN 10002. The average yield stress, tensile strength, and modulus of elasticity are $304 \mathrm{MPa}, 400 \mathrm{MPa}$, and $200000 \mathrm{MPa}$, respectively.

Figure 2 shows the typical stress-strain relation for the each steel coupon measured in the tension tests according to Turkish standard TS 138 EN 10002.

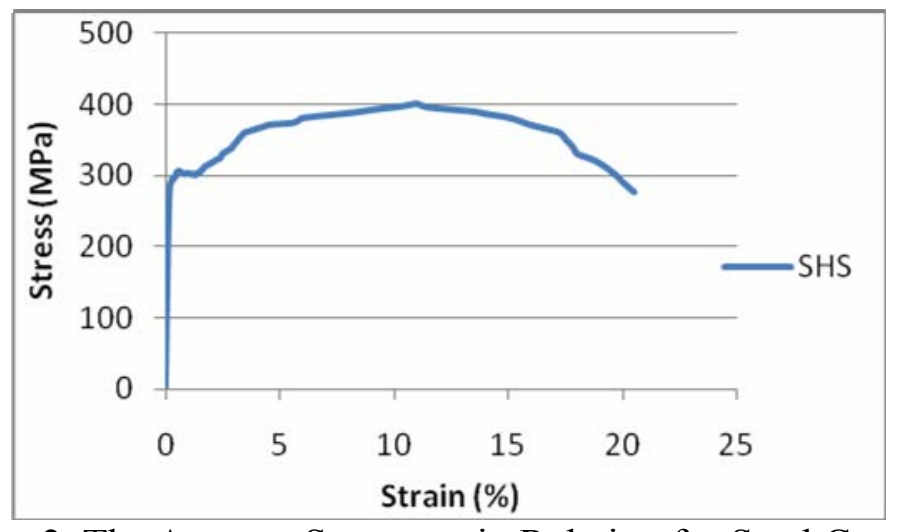

Figure 2. The Average Stress-strain Relation for Steel Coupons

\section{$2.3 \quad$ Test Set-up}

The specimens are loaded at $30 \mathrm{kN}$ intervals at the beginning of the test and at a loading rate of 10 $\mathrm{kN}$ intervals after the column begin to yield. All the tests are performed on a $5000 \mathrm{kN}$ capacity testing machine. Two linear variable differential transducers $\left(\mathrm{LVDT}_{\mathrm{s}}\right)$ are placed in diametrically opposite positions equally placed at each side of the column to measure the axial deformation. Four strain gauges are used for each specimen to measure strains at the middle height, two strain gauges at the top and two strain gauges at the bottom. The test setup is shown in Figure 3.

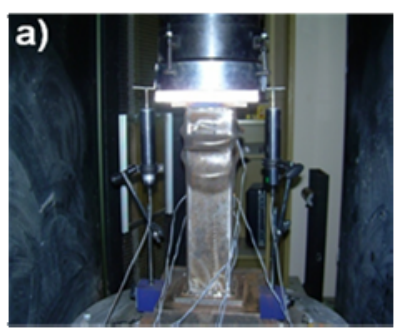

Figure 3. a) The Test Set Up

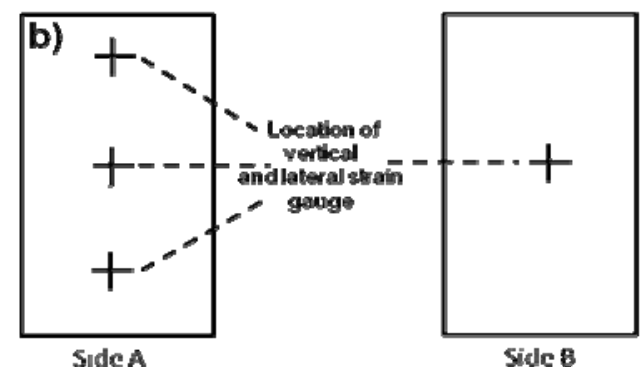

b) Location of Strain Gauges

The specimens are labeled according to their shape of the steel tube, greased or non-greased, the thickness of steel tube and the number of that group. For example, S3G-1, it is denoted ' $S$ ' square, ' 3 ' the thickness of the steel tube, ' $G$ ' greased and ' 1 ' the number of that specimen. S5NG-2, it is denoted ' $S$ ' square, ' 5 ' the thickness of the steel tube, 'NG' non-greased, '2' the number of that specimen. The geometrical and material properties of the specimens are shown in the Table 2 . 
Table 2. Geometric and Material Properties of Specimens

\begin{tabular}{|c|c|c|c|c|c|c|c|}
\hline No & $\begin{array}{c}\mathrm{D} \times \mathrm{B} \times \mathrm{t} \\
(\mathrm{mm})\end{array}$ & $\begin{array}{c}\mathrm{L} \\
(\mathrm{mm})\end{array}$ & $\mathrm{D} / \mathrm{t}$ & $\begin{array}{c}f_{c} \\
(\mathrm{Mpa})\end{array}$ & $\begin{array}{c}f_{y} \\
(\mathrm{Mpa})\end{array}$ & $\begin{array}{c}\mathrm{A}_{\mathrm{s}} \\
\left(\mathrm{mm}^{2}\right)\end{array}$ & $\begin{array}{c}\mathrm{A}_{\mathrm{c}} \\
\left(\mathrm{mm}^{2}\right)\end{array}$ \\
\hline S3G-1 & $100 \times 100 \times 3$ & 400 & 33,3 & 115 & 304 & 1164 & 8836 \\
\hline S3G-2 & $100 \times 100 \times 3$ & 400 & 33,3 & 115 & 304 & 1164 & 8836 \\
\hline S3G-3 & $100 \times 100 \times 3$ & 400 & 33,3 & 115 & 304 & 1164 & 8836 \\
\hline S3NG-1 & $100 \times 100 \times 3$ & 400 & 33,3 & 115 & 304 & 1164 & 8836 \\
\hline S3NG-2 & $100 \times 100 \times 3$ & 400 & 33,3 & 115 & 304 & 1164 & 8836 \\
\hline S4G-1 & $100 \times 100 \times 4$ & 400 & 25 & 115 & 304 & 1536 & 8464 \\
\hline S4G-2 & $100 \times 100 \times 4$ & 400 & 25 & 115 & 304 & 1536 & 8464 \\
\hline S4NG-1 & $100 \times 100 \times 4$ & 400 & 25 & 115 & 304 & 1536 & 8464 \\
\hline S4NG-2 & $100 \times 100 \times 4$ & 400 & 25 & 115 & 304 & 1536 & 8464 \\
\hline S5G-1 & $100 \times 100 \times 5$ & 400 & 20 & 115 & 304 & 1900 & 8100 \\
\hline S5G-2 & $100 \times 100 \times 5$ & 400 & 20 & 115 & 304 & 1900 & 8100 \\
\hline S5NG-1 & $100 \times 100 \times 5$ & 400 & 20 & 115 & 304 & 1900 & 8100 \\
\hline S5NG-2 & $100 \times 100 \times 5$ & 400 & 20 & 115 & 304 & 1900 & 8100 \\
\hline
\end{tabular}

\section{EXPERIMENTAL RESULTS}

\subsection{Load Versus Displacement}

Load - displacement relations for all specimens are shown in Figures 4, 5 and 6. Test results have been separated by the steel tube thickness and bond effects.

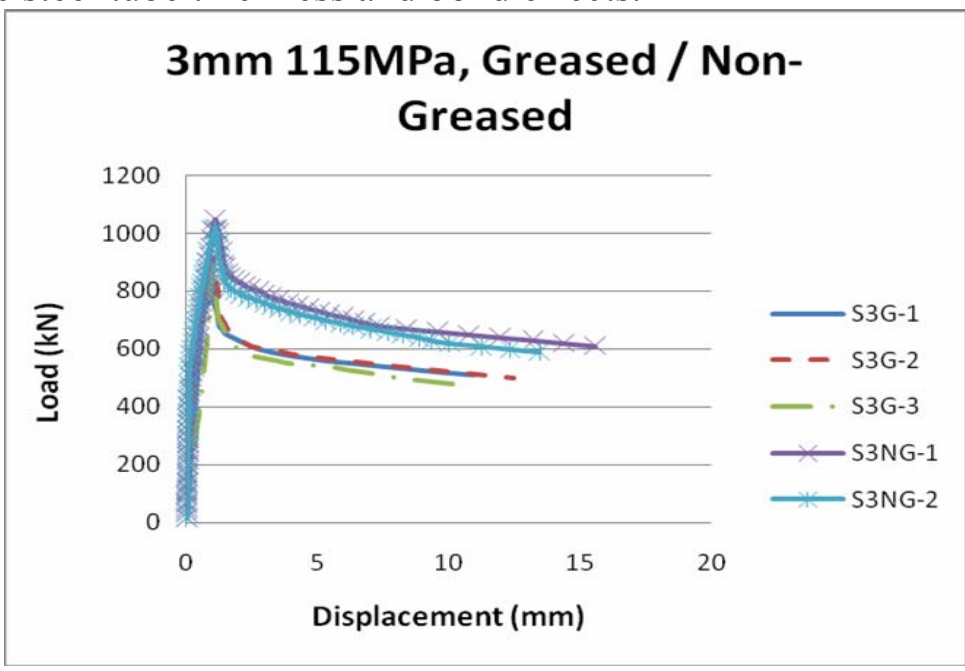

Figure 4. Load-displacement Relation for $3 \mathrm{~mm}$ Steel Tube Thickness 


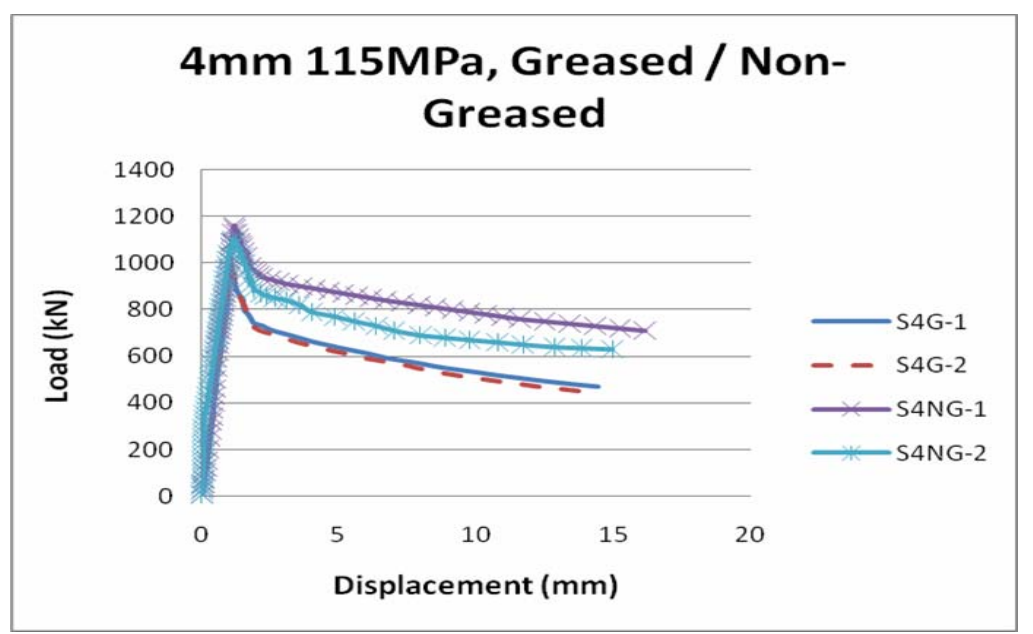

Figure 5. Load-displacement Relation for 4mm Steel Tube Thickness

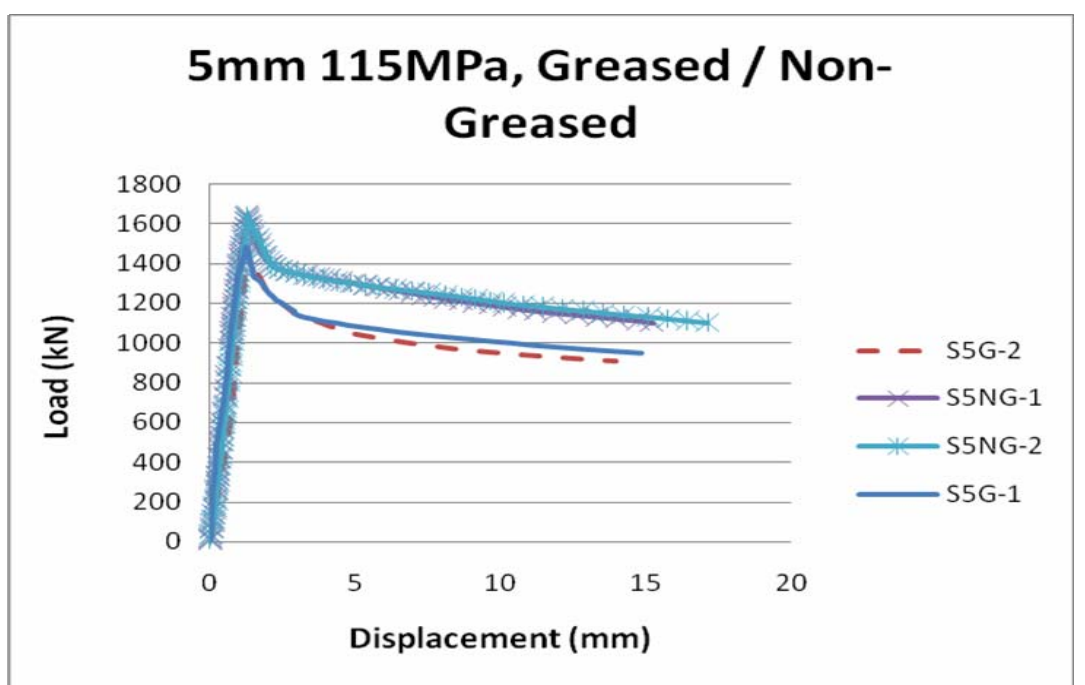

Figure 6. Load-displacement Relation for 5mm Steel Tube Thickness

The load- displacement curves show the axial load capacity and ductility of the SFRC filled steel tube columns. In comparing the load-axial deformation curves for greased and non-greased SFRC filled steel tube columns, the specimens with thicker steel tube wall (smaller $\mathrm{D} / \mathrm{t}$ ratio) show more axial load capacity and ductility. Figures 4, 5 and 6 show the post-yield behavior of each specimen with different steel tube thickness or $\mathrm{D} / \mathrm{t}$ ratio. All specimens exhibit strain-softening characteristic after the specimen reached elastic axial capacity. The difference of the average axial load capacity with respect to steel tube thickness of the greased and non-greased specimens is shown in Table 3.

Table 3. The difference of the average axial load capacity for the greased and non-greased specimens

\begin{tabular}{|c|c|c|c|}
\hline & $\begin{array}{c}\text { The greased } \\
\text { specimens }\end{array}$ & $\begin{array}{c}\text { The non-greased } \\
\text { specimens }\end{array}$ & $\begin{array}{c}\text { The difference of } \\
\text { the average axial } \\
\text { load capacity }\end{array}$ \\
\hline $3 \mathrm{~mm}$ steel tube thickness & $893 \mathrm{kN}$ & $1033 \mathrm{kN}$ & $14 \%$ \\
\hline $4 \mathrm{~mm}$ steel tube thickness & $985 \mathrm{kN}$ & $1130 \mathrm{kN}$ & $13 \%$ \\
\hline $5 \mathrm{~mm}$ steel tube thickness & $1477 \mathrm{kN}$ & $1639 \mathrm{kN}$ & $10 \%$ \\
\hline
\end{tabular}

The local buckling of the steel tubes generally happens on every face of the steel tube. The typical specimen failure modes of the columns are shown in Figure 7. 


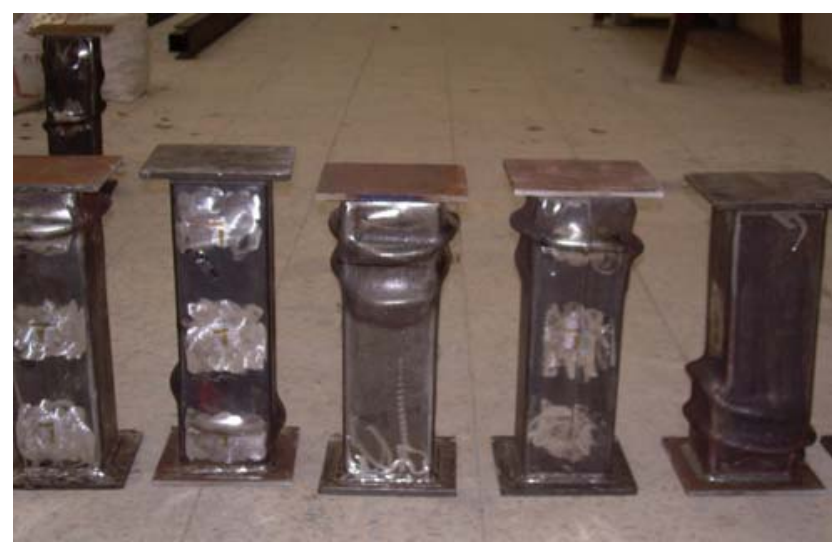

Figure 7. Typical Specimen Failure Modes

\subsection{Ductility Index and Strength Enhancement Index}

Han et al. [9] define some parameters to explain better the strength enhancement and the ductility of the column specimens. These are the strength enhancement index, the ductility index and the

constraining factor. The $\boldsymbol{\xi}$ is the constraining factor defined by Eq. 1, the DI is the ductility index

defined by Eq. 2 and the SI is the strength enhancement index given by Eq. 3.

$$
\xi=\frac{A_{s} f_{y}}{A_{c} f_{c k}}
$$

$D I=\frac{\delta_{85 \%}}{\delta_{u}}$

$S I=\frac{N_{u, \text { Filled }}}{A_{s} f_{y}+A_{c} f_{c k}}$

Here, $\mathrm{N}_{\mathrm{u} \text {,filled }}$ is the ultimate load reached in the tests, $\delta_{\mathrm{u}}$ is the axial shortening at the ultimate load, $\delta_{85 \%}$ is the axial shortening when the load falls to $85 \%$ of the ultimate load, $A_{s}$ is the steel cross-sectional area, $A_{c}$ is the concrete cross-sectional area, $f_{y}$ and $f_{c k}$ are the yielding stress of the steel tube and the compressive strength of the concrete, respectively. The strength enhancement index (SI) and the ductility index (DI) is shown against the tube diameter to the steel tube wall thickness ratio $(\mathrm{D} / \mathrm{t})$ for the square specimens in Table 4. As seen in Table 4, the relationship between the strength enhancement index (SI) and the constraining factor $(\xi)$ or the ductility index (DI) and the constraining factor $(\xi)$ is linear. This proves that the specimens with thicker steel tube wall exhibit greater ductility and the strength enhancement due to stronger confinement. 
Table 4. The Parameters for the Greased and the Non-greased Specimens

\begin{tabular}{|l|c|c|c|}
\hline & $\xi$ & $D I$ & $S I$ \\
\hline S3G-1 & 0.35 & 1.28 & 0.62 \\
\hline S3G-2 & 0.35 & 1.32 & 0.67 \\
\hline S3G-3 & 0.35 & 1.3 & 0.66 \\
\hline S3NG-1 & 0.35 & 1.41 & 0.77 \\
\hline S3NG-2 & 0.35 & 1.38 & 0.74 \\
\hline S4G-1 & 0.48 & 1.51 & 0.69 \\
\hline S4G-2 & 0.48 & 1.49 & 0.68 \\
\hline S4NG-1 & 0.48 & 1.61 & 0.8 \\
\hline S4NG-2 & 0.48 & 1.58 & 0.76 \\
\hline S5G-1 & 0.62 & 1.71 & 0.98 \\
\hline S5G-2 & 0.62 & 1.69 & 0.97 \\
\hline S5NG-1 & 0.62 & 1.74 & 1.09 \\
\hline S5NG-2 & 0.62 & 1.78 & 1.08 \\
\hline
\end{tabular}

\section{COMPARISON OF THE TEST RESULTS WITH DESIGN CODES}

\subsection{Eurocode 4}

Eurocode 4 (EC4) [16] for square concrete filled steel tubes, the design loads are calculated as the summation of the individual ultimate axial capacities of the steel tube and concrete as given by Eq. 4.

$\mathrm{N}_{\mathrm{u}}=A_{\mathrm{s}} \mathrm{f}_{\mathrm{y}}+A_{\mathrm{c}} \mathrm{f}_{\mathrm{ck}}$

Where, the $f_{c k}$ is the average cylinder compressive strength of concrete, $f_{y}$ is the yield strength of steel tube, $A_{s}$ is the cross-sectional area of steel tube and, $A_{s}$ is the cross-sectional area of core concrete, respectively.

When we compare the ultimate axial loads of test result with the EC4 it can be seen that EC4 is safe for the specimens with $5 \mathrm{~mm}$ steel tube thickness. The largest difference between test and EC4 for the greased and the non-greased specimens is $2 \%$ and $8 \%$. The average $\mathrm{N}_{\text {test }} / \mathrm{N}_{\mathrm{EC} 4}$ for the greased columns is 0.98 and for non-greased columns is 1.09 . The EC4 overestimate the axial load capacity for the specimens with $4 \mathrm{~mm}$ and $3 \mathrm{~mm}$ steel tube thickness. The largest difference between test and EC4 for the greased and non-greased specimens with $4 \mathrm{~mm}$ and $3 \mathrm{~mm}$ steel tube thickness is $32 \%, 24 \%$ and $38 \%$ and $26 \%$, respectively. The average $\mathrm{N}_{\text {test }} / \mathrm{N}_{\mathrm{EC} 4}$ of the greased and non-greased specimens with $4 \mathrm{~mm}$ steel tube thickness is 0.69 and 0.79 , respectively. The average $\mathrm{N}_{\text {test }} / \mathrm{N}_{\mathrm{EC} 4}$ of the greased and non-greased specimens with $3 \mathrm{~mm}$ steel tube thickness is 0.66 and 0.76 , respectively.

\subsection{ACI and Australian Standard}

The American Concrete Institute (ACI) [17] and Australian Standard (AS) [18, 19] use the same formula for calculating the ultimate axial load capacity of square concrete filled tube stub columns. The axial load capacity of the square concrete filled tube columns according to ACI and AS is given in the Eq. 5 . 
$\mathrm{N}_{\mathrm{c}, \mathrm{ACI}, \mathrm{AS}}=0.85 \mathrm{~A}_{\mathrm{c}} \mathrm{f}_{\mathrm{ck}}+\mathrm{A}_{\mathrm{s}} \mathrm{f}_{\mathrm{y}}$

The ACI and Australian Standards provide a good prediction of the specimens with thicker (smaller $\mathrm{D} / \mathrm{t}$ ratio) steel tube wall. The average $\mathrm{N}_{\text {test }} / \mathrm{N}_{\mathrm{ACI}, \mathrm{AS}}$ of the greased and non-greased specimens with $5 \mathrm{~mm}$ steel tube wall is 1.08 and 1.2, respectively. The largest difference between test and ACI or Australian Standard for the greased and non-greased specimens is $8 \%$ and $17 \%$, respectively.

For the greased and non-greased specimens with $3 \mathrm{~mm}$ and $4 \mathrm{~mm}$ steel tube thickness, the largest difference between test and ACI or Australian Standard is 30\%, 17\% and 24\% and 15\%, respectively. For the specimens with $3 \mathrm{~mm}$ steel tube thickness the average $\mathrm{N}_{\text {test }} / \mathrm{N}_{\mathrm{ACI}, \mathrm{AS}}$ of the greased and the non-greased columns is 0.74 and 0.85 , respectively. The average $\mathrm{N}_{\text {test }} / \mathrm{N}_{\text {ACI,AS }}$ of the greased and non-greased specimens with $4 \mathrm{~mm}$ steel tube thickness is 0.77 and 0.88 , respectively.

\subsection{AISC-LRFD 1999}

American Institute of Steel Construction (AISC) [20] specifications is limited to columns with concrete cylinder strength and steel yield stress not more than 55 and $380 \mathrm{MPa}$, respectively. The axial load capacity of the concrete filled steel tube columns according to AISC is shown in Eqs. 6 to 9 .

$$
\begin{aligned}
& \mathrm{N}_{\mathrm{c}}=A_{s} f_{c r} \\
& \boldsymbol{f}_{c r}=\left(0.658^{\lambda_{c}{ }^{2}}\right) \boldsymbol{f}_{m y} \\
& \lambda_{c}=\left(\frac{L}{r_{s} \pi}\right) \sqrt{\frac{f_{m y}}{E_{s}+0.4 E_{c} \frac{A_{c}}{A_{s}}}} \\
& f_{m y}=f_{y}+0.85 f_{c k} \frac{A_{c}}{A_{s}}
\end{aligned}
$$

Here, $E_{c}$, modulus of elasticity of concrete; $E_{s}$, modulus of elasticity of steel tube; L, length of column and $r_{s}$ is radius of gyration of steel tube.

AISC provides a good prediction the specimens with thinner steel tube wall compared to thinner ones. For the greased specimens with $3 \mathrm{~mm}, 4 \mathrm{~mm}$ and $5 \mathrm{~mm}$ steel tube thickness, the largest difference between test and AISC is $18 \%, 12 \%$ and $20 \%$, respectively. For the non-greased specimens with $3 \mathrm{~mm}, 4 \mathrm{~mm}$ and $5 \mathrm{~mm}$ steel tube thickness is $3 \%, 4 \%$ and $28 \%$, respectively. The average $\mathrm{N}_{\text {test }} / \mathrm{N}_{\text {AISC }}$ of the greased and non-greased specimens with $3 \mathrm{~mm}, 4 \mathrm{~mm}$ and $5 \mathrm{~mm}$ steel tube thickness is 0.86 and $0.89,1.25$ and $0.99,1.02$ and 1.38 , respectively. The experimental results compared to the design codes are shown in Table 5. 
Table 5. Comparisons of failure loads between test results and design codes

\begin{tabular}{|c|c|c|c|c|c|c|c|}
\hline \multirow[t]{2}{*}{ No } & \multirow[b]{2}{*}{$\begin{array}{l}\mathrm{N}_{\mathrm{ue}} \\
(\mathrm{kN})\end{array}$} & \multicolumn{2}{|l|}{$\mathrm{EC} 4$} & \multicolumn{2}{|c|}{ ACI,AS } & \multicolumn{2}{|c|}{ AISC } \\
\hline & & $\begin{array}{l}\mathrm{N}_{\mathrm{c}} \\
(\mathrm{kN})\end{array}$ & $\begin{array}{l}\mathrm{N}_{\mathrm{ue}} / \mathrm{N}_{\mathrm{c}} \\
(\mathrm{kN})\end{array}$ & $\begin{array}{l}\mathrm{N}_{\mathrm{c}} \\
(\mathrm{kN})\end{array}$ & $\begin{array}{l}\mathrm{N}_{\mathrm{ue}} / \mathrm{N}_{\mathrm{c}} \\
(\mathrm{kN})\end{array}$ & $\begin{array}{l}\mathrm{N}_{\mathrm{c}} \\
(\mathrm{kN})\end{array}$ & $\begin{array}{l}\mathrm{N}_{\mathrm{ue}} / \mathrm{N}_{\mathrm{c}} \\
(\mathrm{kN})\end{array}$ \\
\hline S3G-1 & 856 & 1370 & 0.62 & 1218 & 0.70 & 1047 & 0.82 \\
\hline S3G-2 & 920 & 1370 & 0.67 & 1218 & 0.76 & 1047 & 0.88 \\
\hline S3G-3 & 902 & 1370 & 0.66 & 1218 & 0.74 & 1047 & 0.86 \\
\hline S3NG-1 & 1049 & 1370 & 0.77 & 1218 & 0.86 & 1047 & 1.00 \\
\hline S3NG-2 & 1017 & 1370 & 0.74 & 1218 & 0.83 & 1047 & 0.97 \\
\hline S4G-1 & 990 & 1440 & 0.69 & 1294 & 0.77 & 1114 & 0.89 \\
\hline S4G-2 & 980 & 1440 & 0.68 & 1294 & 0.76 & 1114 & 0.88 \\
\hline S4NG-1 & 1160 & 1440 & 0.81 & 1294 & 0.90 & 1114 & 1.04 \\
\hline S4NG-2 & 1100 & 1440 & 0.76 & 1294 & 0.85 & 1114 & 0.99 \\
\hline S5G-1 & 1481 & 1509 & 0.98 & 1369 & 1.08 & 1187 & 1.25 \\
\hline S5G-2 & 1474 & 1509 & 0.98 & 1369 & 1.08 & 1187 & 1.24 \\
\hline S5NG-1 & 1642 & 1509 & 1.09 & 1369 & 1.20 & 1187 & 1.38 \\
\hline S5NG-2 & 1636 & 1509 & 1.08 & 1369 & 1.20 & 1187 & 1.38 \\
\hline St. Dev. & & & 0.16 & & 0.17 & & 0.19 \\
\hline
\end{tabular}

\section{CONCLUSIONS}

The main conclusion that we observed from current study as highlighted below.

The Poisson ratio is slightly less and the amount of shrinkage is much higher of the high strength concrete than the medium or low strength concrete. Because of these reasons, the confining effect of the steel tube to the concrete core is not seen much for high strength concrete compared to the low or medium strength concrete.

Therefore, the reduction on the axial load capacity of the column due to the loss of bonding is not negligible for the high strength concrete such as SFRC. In comparing the load-displacement curves for the greased and the non-greased specimens with same steel tube thickness (Figures 4, 5, 6), it is shown that there is a difference on the axial load capacity. However, the bond stress capacity is much higher in the columns with thinner steel tube wall than the thicker (smaller D/t ratio) ones. The difference of the axial load capacity between greased and non-greased specimens with steel tube thickness $3 \mathrm{~mm}, 4 \mathrm{~mm}$ and $5 \mathrm{~mm}$ is $14 \%, 13 \%$ and $10 \%$, respectively.

The increase in the axial load capacity due to the confining effect by the steel tube for the high strength concrete filled tube columns is much less than the medium or low strength concrete ones. Therefore, there is no significant increase in the axial load capacity for the greased and non-greased specimens. In addition to this, the increase in the axial load capacity for the specimens with thinner steel tube thickness is much less than the thicker ones as confining effect is not seen much due to the a great number of local buckling of the thinner steel tube ones.

The SFRC filled steel tube columns with thicker steel tube wall has lower slope of descending branch and show more post-ductile behavior than that of thinner ones. The ductility index (DI) and the strength enhancement index (SI) become higher as the thickness of the steel tube wall increases. 
All design codes overestimate the axial load capacity for the greased and the non-greased specimens with thinner steel tube thickness (D/t is 33.3) due to there is little confinement arising from the local buckling of the steel tube. These design codes should use a reduction coefficient in calculating the axial load capacity for the SFRC filled steel tube columns with thinner steel tube thickness to take into account the weak confinement effects.

The specimens with thicker steel tube thickness (D/t is 20) show more axial load capacity due to the effective confinement by the steel tube to the concrete core. These all design codes are conservative in calculating the axial load capacity of the SFRC filled steel tube columns. It can be used a strength enhancement coefficient by these design codes to take into account the confinement effect.

The largest difference between test results and design codes is $38 \%, 30 \%$ and $28 \%$ for the EC4, ACI and AS and AISC, respectively.

\section{REFERENCES}

[1] Furlong, R.W., "Strength of Steel-encased Concrete Beam-columns", J. Struct. Div, 1967, Vol. 93, pp. 113-24.

[2] Schneider, S.P., “Axially Loaded Concrete-filled Steel Tubes”, Structural Engineering, 1998, Vol. 124, pp. 1125-38.

[3] Roeder, C.W., Cameron, B. and Brown, C.B., "Composite Action in Concrete Filled Tubes", Journal of Structural Engineering, 1998, Vol. 125, pp. 477-84.

[4] Giakoumelis, G. and Lam, D., "Axial Capacity of Circular Concrete-filled Tube Columns”, Journal of Constructional Steel Research, 2004, Vol. 60, pp. 1049-68.

[5] Morishita, Y., Tomii, M. and Yoshimura, K., "Experimental Studies on Bond Strength in Concrete Filled on Square and Octagonal Steel Tubular Columns Subjected to Axial Loads", Trans Japan Concrete Institute, Tokyo, 1979, pp.359-66.

[6] Virdi, K.S. and Dowling, P.J., "Bond Strength in Concrete Filled Circular Steel Tubes", CESLIC Rep. CC11, Eng. Strctr. Lab, Civil Engineering Dept, Imperial College, London, 1975.

[7] Campiogne, G., Mindess, S., Scibilia, N. and Zingone, G., "Strength of Hollow Circular Steel Sections Filled with Fiber-reinforced Concrete", Can. Journal of Civil Engineering, 2000, Vol. 27, pp. 364-372.

[8] Uy, B., "Strength of Short Concrete Filled High Strength Steel Box Columns", Journal of Constructional Steel Research, 2001, Vol. 57, pp. 113-34.

[9] Han, L.H., "Tests on Stub Columns of Concrete-filled RHS Sections", Journal of Constructional Steel Research, 2002, Vol. 58, pp. 353-72.

[10] Hu, H.T., Huang, C.H., Wu, M.H. and Wu, Y.M., "Nonlinear Analysis of Axially Loaded Concrete-filled Tube Columns with Confinement Effect", Journal of Structural Engineering, ASCE, 2003, Vol. 129, pp. 1322-1329.

[11] Young, B. and Ellobody, E., "Experimental Investigation of Concrete-filled Cold-formed High Strength Stainless Steel Tube Columns", Journal of Constructional Steel Research, 2006, Vol. 62, pp. 484-92.

[12] Teng, J.G., Yu, T., Wong, Y.L. and Dong, S.L., "Hybrid FRP-concrete-steel Tubular Columns: Concept and Behavior", Construction and Building Materials, 2007, Vol. 21, pp. 846-854. 
[13] Zhong, T., Han, L.H. and Wang, D.Y., "Strength and Ductility of Stiffened Thin-walled Hollow Steel Structural Stub Columns Filled with Concrete", Thin Walled Structures, 2008, Vol. 46, pp. 1113-28.

[14] Liang, Q.Q. and Fragomeni, S., "Nonlinear Analysis of Circular Concrete-filled Steel Tubular Short Columns under Eccentric Loading", Journal of Constructional Steel Research, 2010, Vol. 66, No. 2, pp. 159-169.

[15] Zhao, H.L. and Zhao, Y.G., "Suggested Empirical Models for the Axial Capacity of Circular CFT Stub Columns", Journal of Constructional Steel Research, 2010, Vol. 66, pp. 850-62.

[16] Eurocode4, "Design of Composite Steel and Concrete Structures", Brussels, Belgium, 1994.

[17] ACI 318-05, "Building Code Requirements for Structural Concrete and Commentary", Farmington Hills, American Concrete Institute, 2005.

[18] Australian Standards, "Steel Structures", AS4100-1998, Sydney (Australia): Standards Association of Australia, 1998.

[19] Australian Standards, “Concrete Structures”, AS3600-2001.Sydney (Australia): Standards Association of Australia, 2001.

[20] AISC, "Load and Resistance Factor Design (LRFD) Specification for Structural Steel Buildings", Chicago, American Institute of Steel Construction, 1999. 


\title{
BEHAVIOUR FACTOR EVALUATION OF SHEATHED COLD-FORMED STEEL STRUCTURES
}

\author{
Luigi Fiorino ${ }^{1}$, Ornella Iuorio ${ }^{2, *}$ and Raffaele Landolfo ${ }^{2}$ \\ ${ }^{I}$ Department of Structural Engineering, Faculty of Engineering, University of Naples Federico II \\ ${ }^{2}$ Department of Constructions and Mathematical Methods in Architecture, Faculty of Architecture, \\ University of Naples Federico II, Naples, Italy \\ *(Corresponding author: E-mail: ornella.iuorio@unina.it)
}

Received: 3 November 2011; Revised: 25 June 2012; Accepted: 29 June 2012

\begin{abstract}
The seismic behaviour of sheathed cold-formed steel (SCFS) structures is characterized by the lateral response of shear walls. Basically, if cold-formed steel (CFS) structures are designed according to the "sheathing-design" methodology, then the seismic behavior of shear walls is strongly influenced by the sheathing-to-frame connections response, characterized by a remarkable nonlinear response and a strong pinching of hysteresis loops. In this paper the results of an extensive parametric non linear dynamic analysis, carried out on one story buildings by means of incremental dynamic analysis (IDA), using an ad hoc model of the hysteresis response of SCFS shear walls, are presented. An extended number of wall configurations has been considered investigating several parameters such as sheathing panel typology, wall geometry, external screw spacing, seismic weight and soil type. Based on IDA results, three behavior factors have been defined, which take into account overstrength, ductility and both overstrength and ductility, respectively.
\end{abstract}

Keywords: Behavior factor, Cold formed steel, Parametric study, Seismic design, Sheathing-Braced structures, Seismic dynamic analysis, Seismic force modification factor

\section{INTRODUCTION}

The seismic behaviour of cold-formed steel (CFS) structures sheathed with panels is influenced by the response of shear walls, which are characterized by a highly non-linear structural response. In order to assess the seismic performance of sheathed cold-formed steel (SCFS) structures, some experimental and/or numerical research programs have been carried out on different wall configurations. On the basis of results provided by tests and analysis, different seismic design parameters, such as behaviour factor ( $q$, using the European terminology) or seismic force modification factor ( $R$, according to the USA terminology) (Fülöp and Dubina [1-2], Boudreault et al. [3]) and interstory drift limits (Kawai et al. [4], Boudreault et al. [3], Dubina [5]) have been identified, and interesting seismic design methods have been proposed (Kawai et al. [4]). In addition, other studies, focused on the dynamic characteristics of this type of structures (Kawai et al. [4], Gad et al. [6], Dubina [5]), have identified typical values of vibration period and damping ratio.

According to current standards, the seismic design is widely performed by means of force-based linear approaches, in which the structural inelastic response and overstrength are taken into account by reducing the actions produced by earthquakes through seismic force reduction factors, called behavior factor hereafter. In the case of SCFS structural systems, specific studies on the evaluation of behavior factor are needed to taking into account the peculiarity of their dynamic response, characterized by low natural period (generally from 0.1 to $0.3 s$ ) and highly non-linear pinched force-displacement response. An literature overview on proposed behavior factor is given in Section 2. Nowadays, two main approaches devoted to seismic force reduction factor assessment are available: experimental and numerical. Due to the limited sample of shear wall configurations on which a experimental campaign can be carried out, the evaluation of behavior factor in this research has been mainly performed by a very extensive parametric non-linear time-history dynamic analyses, which are described in Sections 3 and 4. The parametric analysis has been developed through the incremental non-linear dynamic analysis (IDA), in which for the definition 
of the two main parameters related to the structural performance and earthquake record magnitude, the inter-story drift and the adimensionalized elastic spectral acceleration corresponding to the first mode period of the structure have been assumed, respectively. In particular, the IDA has been performed on one-story buildings with and without attic, representative of a large range of solutions of stick-built constructions and considering seismic inputs selected in such a way that they could cover all the soil typologies classified by Eurocode 8 (CEN [8]), for a total number of 529200 single non-linear dynamic analysis. On the basis of IDA results, an evaluation of behavior factors has been carried out (Section 5) by following two different approaches called "classical" and "multi-performance". In particular, for the "classic" approach the evaluation of the behavior factor follows the common assumptions made in the current seismic codes, i.e. it is based on seismic demands required by records representative of $10 \% / 50$ earthquakes, by relating this hazard level to the life safety structural performance. In the "multi-performance" approach, instead, different behavior factors are defined by relating they to different seismic performance levels, in such a way to obtain a "multi-performance" seismic design and to give the possibility to achieve an "enhanced objective" (FEMA [8]).

\section{OVERVIEW ON SEISMIC FORCE REDUCTION FACTORS}

As far as the definition of behaviour factor is concerned, monotonic and cyclic tests on walls sheathed with trapezoidal steel sheets or oriented strand board (OSB) panels with or without openings were carried out by Fülöp \& Dubina [1]. On the basis of this experimental results they developed a numerical model and performed incremental dynamic analysis. Therefore, the Authors define three different behaviour factors (Fülöp and Dubina [2]): $q_{1}$, corresponding to the overstrength, $q_{2}$ corresponding to the ductility, and $q_{3}=q_{1} q_{2}$, which takes into account both effects. The behaviour factor $q_{1}$ ranges from 2.2 to $2.6, q_{2}$ ranges from 1.4 to 1.6 and $q_{3}$ is in the range 3.6 through 3.7. In particular, in the case of walls sheathed with OSB panels and without openings the Authors found the following average behaviour factors: $q_{1}=2.7, q_{2}=1.4$ and $q_{3}=3.7$. Boudreault et al. [3] evaluated the seismic force modification factors $(R)$ due to the ductility $\left(R_{d}\right)$ and overstrength $\left(R_{o}\right)$ as defined by the National Building Code of Canada NBCC [9]. The proposed values $R_{d}=2.5, R_{o}=1.7$, and $R=R_{o} R_{d}=4.3$ were obtained by analyzing the results of monotonic and cyclic tests on different configurations of walls sheathed with plywood and OSB panels (Branston et al. [10]; Blais [11]; Rokas [12]). The values obtained on experimental basis were verified through the results of non-linear dynamic analysis (time-history) carried out on two representative buildings (Boudreault et al. [3]). Values of seismic force reduction factor ( $R$-factor) for CFS buildings are also provided in a number of Codes, as the ASCE / SEI 7-10 [13], and the FEMA P750 [8]. In particular, for shear walls sheathed with wood panels or steel sheets, values of R-factor equal to 7 and 6.5 are provided by ASCE/SEI 7-10 and Fema P750, respectively. In the case of other sheathing typologies, the provided values are 2.5 and 2 for ASCE/SEI 7-10 and FEMA P750, respectively. All the values defined by Authors and codes are summarized in Table 1.

Table 1. Behaviour Factors

\begin{tabular}{ccccc}
\hline Author & Type of sheathing & $q_{1}$ & $q_{2}$ & $q_{3}$ \\
\hline Fülöp \& Dubina & OSB (without openings) & 2.7 & 1.4 & 3.7 \\
\hline Boudreault et al. & Plywood or OSB & 1.7 & 2.5 & 4.3 \\
\hline ASCE & Wood or steel & - & - & 2.5 \\
\hline FEMA P 750 & Wood or steel & - & - & 6.5 \\
\hline FEMA P 750 & Other materials & - & - & 2 \\
\hline
\end{tabular}




\section{MONOTONIC RESPONSE EVALUATION}

\subsection{Model for Monotonic Response Prediction}

In this paper the analytical-numerical model proposed by the authors (Landolfo et al [14]), that allows the evaluation of the monotonic lateral response of a SCFS shear wall, has been used. The method is based on the most common assumptions made for other available approaches, such as full anchorage between frame and foundation or other stories and sheathing-to-frame interaction characterized by a "rigid body" behaviour. The model allows the evaluation of each wall deflection contribution, from which the total wall deflection can be obtained by adding the deformation due to bending $\left(d_{F}\right.$, $)$, sheathing fasteners $\left(d_{F-S}\right)$, sheathing panels $\left(d_{S}\right)$, and anchorages $\left(d_{F-F}\right): d=d_{F}+d_{F-S}+$ $d_{S}+d_{F-F}$.
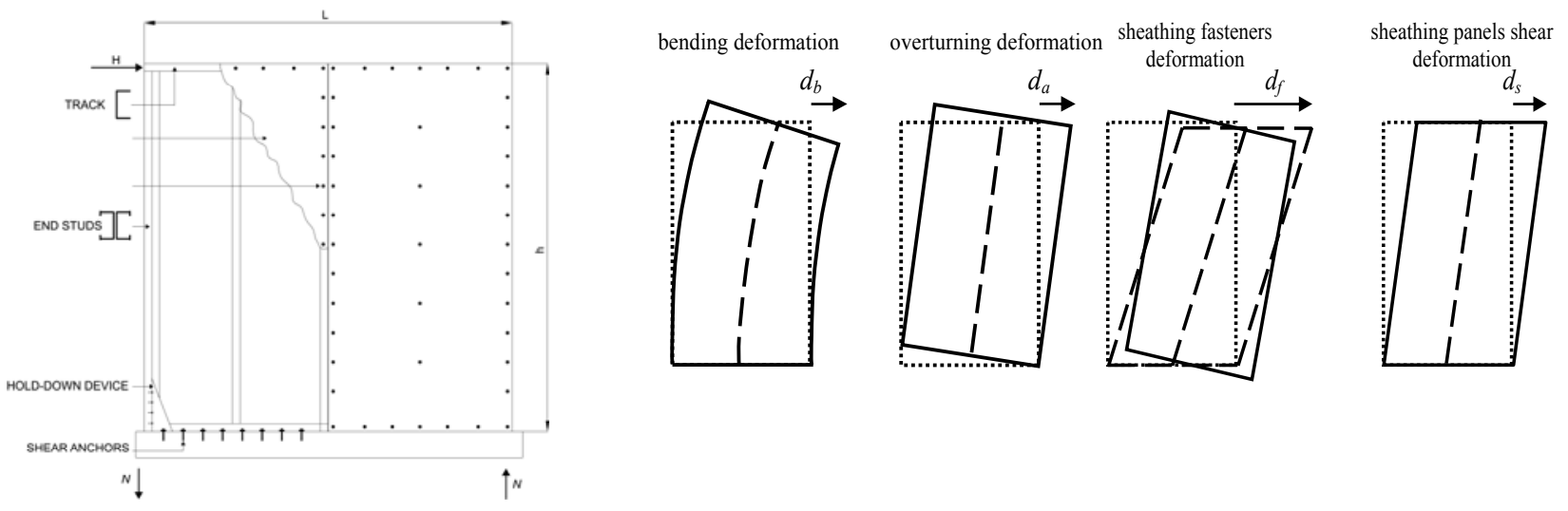

Figure 1. Wall Components and Deformation Contributions

The model has been calibrated on the basis of monotonic tests on full scale specimens (Landolfo et al. [15]) carried out on CFS shear walls sheathed with OSB and gypsum board (GWB) and tests performed on sheathing connections (Iuorio, [16]) that are nominally identical to that used for the walls. Further details about hypothesis and applicability of the model can be found in Fiorino et al. [17].

\subsection{Parametric Study}

In order to study the behaviour of different wall configurations, the model has been applied to simulate the monotonic response of 72 different wall configurations. All the walls are made of $100 \times 50 \times 10 \mathrm{~mm}$ (outside-to-outside web depth $\times$ outside-to-outside flange size $\times$ outside-to-outside lip size) lipped channel studs, spaced at $600 \mathrm{~mm}$ and sheathed with GWB panels on both sides $(\mathrm{G}+\mathrm{G})$ or GWB on one side and OSB panels on the other side $(\mathrm{G}+\mathrm{O})$. The thicknesses of $\mathrm{GWB}$ and OSB panels are $12.5 \mathrm{~mm}$ and $9.0 \mathrm{~mm}$, respectively. For connecting sheathing panels and frame $4.2 \times 25 \mathrm{~mm}$ (diameter $\times$ length) flat head self drilling screws have been considered for OSB and $3.5 \times 25 \mathrm{~mm}$ bugle head for GWB. The fasteners have spacing equal to $300 \mathrm{~mm}$ in the field, while different external screw spacing have been investigated. Hold down devices type Simpson Strong-Tie [18] and chemical anchorage (type HIT-RE 500 with HIS-N 8.8 by Hilti [19]) have been considered at each end of the wall, while mechanical shear anchors (type HST M8 by Hilti) have been hypothesized. Sheathing panel typology, wall geometry (height $h$ and length $l$ ) and external screw spacing $(s)$ have been varied as summarized in Table 2. For each wall configuration obtained by combining the parameters given in Table 1 , the stud thickness $\left(t_{F}\right)$ and hold-down device typology have been selected in such a way to promote the sheathing fasteners collapse, as shown in Table 2 . The monotonic response of the walls has been obtained by considering a shear modulus $(G)$ 
of $1400 \mathrm{MPa}$ for OSB panels and $750 \mathrm{MPa}$ for GWB panels. In addition, a Young modulus $(E)$ for the steel equal to $200000 \mathrm{MPa}$ has been adopted, while the assumed values of hold down device axial stiffness $\left(K_{a}\right)$ are given in Table 3 .

Table 2. Variables Assumed in the Parametric Study

\begin{tabular}{ll}
\hline Sheathing panel typology & $\mathrm{GWB}+\mathrm{GWB}(\mathrm{G}+\mathrm{G}), \mathrm{GWB}+\mathrm{OSB}(\mathrm{G}+\mathrm{O})$ \\
\hline Wall height $(h)[\mathrm{mm}]$ & $2400,2700,3000$ \\
\hline Wall length $(l)[\mathrm{mm}]$ & $1200,2400,9600$ \\
\hline External screw spacing $(s)[\mathrm{mm}]$ & $50,75,100,150$ \\
\hline
\end{tabular}

Table 3. Selected Stud Thicknesses and Hold Down Devices

\begin{tabular}{llll}
\hline $\begin{array}{l}\text { Wall typology } \\
{[s \text { and } h \text { in mm }]}\end{array}$ & Hold down & $\begin{array}{l}\text { stud }\left(t_{F}\right) \\
{[\mathrm{mm}]}\end{array}$ & $\begin{array}{l}K_{a} \\
{[\mathrm{kN} / \mathrm{mm}]}\end{array}$ \\
\hline $\begin{array}{l}\mathrm{G}+\mathrm{G} ; s=75,100,150 \\
\mathrm{G}+\mathrm{O} ; s=150\end{array}$ & $\mathrm{~S} / \mathrm{HD} 8 \mathrm{~B}$ & 1.0 & 28 \\
\hline $\begin{array}{l}\mathrm{G}+\mathrm{O} ; s=75 ; h=2400,2700 \\
\mathrm{G}+\mathrm{O} ; s=100 ; h=2400\end{array}$ & S/HD 8B & 1.5 & 28 \\
\hline $\begin{array}{l}\mathrm{G}+\mathrm{G} ; s=50 \\
\mathrm{G}+\mathrm{O} ; s=100 ; h=2700,3000\end{array}$ & $\mathrm{~S} / \mathrm{HD} 10 \mathrm{~B}$ & 1.0 & 27 \\
\hline $\mathrm{G}+\mathrm{O} ; s=50 ; h=2400$ & & & \\
\hline $\mathrm{G}+\mathrm{O} ; s=50 ; h=2700,3000$ & $\mathrm{~S} / \mathrm{HD} 10 \mathrm{~B}$ & 1.5 & 27 \\
\hline $\mathrm{G}+\mathrm{O} ; s=75 ; h=3000$ & S/HD 15B & 1.5 & 31 \\
\hline
\end{tabular}

\section{EVALUATION OF CYCLIC RESPONSE}

\subsection{Cyclic Response Modelling}

In this study an upgraded version of the cyclic model proposed in Della Corte et al [20], which takes into account the strength degradation, has been used. According to this approach, in order to model the cycle lateral response of shear walls in terms of horizontal force $(H)$ vs. lateral deflection $(d)$, the definition of three limit curves, together with the definition of transition and strength degradation laws are needed (Figure 2). The first curve (monotonic curve) represents the monotonic response, while the other curves represent the upper bound cyclic (UBC) curve and the lower bound cyclic (LBC) curve to all possible $H-d$ values obtained in the cyclic response. For each curve a 6 independent parameters Richard-Abbott type law is assumed, with the following parameters for the monotonic curve: $K_{0}$ is the initial stiffness; $H_{0}$ is the intersection between the hardening line and the $d=0$ axis; $K_{h}$ is the slope of the hardening line; $n$ is the shape parameter regulating the sharpness of transition from the elastic to the plastic behaviour; $d_{p}$ is the peak deflection; $K_{d}$ is the post-peak stiffness; $d_{u}$ is the conventional ultimate deflection corresponding to a load equal to 0.80 time the peak horizontal force $\left(H_{p}\right)$ on the post-peak branch of response curve (dependent parameter). The same parameters are needed for the definition of UBC curve $\left(K_{0 U}, H_{0 U}, K_{h U}, n_{U}, d_{p U}, K_{d U}, d_{u U}\right)$ and LBC curve $\left(K_{0 L}, H_{0 L}, K_{h L}, n_{L}, d_{p L}, K_{d L}, d_{u L}\right)$.

The model assumes that the UBC and LBC curves can be derived from the monotonic response curve on the basis of these assumptions:

$X_{U}=U_{X} \cdot X$

$X_{L}=L_{X} \cdot X$ 
where $X, X_{U}$, and $X_{L}$ represent the generic independent parameters defining the monotonic, UBC and LBC curve, respectively (i.e. $X=K_{0}, X_{U}=K_{0 U}$ and $X_{L}=K_{0 L}$ ); $U_{X}$ and $L_{X}$ are the relevant constant (i.e. $U_{X}=U_{K 0}$ and $L_{X}=L_{K 0}$, thus $K_{0 U}=U_{K 0} K_{0}$ and $K_{0 L}=L_{K 0} K_{0}$ ).

Other assumption of the proposed methodology is that the generic point of a cyclic loading branch belongs to a Richard-Abbott type curve (transition curve), whose the relevant independent parameters $K_{0 t}, H_{0 t}, K_{h t}, n_{p t}, d_{p t}, K_{d t}$ are given by the linear convex combination of analogous parameters of the LBC and UBC curves:

$$
X_{t}=X_{L}+\left(X_{U}-X_{L}\right) t
$$

where $X_{t}$ represents the generic independent parameter defining the transition curve (i.e. $X_{t}=K_{0 t}$, thus $K_{0 t}=K_{0 L}+\left(K_{0 U}-K_{0 L}\right) t$ ), and $t$ defines the transition law from the LBC to the UBC curve:

$$
t=\left[\frac{\left[d /\left(\lambda\left(\left|d_{0}\right|+d_{\max }\right)\right)\right]}{\left[d /\left(\lambda\left(\left|d_{0}\right|+d_{\max }\right)\right)\right]^{t_{1}}+1}\right]^{t_{2}} \quad \text { with } 0 \leq t \leq 1
$$

in which $d_{0}$ is the deflection corresponding to the initial point of the current excursion and $d_{\max }$ is the maximum deflection value reached in all previous loading history in the direction to be described. Therefore, $t$ can be defined by assigning $t_{1}, t_{2}$ and $\lambda$.

The strength degradation is taken into account following the methodology proposed by Park and Ang (Park [21]):

$$
H_{0, \text { red }}=H_{0}\left(1-D_{F}\right)
$$

where $H_{0, \text { red }}$ is the reduced value of $H_{0}$ in the current cycle excursion and $D_{F}$ represent the parameter accounting for the strength reduction.

As results, the proposed model depends on 22 independent parameters $\left(K_{0}, H_{0}, K_{h}, n, d_{p}, K_{d}, U_{K 0}\right.$, $\left.U_{H 0}, U_{K h}, U_{n}, U_{d p}, U_{K d}, L_{K 0}, L_{H 0}, L_{K h}, L_{n}, L_{d p}, L_{K d}, t_{1}, t_{2}, \lambda, D_{F}\right)$.

The calibration of the parameters describing the whole cyclic response has been carried out on the basis of available results of experimental monotonic and cyclic full scale tests (Landolfo et al. [15]). The values of the monotonic curve parameters $\left(K_{0}, H_{0}, K_{h}, n, d_{p}, K_{d}\right)$ have been obtained in such a way that this curve matches the experimental monotonic response curve, while the UBC curve parameters $\left(U_{K 0}, U_{H 0}, U_{K h}, U_{n}, U_{d p}, U_{K d}\right)$ have been defined in order to match the envelope of the experimental cyclic response curve. Finally, the values of the LBC curve $\left(L_{K 0}, L_{H 0}, L_{K h}, L_{n}, L_{d p}, L_{K d}\right)$, transition $\left(t_{1}, t_{2}\right.$, and $\left.\lambda\right)$ and strength degradation $\left(D_{F}\right)$ parameters have been defined in such a way that the numerical cyclic response would be as much as possible similar to the experimental cyclic response in terms of $H-d$ curve and dissipated energy. The parameters values obtained as result of calibration are given in Table 4, while the comparison in terms of response is shown in Figure 2. 


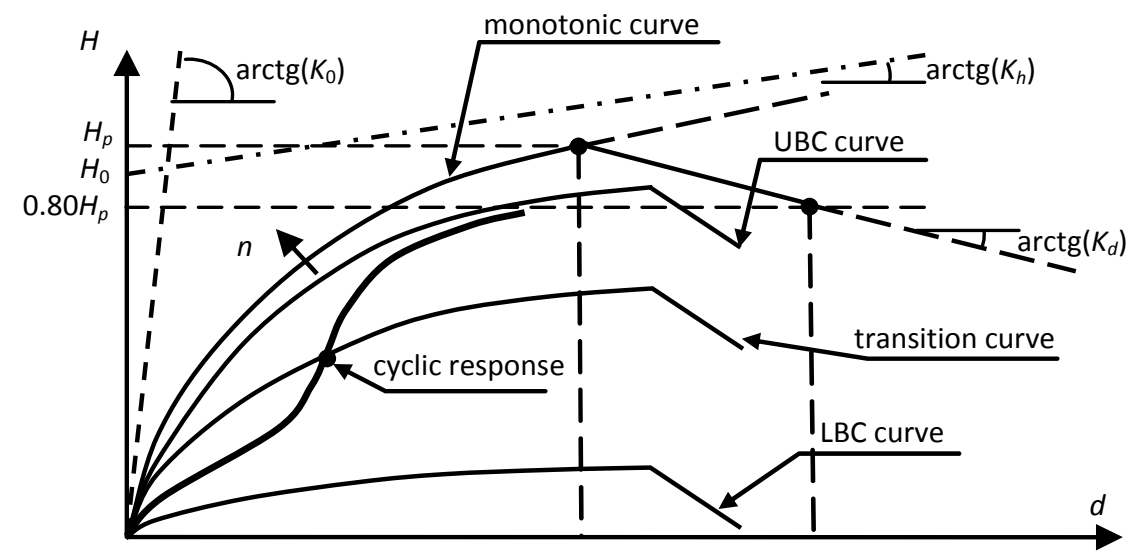

Figure 2. Model of the Cycle Lateral Response of SCFS Shear Walls

Table 4. Parameters Defining the Cyclic Response, as Result of Calibration

\begin{tabular}{lllllll}
\hline Monotonic curve parameters & $K_{0}=6.05 \mathrm{kN} / \mathrm{mm} / \mathrm{m}$, & $H_{0}=24 \mathrm{kN} / \mathrm{m}$, & $K_{h}=0.03, \quad n=0.78, \quad d_{p}=24 \mathrm{~mm}$, & $K_{d}=-0.15$ \\
\hline UBC curve parameters & $U_{K 0}=0.67$, & $U_{H 0}=0.88$, & $U_{K h}=0.0$, & $U_{n}=1.0, U_{d p}=1.5$, & $U_{K d}=7.0$ \\
\hline LBC curve parameters & $L_{K 0}=0.67$, & $L_{H 0}=0.01$, & $L_{K h}=0.0$, & $L_{n}=1.0, L_{d p}=1.5$, & $L_{K d}=1.0$ \\
\hline Transition parameters & $t_{l}=12$, & $t_{2}=0.8$, & $\lambda=0.9$ & & \\
\hline Strength degradation parameter & $D_{F}=0.10$ & & & & \\
\hline
\end{tabular}

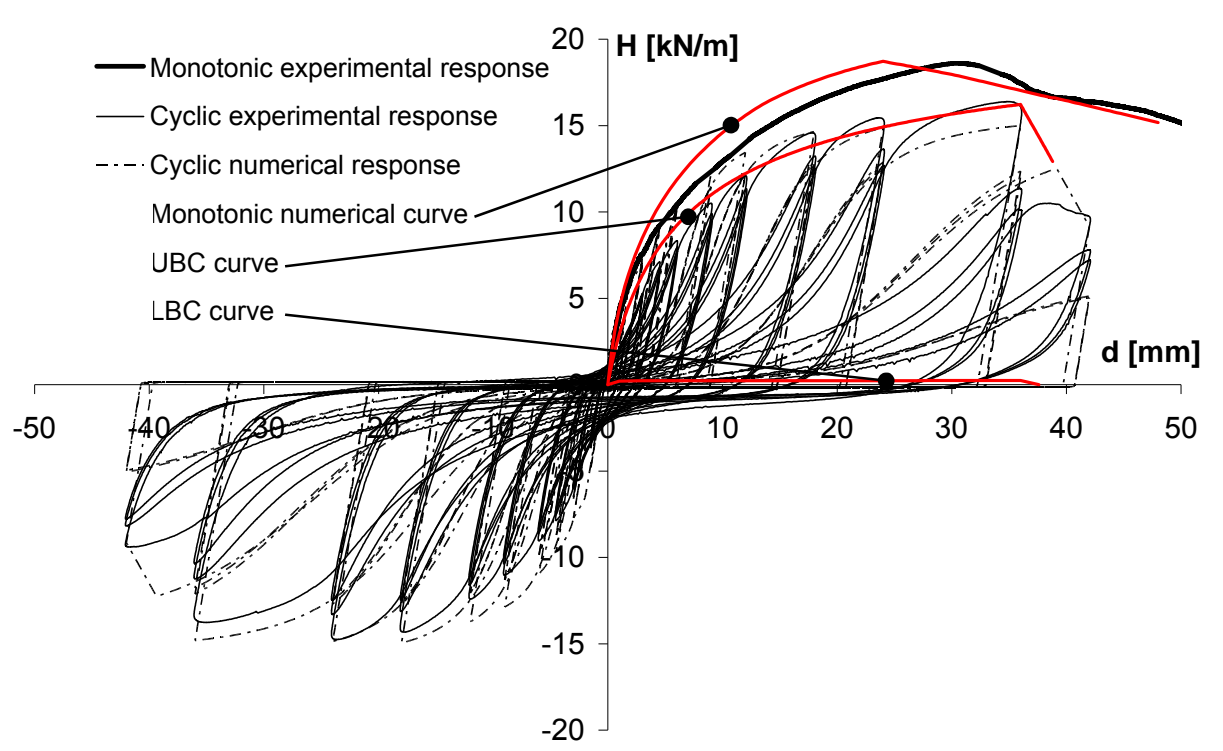

Figure 3. Calibration Results in Terms of Force vs. Displacement Response

\subsection{Building Case Study}

One-story buildings have been considered as case studies. They refer to stick built constructions in which both floors and walls are realized with CFS framing sheathed with structural panels. In particular, in order to obtain a large range of solutions, a schematic plan has been considered with wall length $(L)$ variable between 3 and $7 \mathrm{~m}$ (Figure 4) and lengths of full height (resisting) wall segment $(l)$ in the range $l=0.4 L$ through $l=0.7 \mathrm{~L}$. 

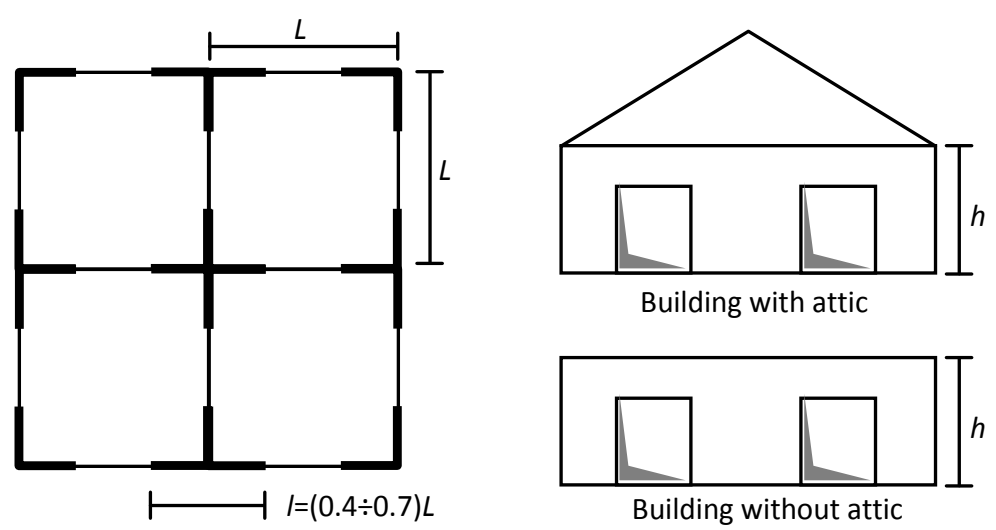

Building with attic

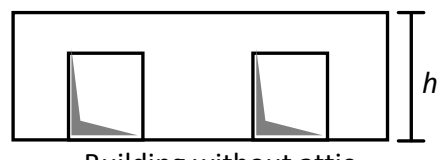

Building without attic

Figure 4. Case Study: The Schematic Stick Built Construction

\subsection{Actions}

Unit weights ranging from 0.4 to $1.5 \mathrm{kN} / \mathrm{m}^{2}$ and from 0.3 to $1.2 \mathrm{kN} / \mathrm{m}^{2}$ have been considered for floors and walls, respectively (Table 5). Moreover, the building has been considered without and with attic. In the first case, a variable live load of $2.0 \mathrm{kN} / \mathrm{m}^{2}$ has been considered and, in the latter case, a snow variable load ranging from 0.60 to $1.20 \mathrm{kN} / \mathrm{m}^{2}$ has been added. The seismic weights have been defined according to the following relationship:

$\Sigma G_{K i}+\Sigma_{j}\left(0,3 \cdot Q_{K j}\right)$

where $G_{k i}$ are the characteristic value of permanent actions and $Q_{k i}$ are the variable loads. With this conditions, a seismic weight for unit wall length ranging between 2 and $38 \mathrm{kN} / \mathrm{m}$ has been obtained. Therefore, 7 seismic weights per unit wall length have been considered $(10,15,20,25,30,35$ and 40 $\mathrm{kN} / \mathrm{m}$ ) and have been applied to the 72 wall configurations defined previously in the parametric study in such a way to obtain a total number of $7 \times 72=504$ cases.

Table 5. Unit Weights

\begin{tabular}{ll}
\hline Floor and roof & \\
\hline Steel members & $0.08 \div 0.25 \mathrm{kN} / \mathrm{m}^{2}$ \\
\hline OSB panels & $0.10 \div 0.15 \mathrm{kN} / \mathrm{m}^{2}$ \\
\hline GWB panels & $0.00 \div 0.10 \mathrm{kN} / \mathrm{m}^{2}$ \\
\hline Insulation & $0.02 \div 0.30 \mathrm{kN} / \mathrm{m}^{2}$ \\
\hline Floor finishing & $0.10 \div 0.40 \mathrm{kN} / \mathrm{m}^{2}$ \\
\hline False ceiling & $0.10 \div 0.30 \mathrm{kN} / \mathrm{m}^{2}$ \\
\hline Total & $\mathbf{0 . 4 0} \div \mathbf{1 . 5 0} \mathbf{k N} / \mathbf{m}^{2}$ \\
\hline
\end{tabular}

\begin{tabular}{ll}
\hline Wall & \\
\hline Steel members & $0.03 \div 0.08 \mathrm{kN} / \mathrm{m}^{2}$ \\
\hline External board - OSB & $0.05 \div 0.20 \mathrm{kN} / \mathrm{m}^{2}$ \\
\hline Internal board $-\mathrm{GWB}$ & $0.10 \div 0.20 \mathrm{kN} / \mathrm{m}^{2}$ \\
\hline Insulation & $0.02 \div 0.30 \mathrm{kN} / \mathrm{m}^{2}$ \\
\hline Internal finishing & $0.00 \div 0.20 \mathrm{kN} / \mathrm{m}^{2}$ \\
\hline External finishing & $0.10 \div 0.30 \mathrm{kN} / \mathrm{m}^{2}$ \\
\hline Total & $\mathbf{0 . 3 0} \div \mathbf{1 . 2 0} \mathbf{~ k N} / \mathrm{m}^{2}$ \\
\hline
\end{tabular}

\subsection{Ground Motion}

In order to develop a non-linear dynamic seismic analysis, the seismic inputs have been selected in such a way that they could cover all the soil typologies classified by Eurocode 8 (CEN, [7]). In particular, Eurocode 8 provides five different soil types A, B, C, D, and E, but in this study only three spectra are adopted grouping the soil types B, C and E under one spectrum type. Therefore, 21 earthquake records have been selected from the ESD (European Strong-motion Database, www.isesd.cv.ic.ac.uk). For each soil type 7 accelerograms have been considered so that the shape of the average elastic response spectrum is close as much as possible to the shape of the corresponding Eurocode 8 elastic acceleration spectrum (Iervolino et al. [22]). As results, a total number of $504 \times 21$ $=10584$ cases have been obtained. The selected earthquakes include records from different European 
and Mediterranean regions. For these earthquakes the Richter magnitude range from 5.8 to 7.6. In order to match the design spectra the natural accelerograms have been scaled by the peak ground acceleration (PGA).

\subsection{Wall Response Modelling}

Each wall defined previously in the parametric study has been schematized as single degree of freedom structure, in which the hysteretic behaviour under horizontal loads is described by the model presented in Section 3.1. In particular, for the generic wall configuration the parameters defining the cyclic response have been set in such a way that the monotonic curve parameters give a function matching the relevant monotonic curve obtained in the parametric study, while the other parameters (UBC curve, LBC curve transition and strength degradation parameters) have been set equal to the value given in Table 4. This assumption implicates that in all the wall configurations examined in the parametric study the cyclic load produces the same effects observed in the tests carried out by Landolfo et al. [15].

In order to account the second order effects, a vertical load equal to the $100 \%$ of the mass has been considered. The viscous damping ratio has been set equal to $5 \%$, according to the experimental results obtained by Kawai et al. [4], Gad et al. [6] and Dubina [5]. The adopted procedure is the incremental dynamic analysis (IDA). Outputs of the analysis are the IDA curves, that are presented as adimentionalized elastic spectral acceleration $\left(S_{a, e} / g\right.$, intensity measure of the seismic record) vs. maximum required interstory drift angle $(d / h$, performance parameter). In particular, for obtaining a single IDA curve, which represents the response for a specific wall condition (wall geometry and materials, seismic weight and soil type), each accelerogram has been scaled in the range from 0.05 to 1.95 by considering 50 values. Therefore, a total number of $10584 \times 50=529200$ single non-linear dynamic analysis has been performed. Figure 5 shows typical IDA curves obtained in the present study by changing the accelerograms for a $2400 \mathrm{~mm}$ high and $1200 \mathrm{~mm}$ long wall, sheathed with GWB panels on both sides, having external screw spacing of $50 \mathrm{~mm}$ and a seismic weight of $15 \mathrm{kN} / \mathrm{m}$.

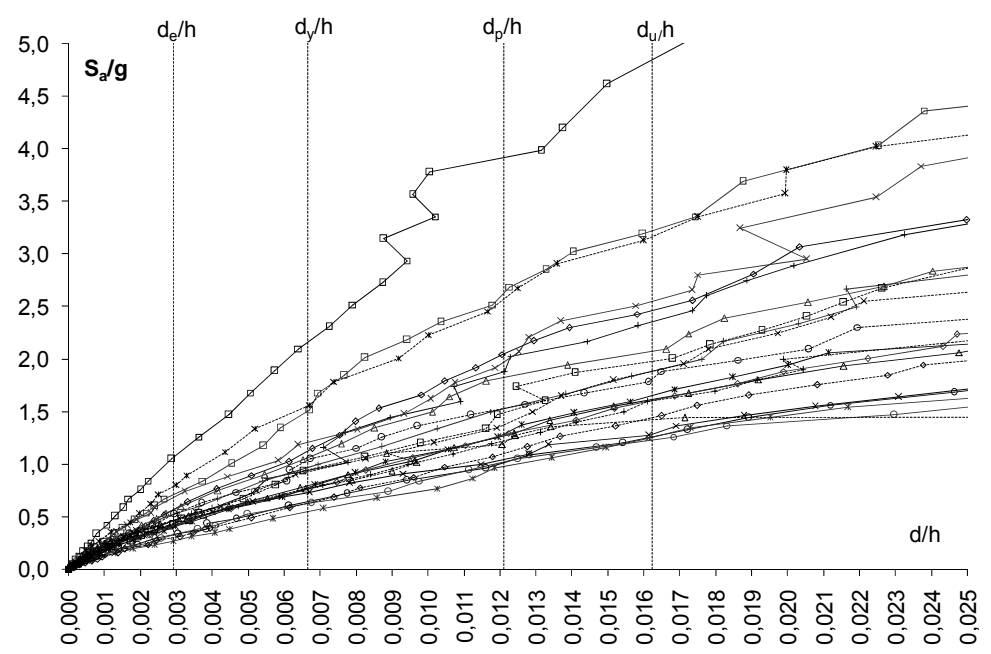

Figure 5. Typical IDA Curves 


\section{BEHAVIOUR FACTOR EVALUATION}

\subsection{General Assumptions}

Based on the results of performed dynamic analyses, the non-linear capacity of SCFS shear walls, in terms of behaviour factor, has been assessed. The numerical results have been interpreted by considering three different limit displacements on the generic response curve (Figure 6): the peak $\left(d_{p}\right)$ and ultimate $\left(d_{u}\right)$ displacements, as defined in Section 3.1, and the yielding displacement of the idealized bilinear curve $\left(d_{y}\right)$ created according to an equivalent energy elastic-plastic approach (Park [21]), following the recommendations given by Branston et al. [10].

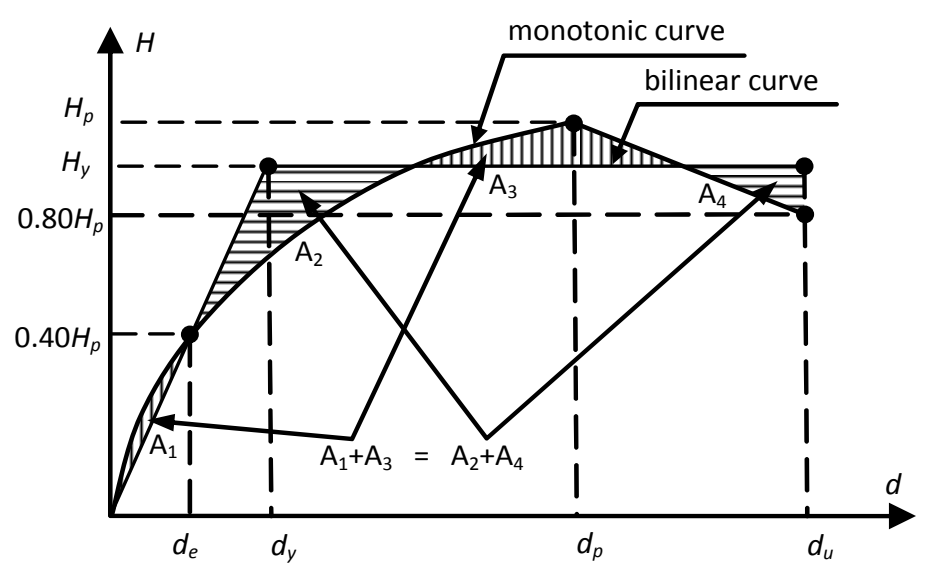

Figure 6. Monotonic Response Curve of a SCFS Shear Wall: Definition of the Idealized Bilinear Curve

For each IDA curve the seismic intensity measures $S_{a, y}, S_{a, p}$ and $S_{a, u}$ corresponding to the limit displacements $d_{y}, d_{p}$ and $d_{u}$, respectively, have been evaluated and these spectral accelerations have been used to define three different behaviour factors, as follows (Figure 7):

$q_{1}=S_{a, p} / S_{a, y}, \quad q_{2}=S_{a, u} / S_{a, p}, \quad q_{3}=S_{a, u} / S_{a, y}$

in which $q_{1}$ takes into account the overstrength, $q_{2}$ takes into account the ductility and $q_{3}=q_{1} q_{2}$ takes into account both overstrength and ductility.

In order to obtain an assessment of the behaviour factors $q_{1}, q_{2}$ and $q_{3}$ on the basis of significant IDA results, only the IDA curves representing realistic design conditions have been selected. The selection has been performed by comparing the displacement demand $\left(d_{D}\right)$ obtained for a given earthquake hazard level and different seismic intensity zones (i.e. peak ground acceleration on soil type A $\left(a_{g}\right)$ for a $10 \%$ probability of exceedance in 50 years equal to $0.15,0.25$ and $0.35 \mathrm{~g}$ for low, medium and high seismic intensity zone, respectively) with the relevant displacement capacity $\left(d_{C}\right)$ (i.e. conventional ultimate displacement, $d_{C}=d_{u}$ ). As result of this comparison, a performance coefficient $\left(p=d_{D} / d_{C}\right)$ has been defined and only the IDA curves for which $p$ satisfies specified target conditions (i.e. $0.5 \leq p \leq 1.0$ ) have been chosen. In particular, the selection of IDA curves has been performed by adopting two different approaches: "classical" and "multi-performance", in which the difference consists on the required performance objectives, as discussed in following Sections. 


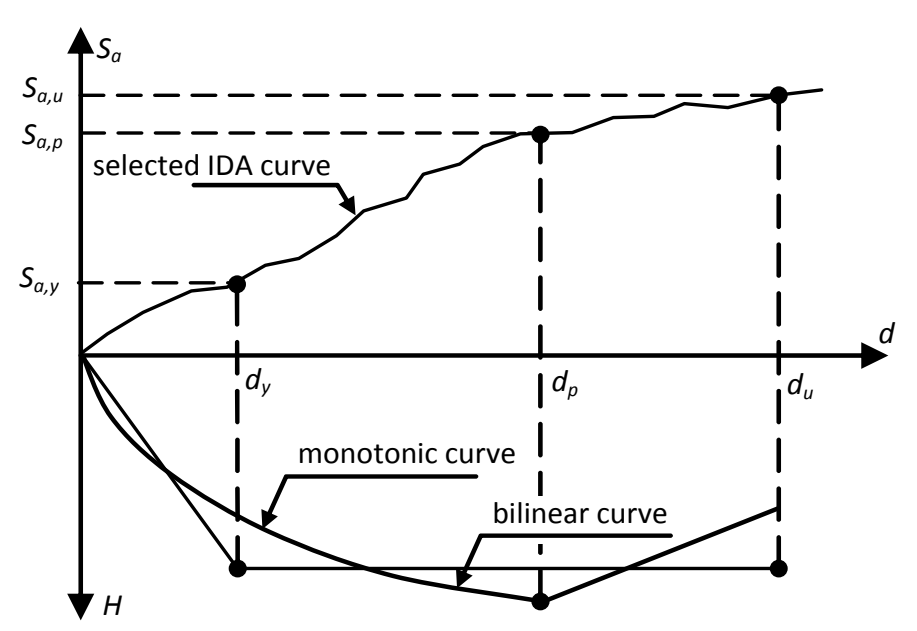

Figure 7. Definition of Behaviour Factors

\section{2 “Classic” Approach}

Nowadays, generally the seismic design according to current standards is performed by means of force-based approaches, in which in the case of the ultimate limit state the structural inelastic response and overstrength are taken into account by reducing the seismic force, that usually corresponds to an hazard seismic level equal to $10 \%$ probability of exceedance in 50 years $(10 \% / 50)$. Therefore, the evaluation of behaviour factors should be carried out on the basis of seismic demands required by records representative of 10\%/50 earthquakes, typically by relating this hazard level to the life safety structural performance. As result, these approaches allow significant structural damage under 10\%/50 earthquakes, by neglecting the seismic performance evaluation in the case of seismic events having lower probability of exceedance.

Following this approach, one required performance objective only has been selected, in which the displacement demand $\left(d_{D}\right)$ has been obtained under $10 \% / 50$ earthquakes, with $a_{g}$ equal to $0.15 g$, $0.25 \mathrm{~g}$, and $0.35 \mathrm{~g}$ for low (LO), medium (ME) and high (HI) seismic intensity zone, respectively, and by adopting a displacement capacity corresponding to the ultimate displacement $\left(d_{C}=d_{u}\right)$. For each IDA curve for which the performance coefficient $p=d_{D} / d_{C}$ is in the range from 0.5 to 1.0 (Figure 8), the behaviour factors $q_{1}, q_{2}$ and $q_{3}$ have been evaluated.

The obtained average, standard deviation and coefficient of variation values of behaviour factors for $\mathrm{G}+\mathrm{G}, \mathrm{G}+\mathrm{O}$ and all walls $(\mathrm{G}+\mathrm{G}$ and $\mathrm{G}+\mathrm{O}$ together) are shown in Table 7. The results show that $q_{1}$ is about 2.4 for all types of wall configurations, $q_{2}$ is about 1.3, even if in case of walls sheathed with $\mathrm{G}+\mathrm{O}$ the value decreases to about 1.2 , and $q_{3}$ is about 3.0 for all walls, while for $\mathrm{G}+\mathrm{G}$ and $\mathrm{G}+\mathrm{O}$ configurations is about 3.2 and 2.9, respectively. As for as the dispersion of the data is concerned, the coefficient of variation ranges from 0.10 to 0.32 , which corresponds to moderately scattered results.

On the basis of results shown in Table 7 a behaviour factor $q=q_{3}=3.0$ is proposed for the "classic" seismic design under 10\%/50 earthquakes. 
Table 6. Performance Objective Matrix : “Classic” vs. "Multi-performance” Approach

\begin{tabular}{ccccc}
\cline { 2 - 4 } & & \multicolumn{3}{c}{ Performance levels } \\
\cline { 2 - 5 } & & IO & LS & CP \\
\hline \multirow{2}{*}{$\begin{array}{c}\text { Earthquake } \\
\text { hazard level }\end{array}$} & $50 \% 50$ & $\odot$ & & \\
\cline { 2 - 5 } & $10 \% 50$ & & $\odot$ & \\
\cline { 2 - 4 } & $2 \% 50$ & & & $O$ \\
\hline
\end{tabular}

- goal achieved by "classic" approach

O goal achieved by "multi-performance" approach

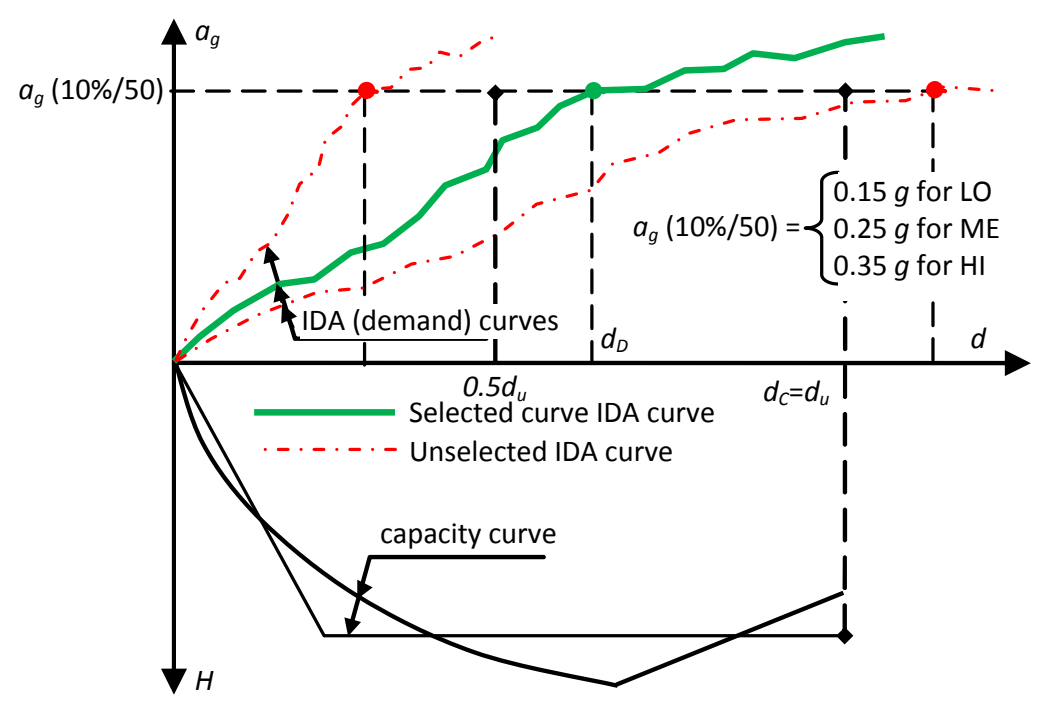

Figure 8. Selection of IDA Curves for the "Classic" Approach

Table 7. Behaviour Factors for the "Classic" Approach

\begin{tabular}{lllll}
\hline Wall configuration & & $q_{1}$ & $q_{2}$ & $q_{3}$ \\
\hline $\mathrm{G}+\mathrm{G}$ & Average & 2.37 & 1.32 & 3.16 \\
\cline { 2 - 5 } & St. Dev. & 0.53 & 0.20 & 1.02 \\
\cline { 2 - 5 } & C.o.V. & 0.22 & 0.15 & 0.32 \\
\hline $\mathrm{G}+\mathrm{O}$ & Average & 2.40 & 1.20 & 2.87 \\
\cline { 2 - 5 } & St. Dev. & 0.41 & 0.12 & 0.58 \\
\cline { 2 - 5 } & C.o.V. & 0.17 & 0.10 & 0.20 \\
\hline \multirow{2}{*}{$\begin{array}{llll}\text { All types } \\
\text { (G+G and G+O) }\end{array}$} & Average & 2.38 & 1.27 & 3.04 \\
\cline { 2 - 5 } & St. Dev. & 0.49 & 0.19 & 0.88 \\
\cline { 2 - 5 } & C.o.V. & 0.20 & 0.15 & 0.29 \\
\hline
\end{tabular}

\section{3 “Multi-performance” Approach}

As attempt to overcome the limitations of as called "classic" approach, in this paper is proposed a methodology in which the different behaviour factors defined in Section 4.1 are related to different seismic performance levels, in such a way to obtain a "multi-performance" seismic design. The peculiarity of the proposed approach is to give the possibility to achieve an "enhanced objective" (FEMA 2010), consisting of the following goals (Table 5): (1) immediate occupancy (IO) performance level for earthquakes having $50 \%$ probability of exceedance in 50 years $(50 \% / 50)$, that is ground motions with mean return period of about 75 years or so called "frequent" earthquakes; (2) life safety (LS) performance level for earthquakes having $10 \%$ probability of exceedance in 50 years $(10 \% / 50)$, that is ground motions with mean return period of about 500 years or so called 
"rare" earthquakes; (3) collapse prevention (CP) performance level for earthquake with $2 \%$ probability of exceedance in 50 years $(2 \% / 50)$, that is ground motions with mean return period of about 2500 years or so called "very rare" earthquakes. Therefore, if the displacement capacities of the generic SCFS shear wall associated to the different performance levels are assumed as follows: yield displacement for IO $\left(d_{C, I O}=d_{y}\right)$, peak displacement for $\operatorname{LS}\left(d_{C, L S}=d_{p}\right)$ and ultimate displacement for $\mathrm{CP}\left(d_{C, C P}=d_{u}\right)$; then a seismic design which allows an adequate damage control for all selected earthquake hazard levels should be reached. In fact, for IO performance level the assumed displacement capacities correspond to the interstory drift limits $(d / h)$ ranging from $0.13 \%$ to $0.97 \%$, which are less than those (1.5\%) given by Dubina (2008). For LS and CP performance levels the assumed limits of $d / h$ range from $0.61 \%$ to $1.87 \%$ and from $0.73 \%$ to $2.44 \%$, respectively, which are generally more conservative values respect to those suggested by different Authors: 2.5\% for Dubina [5], 2.0\% for Kawai et al. [4], and from 1.91 to 2.23 for Blais [11].

The possibility of damage containment based on the assumed interstory drift limits is also supported by available experimental experiences, which confirm a damage of sheathing connections negligible for $d / h$ less than $1.0 \%$ (Figure 9a), which became tolerable for $d / h$ in the range $1.0 \%$ through $2.5 \%$ (Figure $9 b, c$ ).

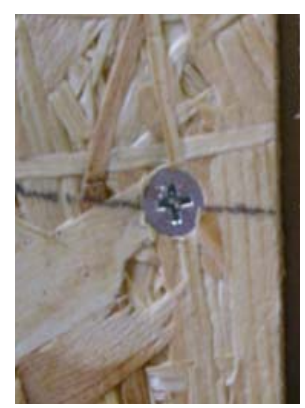

(a) $\mathrm{d} / \mathrm{h} \approx 0.6 \%$

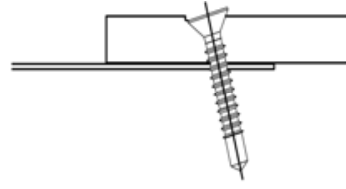

(a) Tilting in initial phase

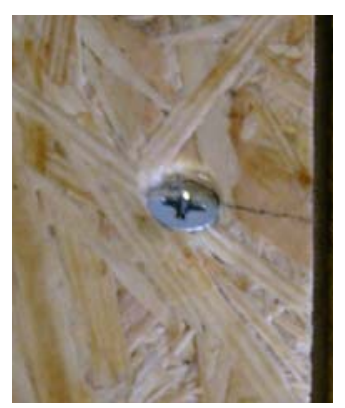

(b) $d / h \approx 1.4 \%$

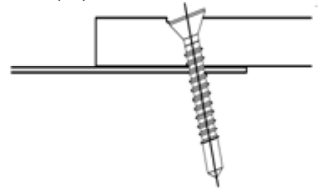

(b) Tilting in advanced phase and pull-trough in initial phase

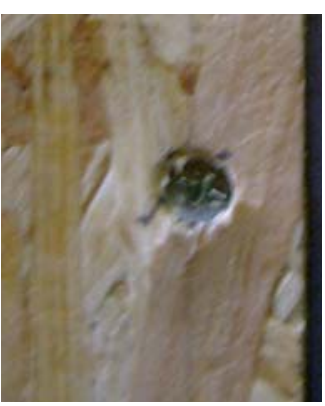

(c) $d / h \approx 2.0 \%$

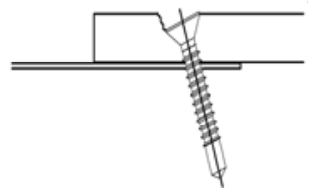

(c) Tilting and pull-trough in advanced phase

Figure 9. Experimental Observation of the Sheathing Fastener Damage during a Monotonic Test

According to this approach, for each selected seismic hazard level, three different seismic intensities have been assumed: $a_{g}$ equal to $0.06,0.10$, and $0.14 \mathrm{~g}$ for "frequent" earthquakes; 0.15 , 0.25 , and $0.35 \mathrm{~g}$ for "rare" earthquakes; and $0.23,0.38$, and $0.53 \mathrm{~g}$ for "very rare" earthquakes. Hence, in order to choose realistic cases, only IDA curves satisfying the following criterion (Figure 10) have been considered:

$$
\left(p_{I O}=d_{D, I O} / d_{C, I O} \leq 1\right) \cap\left(0.5 \leq p_{L S}=d_{D, L S} / d_{C, L S} \leq 1.0\right) \cap\left(p_{C P}=d_{D, C P} / d_{C, C P} \leq 1\right)
$$

The obtained average, standard deviation and coefficient of variation values of the behaviour factors $q_{1}, q_{2}$ and $q_{3}$ are shown in Table 7. From the obtained results, it can be observed that $q_{1}$ is about 2.2, 2.4 and 2.3 for walls sheathed with $\mathrm{G}+\mathrm{G}, \mathrm{G}+\mathrm{O}$ and all walls, respectively; $q_{2}$ is about 1.3 considering all types of wall configurations, while it is about 1.4 and 1.2 for $\mathrm{G}+\mathrm{G}$ and $\mathrm{G}+\mathrm{O}$ 
configurations, respectively; $q_{3}$ is about $3.1,2.9$ and 3.0 for walls sheathed with $\mathrm{G}+\mathrm{G}, \mathrm{G}+\mathrm{O}$ and all wall typologies. The results in terms of dispersion are very similar to those observed in case of the "classic" approach, with a coefficient of variation in the range from 0.10 to 0.27 .

According to the proposed multi-performance approach and by considering the obtained results, a behaviour factor $q=q_{1}=2.0$ is proposed in the case of "rare" $(10 \% / 50)$ earthquakes, while its value should be assumed equal to $q=q_{3}=3.0$ for "very rare" $(2 \% / 50)$ earthquakes.

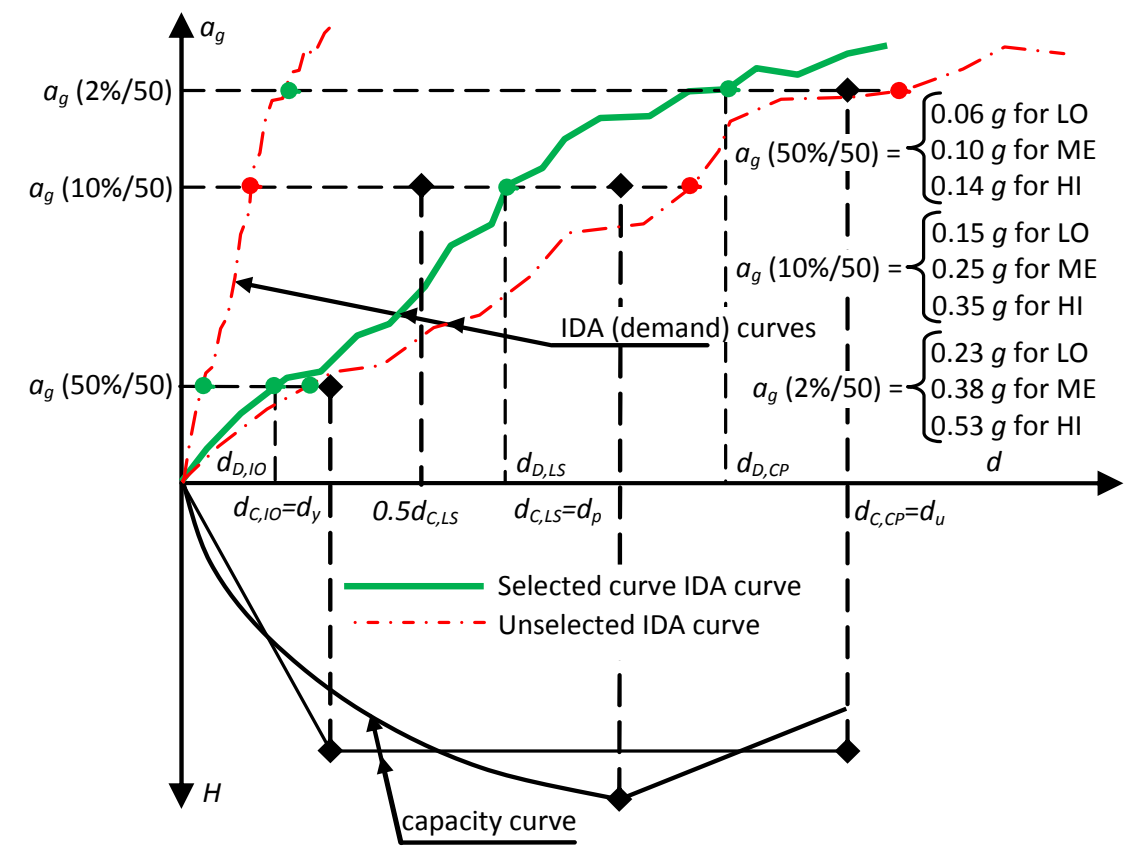

Figure 10. Selection of IDA Curves for the "Multi-performance" Approach

$\underline{\text { Table 8. Behaviour Factors for the "Multi-performance" Approach }}$

\begin{tabular}{lllll}
\hline $\begin{array}{l}\text { Wall } \begin{array}{l}\text { lany } \\
\text { configuration }\end{array} \\
\mathrm{G}+\mathrm{G}\end{array}$ & & $q_{1}$ & $q_{2}$ & $q_{3}$ \\
& Average & 2.23 & 1.35 & 3.05 \\
\cline { 2 - 5 } & St. Dev. & 0.44 & 0.17 & 0.83 \\
\cline { 2 - 5 } & C.o.V. & 0.20 & 0.13 & 0.27 \\
\hline \multirow{2}{*}{$+\mathrm{O}$} & Average & 2.35 & 1.23 & 2.88 \\
\cline { 2 - 5 } & St. Dev. & 0.40 & 0.12 & 0.57 \\
\cline { 2 - 5 } & C.o.V. & 0.17 & 0.10 & 0.20 \\
\hline \multirow{2}{*}{$\begin{array}{l}\text { All types } \\
(\mathrm{G}+\mathrm{G} \text { and } \mathrm{G}+\mathrm{O})\end{array}$} & Average & 2.29 & 1.29 & 2.96 \\
\cline { 2 - 5 } & St. Dev. & 0.43 & 0.16 & 0.71 \\
\cline { 2 - 5 } & C.o.V. & 0.19 & 0.12 & 0.24 \\
\hline
\end{tabular}

\subsection{Comparison with Literature Results and Code Prescriptions}

Considering the behaviour factors defined on the basis of non-linear dynamic analysis results using "classic" and "multi-performance" approaches, they range between 2.2 and 2.4 for $q_{1}$ (overstrength) between 1.2 and 1.4 for $q_{2}$ (ductility) and from 2.9 to 3.2 for $q_{3}$ (both overstrength and ductility).

The values of overstrength related factor $\left(q_{1}\right)$ achieved in this study are very similar to those $\left(q_{1}=2.2 \div 2.6\right)$ proposed by Fülöp and Dubina [1], while they are larger than the corresponding result $\left(R_{o}=1.7\right)$ given by Boudreault et al. [3]. For the values of the ductility related factor $\left(q_{2}\right)$, they are 
slightly smaller than the results $\left(q_{2}=1.4 \div 1.6\right)$ obtained by Fülöp and Dubina [2] and quite smaller than the factor $\left(R_{d}=2.5\right)$ proposed by Boudreault et al. [3]. As consequence, the results obtained in terms of global behaviour $\left(q_{3}\right)$, which represents the product of $q_{1}$ and $q_{2}$ are smaller than those achieved by Fülöp \& Dubina [2] $\left(q_{3}=3.6 \div 3.7\right)$ and Boudreault et al. [3] $\left(R_{o} \times R_{d}=4.3\right)$. Finally, considering the global behaviour factor $\left(q_{3}\right)$, the comparison with the prescriptions of applicable Codes shows that the value proposed in this paper is in the very large range $\left(q_{3}=R=2 \div 6.5\right)$ of those given by ASCE/SEI 7-10 [13] and FEMA P-750 [8].

\section{CONCLUSIONS}

In the last years a large number of research teams have been involved in the evaluation of seismic capacity of SCFS structures and seismic design parameters as behaviour factors and interstory drift limits so as dynamic characteristics as vibration periods and damping ratios have been evaluated. In this paper the results of extensive parametric dynamic analyses on sheathed cold-formed steel (SCFS) shear walls, performed by a presented cyclic model able to predict the non linear force deflection response, have been presented. Based on the results of the analyses the seismic performance of SCFS shear walls, in terms of behaviour factors has been assessed. In particular, three behaviour factors related to overstrength $\left(q_{1}=2\right)$, ductility $\left(q_{2}=1.5\right)$ and both overstrength and ductility $\left(q_{3}=3\right)$ have been defined.

In addition, two different seismic design approaches have been proposed. For the first approach, named "classic", in which 10\%/50 hazard level is related to the life safety structural performance, a behaviour factor $q=q_{3}=3$ is proposed to be used. For the second approach, named "multi-performance", different behaviour factors are related to different seismic performance levels, in such a way to achieve an "enhanced objective" by allowing an effective damage control. Under this assumption, a behaviour factor equal to $q=q_{2}=2$ is proposed for $10 \% / 50$ hazard level, which is related to live safety structural performance; while a behaviour factor of $q=q_{3}=3$ should be used for $2 \% / 50$ hazard level, which correspond to collapse prevention structural performance.

\section{REFERENCES}

[1] Fülöp, L.A. and Dubina, D., "Performance of Wall-stud Cold-formed Shear Panels under Monotonic and Cyclic Loading Part I: Experimental Research", Thin Walled Structures, Elsevier, 2004, Vol. 42, No. 2, pp. 321-338.

[2] Fülöp, L.A. and Dubina, D., "Performance of Wall-stud Cold-formed Shear Panels under Monotonic and Cyclic Loading Part II: Numerical Modelling and Performance Analysis", Thin Walled Structures, Elsevier, 2004, Vol. 42, No. 2, pp. 339-349.

[3] Boudreault, F.A., Blais, C. and Rogers, C.A., "Seismic Force Modification Factors for Light-gauge Steel-frame - Wood Structural Panel Shear Walls", Canadian Journal of Civil Engineering. 2007, Vol. 3, No. 1. pp. 56-65.

[4] Kawai, Y., Kanno, R., Uno, N. and Sakumoto, Y., "Seismic Resistance and Design of Steel Framed-houses, Nippon Steel Technical Report, No. 79, 1999.

[5] Dubina, D., "Behaviour and Performance of Cold-formed Steel-framed Houses under Seismic Action", Journal of Constructional Steel Research, 2008, Vol. 64, pp. 896-913.

[6] Gad, E.F., Duffield, C.F., Hutchinson, G.L., Mansell, D.S. and Stark, G., "Lateral Performance of Cold-formed Steel-framed Domestic Structures", Engineering Structures, Elsevier, 1999, Vol. 21, pp. 83-95. 
[7] CEN. EN 1998-1 - Eurocode 8: Design of Structures for Earthquake Resistance - Part 1: General Rules, Seismic Actions and Rules for Buildings, European Committee for Standardization, Bruxelles, 2004.

[8] FEMA P-750, NEHRP Recommended Provision for Seismic Provisions for New Buildings and Other Structures, Federal Emergency Management Agency, Washington, D.C., 2010.

[9] NRCC. National Building Code of Canada (NBCC), National Research Council Canada, Ottawa, Ontario, 2005.

[10] Branston, A.E., Chen, C.Y., Boudreault, F.A. and Rogers, C.A., "Testing of Light-gauge Steel-frame - Wood Structural Panel Shear Walls", Canadian Journal of Civil Engineering, 2006, Vol. 33, No. 5, pp. 561-572.

[11] Blais, C., "Testing and Analysis of Light Gauge Steel Frame / 9mm OSB Wood Panel Shear Walls, Master's Thesis, Dept. of Civil Engineering and Applied Mechanics, McGill University, Montreal, Canada, 2006.

[12] Rokas, D., "Testing and Evaluation of Light Gauge Steel Frame / $9.5 \mathrm{~mm}$ CSP Wood Panel Shear Walls, Master's Thesis, Dept. of Civil Engineering and Applied Mechanics, McGill University, Montreal, Canada, 2006.

[13] ASCE/SEI 7-10, "Minimum Design Loads for Buildings and Other Structures", American Society of Civil Engineers, Reston, 2010.

[14] Landolfo, R., Fiorino, L. and Iuorio, O., "A Specific Procedure for Seismic Design of Cold-Formed Steel Housing", Advanced Steel Construction, 2010, Vol. 6, No.1, pp. 603-618.

[15] Landolfo, R., Fiorino, L. and Della Corte, G., "Seismic Behaviour of Sheathed Cold-formed Structures: Physical Tests", Journal of Structural Engineering, 2006, Vol. 132, No. 4, pp. 570-581.

[16] Iuorio, O., "Design Procedures for Cold Formed Steel Housing in Seismic Area", PhD Thesis, University of G. D’Annunzio, Chieti, Pescara, Italy, 2009.

[17] Fiorino, L., Iuorio, O. and Landolfo, R., "Sheathed Cold-formed Steel Housing : A Seismic Design Procedure", Thin- Walled Structures, 2009, Vol. 47, No. 8-9, pp. 919-930.

[18] Simpson Strong-Tie Company, 2007, www.strongtie.com.

[19] Hilti. North America Product Technical Guide, 2005.

[20] Della Corte, G., Landolfo, R., and Fiorino, L., "Seismic Behaviour of Sheathed Cold Formed Structures : Numerical Study", Journal of Structural Engineering, ASCE, 2006, Vol.132, No. 4, pp. 558-69.

[21] Park, R., "Evaluation of Ductility of Structures and Structural Assemblages from Laboratory Testing", Bulletin of the New Zealand National Society for Earthquake Engineering, 1989, Vol. 22, No. 3, pp. 155-166.

[22] Iervolino, I., Maddaloni, G. and Cosenza, E., "Unscaled Real Record Sets Compliant with Eurocode 8, First European Conference on Earthquake Engineering and Seismology, Geneva, Switzerland, 2006. 


\title{
INVESTIGATION ON TEMPERATURE DISTRIBUTION AND THERMAL BEHAVIOR OF LARGE SPAN STEEL STRUCTURES CONSIDERING SOLAR RADIATION
}

\author{
Hongbo Liu ${ }^{1}$, Zhihua Chen ${ }^{1,2, *}$ and Ting Zhou ${ }^{1}$ \\ ${ }^{1}$ Department of Civil Engineering, Tianjin University, Tianjin, 300072, China \\ ${ }^{2}$ Tianjin Key Laboratory of Civil Engineering Structure \& New Materials, Tianjin University, \\ Tianjin, 300072, China \\ *(Corresponding author: E-mail: zhchen@tju.edu.cn)
}

Received: 23 November 2011; Revised: 10 December 2011; Accepted: 7 February 2012

\begin{abstract}
The temperature change is very large for steel structures under solar radiation, and this temperature change can induce remarkable nodal displacement and member stress. In order to obtain the temperature distribution and thermal behavior of large span steel structures under solar radiation, a numerical simulation method was presented in this paper based on the ASHRAE model. In order to provide insights into temperature distribution and provide data to verify the presented numerical simulation method, ten steel plate specimens with different aspect ratios and orientations were investigated by measuring their temperatures under solar radiation. The parameter values in the numerical simulation model were modified by the tests results. Using the temperature numerical simulation method, the temperature distribution and thermal behavior of a typical steel structure, the lattice shell structures, were studied. The study showed that: 1) the solar radiation had a significant effect on the temperature distribution of steel structures. Considering the solar radiation, the temperature of steel structures is about $20^{\circ} \mathrm{C}$ higher than the corresponding ambient air temperature; 2) the temperature change is similar to sine curve from sunrise to sunset; 4) the solar radiation has a remarkable effect on the member stress, nodal displacement and reaction force.
\end{abstract}

Keywords: large span steel structures, steel plate, temperature, solar radiation, experimental research, numerical method

\section{INTRODUCTION}

Steel structures have been popular in recent years. They have many engineering advantages, such as light weight, fast assembly, large span capability and ease to form various attractive geometrical surfaces. Therefore, steel structures are applied particularly in sport stadiums and gymnasiums, exhibition centers, airport, factory buildings.

In the past decades, most researches were devoted to design approaches and investigation on the structural behavior of steel structures. In the design process of steel structures, the structural behavior under the gravity load, dead load, live load, wind load, thermal load, snow load and earthquake action are analyzed. For large span steel structures, the thermal load has a significant effect on its structural behavior. The thermal load includes two types. The first thermal load is that induced by ambient. The second thermal load is that induced by fire. Some investigations were carried out in the past years to understand the structural behavior of steel structures under both thermal load types [1-4].

The first thermal load for all steel structures was considered uniformly in the past years. However, the thermal load of some special steel structures induced by ambient is more no-uniform and higher than the corresponding ambient air temperature due to the solar radiation. The special steel structures include three types. The first type is the steel structures exposed to solar radiation, such as the steel arches shown in Figure 1. The second type is the steel structures which use glass or ETFE as its roof materials, such as the steel arches shown in Figure 2. The third type is the steel structures which use light steel as its roof materials, such as the steel structure shown in Figure 3. 
For the first and the second type steel structures, the solar radiation can irradiate on the steel surface directly. For the third type, the temperature of the steel roof above steel structures is very high because the solar radiation can irradiate on its surface directly, and the distance between the steel structure member and the steel roof is very small. Therefore, the temperature of steel structures was similar to the above light steel roof. Therefore, the solar radiation can induce higher and more no-uniform thermal load for the above three types steel structures.

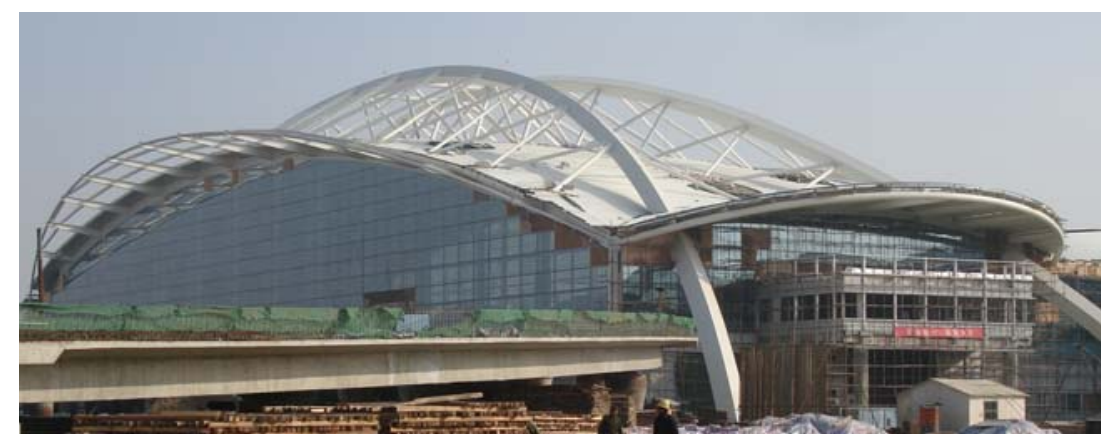

Figure 1. The Steel Arches Exposed to Solar Radiation

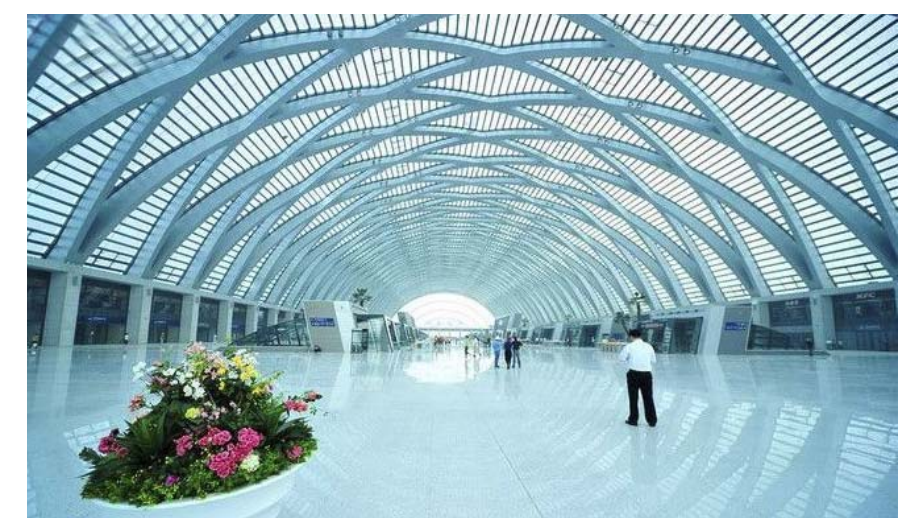

Figure 2. The Steel Arches which use Glass as its Roof

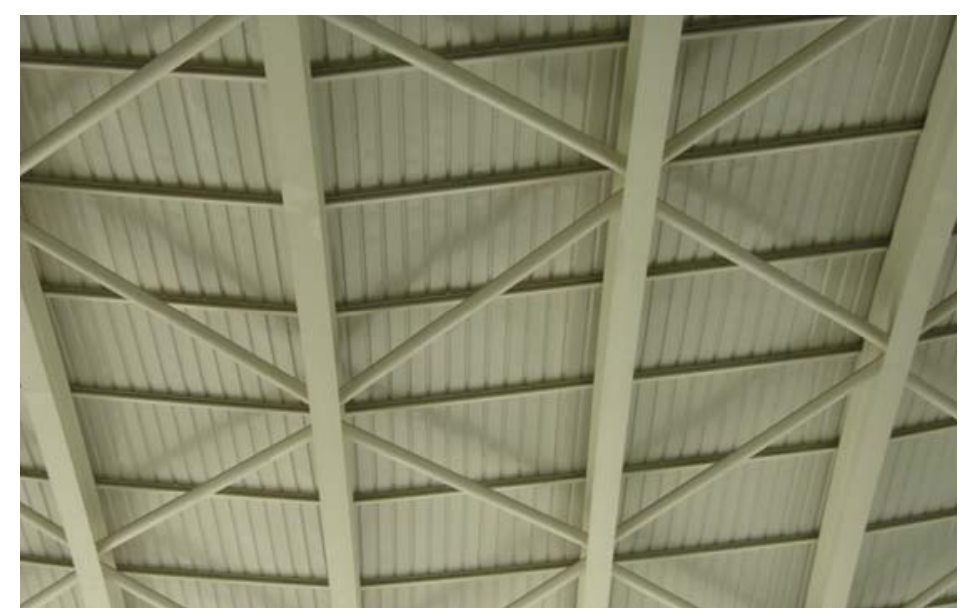

Figure 3. The Steel Structures which use Light Steel as its Roof

For large-span steel spatial structures, thermal load caused by solar radiation may lead some members to ultimate state [5-10]. However, a precise numerical simulation method for the temperature distribution under solar radiation is scarcely mentioned in the published papers. Therefore, the thermal load is difficult to determine in the design process of steel structures. This limitation motivates this study on the numerical simulation method of temperature distribution of steel structures under solar radiation. 


\section{NUMERICAL SIMULATIONS METHOD}

In 1950s, many researchers had already begun to evaluate the temperature distribution of pavements [11-12], bridges [13-15] and dams [16] considering the solar radiation. In these studies, the one-dimensional or two-dimensional heat conductivity model was adopted in the numerical simulation. However, the temperature distribution of the spatial steel structures cannot be predicted using these numerical methods under solar radiation because of its three-dimension spatial property. In this paper, a three-dimensional transient thermal FE model was developed for the analysis on the temperature distribution of large span steel structures under solar radiation based ASHRAE model in ANSYS software.

\subsection{Boundary Condition}

For any steel members exposed to solar radiation, the heat flow acting on its surface includes convection heat, solar radiation and long wave radiation among ground, sky and steel surface. Therefore, the temperature boundary condition for the steel members exposed to solar radiation is defined as:

$\left.\lambda \frac{\partial T}{\partial n}\right|_{\Gamma}=h\left[T_{a}(t)-T\right]+q_{S}(t)+q_{L}(t)$

Where $h$ is heat convection coefficient $\left(w / m^{2}{ }^{0} C\right) ; T_{a}$ is ambient air temperature; $q_{s}$ is solar radiation $\left(\mathrm{w} / \mathrm{m}^{2}\right) ; q_{l}$ is long wave radiation $\left(\mathrm{w} / \mathrm{m}^{2}\right) ; \lambda$ is thermal conductivity $\left(\mathrm{w} / \mathrm{m}^{2}{ }^{0} \mathrm{C}\right)$. The thermal properties of steels were acquired from the corresponding codes as listed in Table 1.

Table 1. Thermal Properties of Steel

\begin{tabular}{|c|c|c|c|}
\hline properties & $\begin{array}{l}\text { density } \\
\mathrm{kg} / \mathrm{m}^{3}\end{array}$ & $\begin{array}{l}\text { Heat conduction coefficient } \\
\qquad \mathrm{J} /\left(\mathrm{m} \cdot \mathrm{s} \cdot{ }^{0} \mathrm{C}\right)\end{array}$ & $\begin{array}{l}\text { Specific heat } \\
\mathrm{J} /\left(\mathrm{kg} \cdot{ }^{0} \mathrm{C}\right)\end{array}$ \\
\hline value & 7850 & 56 & 480 \\
\hline
\end{tabular}

The heat convection coefficient can calculated using following equation presented by Yazdanian and Klems [17]:

$$
h=\sqrt{\left[C_{t}(\Delta T)^{1 / 3}\right]^{2}+\left[a V_{0}^{b}\right]^{2}}
$$

Where $C_{t}$ is the turbulent natural convection constant; $\Delta T$ is the temperature difference between the exterior surface and the ambient air; $a, b$ is the constants; $V_{0}$ is the wind speed at standard conditions.

\subsection{Solar Radiation}

The ASHRAE clear-sky model was adopted in this study to calculate the solar radiation striking the surface of steel members. In this model, the total global solar radiation is assumed to be the sum of direct radiation, diffuse radiation, and the solar radiation reflected from the surrounding surface. At the earth's surface on a clear day, the value of solar radiation is defined as [16] 
$G_{N D}=\frac{A}{\exp (B / \sin \beta)} C_{N}$

Where $G_{N D}=$ normal direct radiation, $W / \mathrm{m}^{2} ; A=$ apparent solar radiation at air mass equal to zero, $W / m^{2} ; B=$ atmospheric extinction coefficient; $\beta=$ solar altitude as it shown in Figure 4; $C_{N}=$ clearness number.

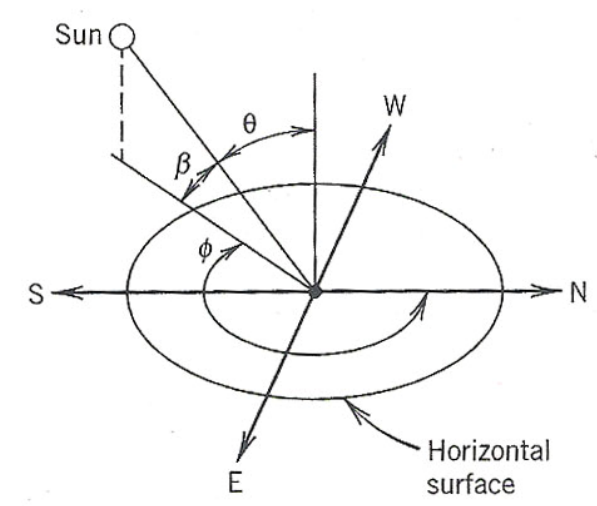

Figure 4. The Solar Altitude Angle $\beta$ and Azimuth Angle $\phi$

On a surface of arbitrary orientation, the direct radiation, corrected for clearness, is [16]:

$G_{D}=G_{N D} \max (\cos \theta, 0)$

Where $\theta$ is the angle of incidence between the sun's rays and the normal to the surface as shown in Figure 4. Note that if $\theta$ is less than zero, there is no direct radiation incident on the surface-it is in the shade. The angle $\theta$ can be calculated by following equations[16]:

$\left\{\begin{array}{l}\cos \theta=\cos \beta \cos \gamma \sin \alpha+\sin \beta \cos \alpha \quad \text { for a tilt surface } \\ \cos \theta=\cos \beta \cos \gamma \quad \text { for a vertical surface } \\ \cos \theta=\sin \beta \quad \text { for a horizontal surface }\end{array}\right.$

$\gamma=|\phi-\psi|$

Where $\gamma$ is surface solar azimuth as it shown in Figure 5; $\alpha$ is tilt angle as it shown in Figure 5; $\phi$ is solar azimuth as it shown in Figure 5; $\psi$ is surface azimuth as it shown in Figure 5.

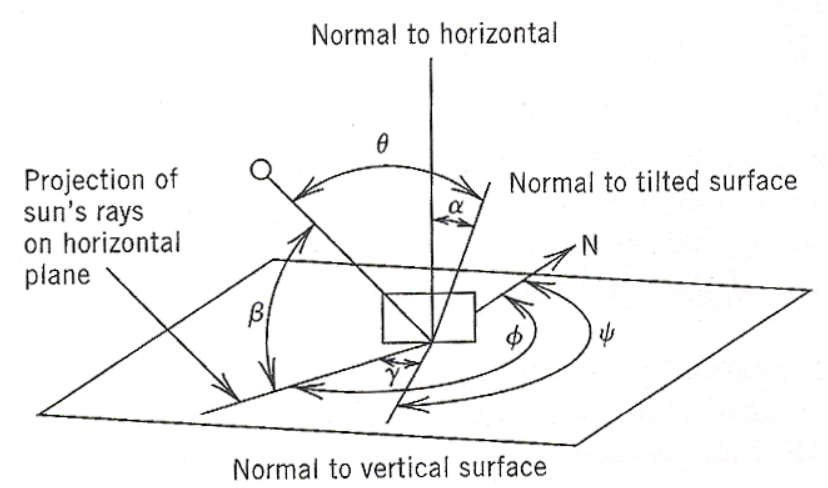

Figure 5. Surface Solar Azimuth $\gamma$, Surface Azimuth $\psi$ and Angle of Tilt $\alpha$ for an Arbitrary Tilted Surface 
The diffuse radiation [16] on a non-horizontal surface is given as follows

$G_{d}=C G_{N D} F_{w s}$

Where $C$ is the ratio of diffuse irradiation on a surface to direct normal radiation; $F_{w s}$ the angle factor between the surface and the sky, and it can be evaluated by $F_{w s}=(1+\cos \alpha) / 2$.

Then, for vertical surface, the diffuse sky radiation [16] is given by:

$$
\begin{aligned}
& G_{d \theta}=\frac{G_{d V}}{G_{d H}} C G_{N D} \\
& \frac{G_{d V}}{G_{d H}}=\left\{\begin{array}{lr}
0.55+0.437 \cos \theta+0.313 \cos ^{2} \theta & \theta>-0.2 \\
0.45 & \text { otherwise }
\end{array}\right.
\end{aligned}
$$

In determining the total rate at which radiation strikes a non-horizontal surface at any time, one must also consider the energy reflected from the ground or surroundings onto the surface. Assuming the ground and surroundings diffusely reflect, the reflected radiation[16] incident on the surface is:

$$
G_{R}=\left(G_{D}+G_{d \theta}\right) \rho_{g} F_{w g}
$$

Where: $G_{R}=$ rate at which energy is reflected onto the surface, $W / m^{2} ; \rho_{g}=$ reflectance of ground or horizontal surface; $F_{w g}=$ configuration or angle factor from surface wall to ground, defined as the fraction of the radiation leaving the surface of interest that strikes the horizontal surface or ground directly. For a surface at a tile angle $\alpha$ to the horizontal: $F_{w g}=(1-\cos \alpha) / 2$.

To summarize, the total solar radiation incident on a non-vertical surface would be found by adding the individual components: direct component, sky diffuse and reflected component:

$$
q_{s}=\varepsilon\left(G_{D}+G_{d}+G_{R}\right)=\varepsilon\left[\max (\cos \theta, 0)+C F_{w s}+\rho_{g} F_{w g}(\sin \beta+C)\right] G_{N D}
$$

Similarly, the total solar radiation incident on a vertical surface would be found by adding the individual components: direct component, sky diffuse and reflected component:

$$
q_{s}=\varepsilon\left(G_{D}+G_{d}+G_{R}\right)=\varepsilon\left[\max (\cos \theta, 0)+\frac{G d V}{G_{d H}} C+\rho_{g} F_{w g}(\sin \beta+C)\right] G_{N D}
$$

Where $\varepsilon$ is the solar absorption coefficient. The solar radiation absorption is affected by its color and smoothness of steel plates. 0.6 was adopted in this study based on the test data.

The parameters $\mathrm{A}, \mathrm{B}$, and $\mathrm{C}$ in the above equations should be determined based on the characteristics of solar radiation at the experiment site. Unfortunately, this information is not yet available. To overcome this problem, the following expressions of parameters $\mathrm{A}, \mathrm{B}$, and $\mathrm{C}$ for Beijing were adopted [18]. The parameters A, B, and C are given as $1326.54 \mathrm{~W} / \mathrm{m}^{2}, 0.404$, and 0.181 on $22^{\text {th }}$ July, 2010. 
Based on the environmental conditions of the experiment site, the parameter for the ASHRAE clear sky model was chosen as $c_{N}=1.0$.

The ground radiation reflectance is affected by its color and smoothness. The value of ground radiation reflectance of bituminous surface is 0.15 based on test data.

\subsection{Long Wave Radiation}

The long wave radiation on the surface of steel plates can be expressed by Stefan-Boltzmann equation [6]:

$q_{l}=\varepsilon_{f} \sigma\left(F_{w g}\left(T_{g}^{4}-T^{4}\right)+F_{w s}\left(T_{s k y}^{4}-T^{4}\right)\right)$

Where $\varepsilon_{f}$ is the ratio of the radiation emitted by a surface; $\sigma$ is Stefan-Boltzmann constant $=5.67 \times 10^{-8} \mathrm{~W} /\left(\mathrm{m}^{2} \cdot \mathrm{K}^{4}\right) ; T_{\text {sky }}$ is the effective temperature of sky, usually calculated by $T_{a}-6 ; T_{g}$ is the ground temperature.

The ambient temperature is a critical parameter affecting the steel temperature, because the convection heat transfer between steel surface and air is determined by the ambient temperature and the long wave radiation irradiating on steel surface. In this paper, the air temperature data for the experiment site were used as shown in Figure 6 and Figure 7.

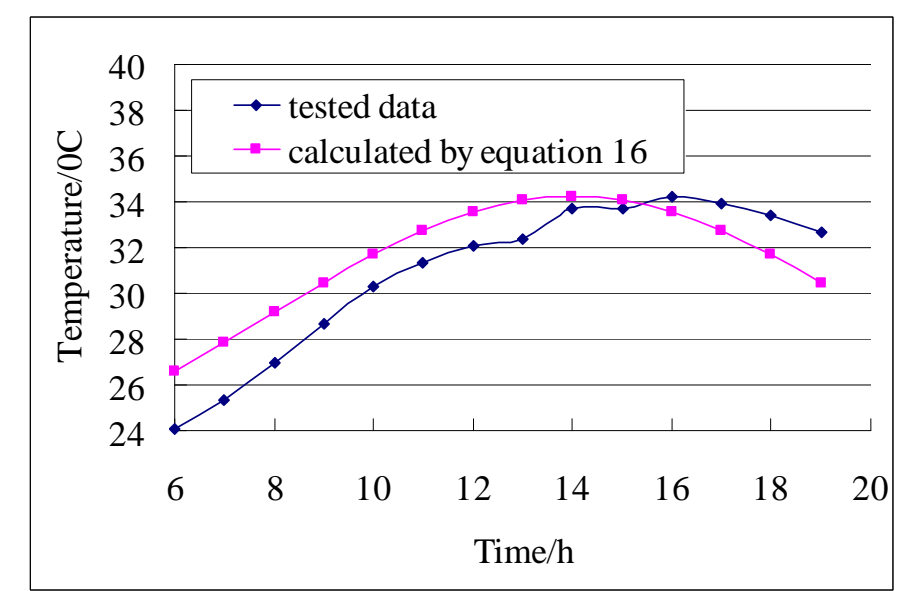

Figure 6. Air Temperature on $22^{\text {th }}$ July on Test Site

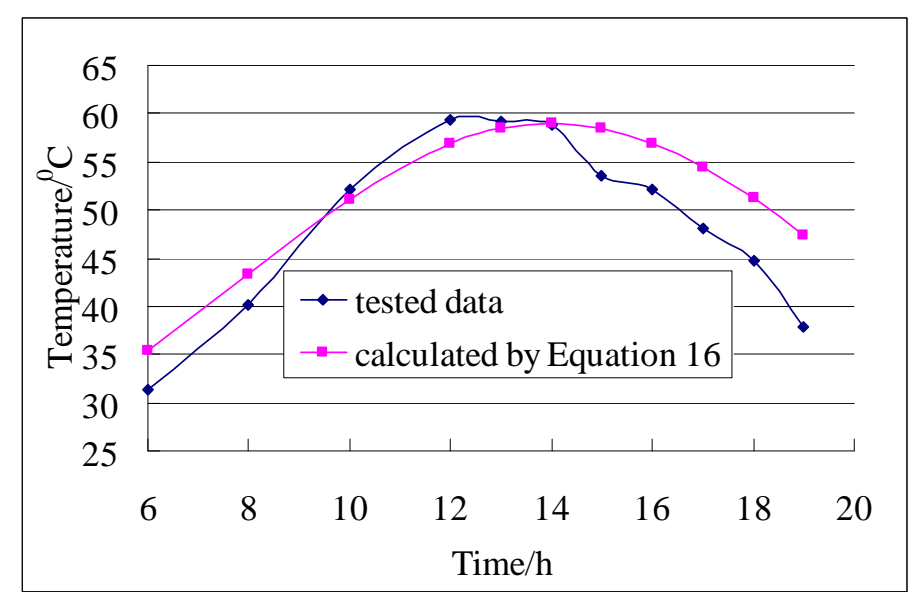

Figure 7. Ground Temperatures on $22^{\text {th }}$ July on Test Site 
If the temperature data is not available in some case, the following equation can be used to define the temperature daily variation:

$T_{a}(t)=T_{a v}+T_{a m} \sin \frac{\left(t-t_{0}\right) \pi}{12}$

Where $T_{a v}$ is the daily mean temperature, defined as $T_{a v}=\left(T_{a \max }+T_{a \min }\right) / 2 ; T_{a m}$ is the amplitude, defined as $T_{a m}=\left(T_{a \max }-T_{a \min }\right) / 2 ; T_{a \max }$ and $T_{a \min }$ are the maximal temperature and minimal temperature. $t_{0}$ is the time when the maximal temperature occurs.

Compared with the temperature data measured on the experimental site, the temperature defined by Eq. 17 is consistent with the temperature data. Therefore, the Eq. 17 can be used to determine the temperature daily variation in the case that the temperature cannot be available.

\section{$2.4 \quad$ Detailed Steps}

Except for steel tubes, the members of steel structures can be divided into some steel plates, for example, the box-sectional steel member is comprised of four rectangular steel plates or eight triangle steel plates. Therefore, here a arbitrary triangle steel plate was used to describe the detailed steps of the three-dimensional transient thermal FE in ANSYS:

Step 1: Build FE model using Shell57 element, and the triangular option was adopted.

Step 2: Calculate the geometric parameters of Shell57 referred by the solar radiation and long wave radiation.

Step 3: Calculate the solar radiation using calculation formulae presented in Section 2.2.

Step 4: Calculate the long wave radiation using calculation formulae presented in Section 2.3.

Step 5: Carry out transient thermal analysis at initial time $t$

Step 6: Calculate the long wave radiation at $t+\Delta t$ using calculation formulae presented in Section 2.3.

Step 7: Re-carry out transient thermal analysis; Step 6 through Step 7 are repeated until the time is up to the end time.

\section{TEST VERIFICATION}

\subsection{Experimental Program}

Ten steel plate specimens were tested to provide insights into temperature distribution of steel structures under solar radiation in summer, and provide data to verify the above numerical simulation method. In order to study the effect of cross-section dimensions and orientation on the temperature distribution, these specimens had different cross-section dimensions and orientations from each other. The cross-section dimension and orientation of each specimen is listed in Table 2 as well as shown in Figure 8. 


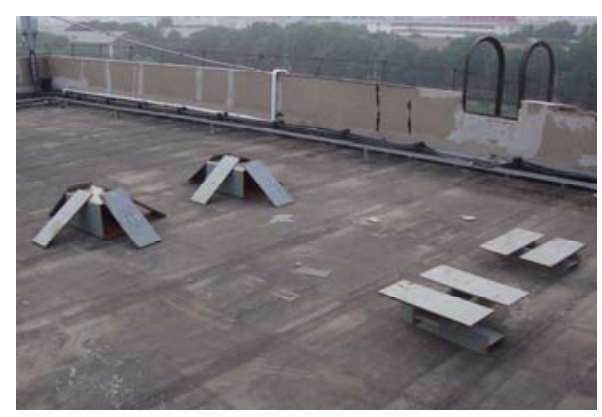

Figure 8. Steel Plate Specimens on Experiment Site

Table 2. The Cross-section Dimension and Orientation of Each Specimens

\begin{tabular}{|c|c|c|c|c|c|}
\hline NUM & PT1 & PT2 & PT3 & PT4 & PT5 \\
\hline cross-section dimension & \multicolumn{5}{|c|}{$500 \times 200 \times 8$} \\
\hline surface azimuth $\psi$ & 0 & 90 & 270 & 180 & 0 \\
\hline Tilt $\alpha$ & 0 & 45 & 45 & 45 & 45 \\
\hline NUM & PT6 & PT7 & PT8 & PT9 & PT10 \\
\hline cross-section dimension & \multicolumn{5}{|c|}{$500 \times 200 \times 14$} \\
\hline surface azimuth $\psi$ & 0 & 90 & 270 & 180 & 0 \\
\hline Tilt $\alpha$ & 0 & 45 & 45 & 45 & 45 \\
\hline
\end{tabular}

In order to obtain the temperature distribution of steel plates, four measured point were designed for ten specimens. An additional measured point was designed for Specimen PT1 and PT6, which was located on the back of measured Point 1 . In this test, infra-red temperature meter was used to obtain the temperature of each measured point.

For all the steel plate specimens, the temperature measure points are arranged as Figure 9 shows. The data were obtained at 6:00 am, 8:00 am, 10:00 am, 12:00 am, 13:00 pm, 14:00 pm, 15:00 pm, 16:00 pm, 17:00 pm, 18:00 pm and 19:00 pm on 22th and 23rd July, 2010.

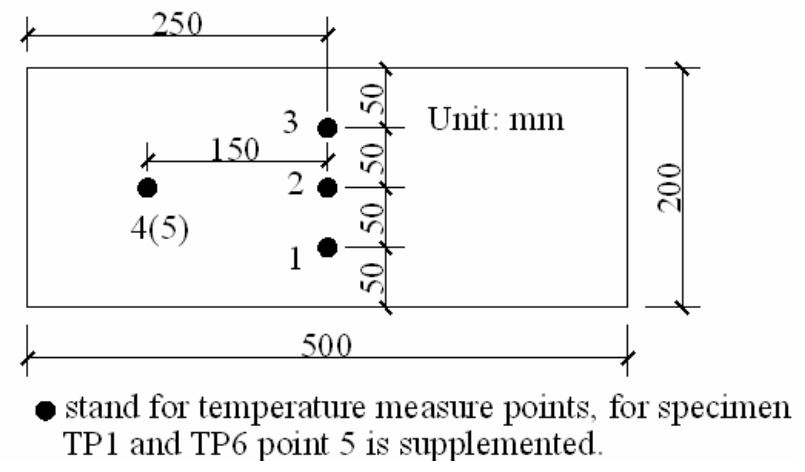

Figure 9. Arrangement of Measure Points

\subsection{Results Analysis}

The temperature-time curves at the maximal temperature and the minimal temperature for each specimen are represented in Figure 10. The temperature-time curves for measure Point 4 and 5 of Specimen PT1 and PT6 are given in Figure 11. The temperature obtained from the transient analysis of each specimen is also shown in Figure 10 and Table 3. 


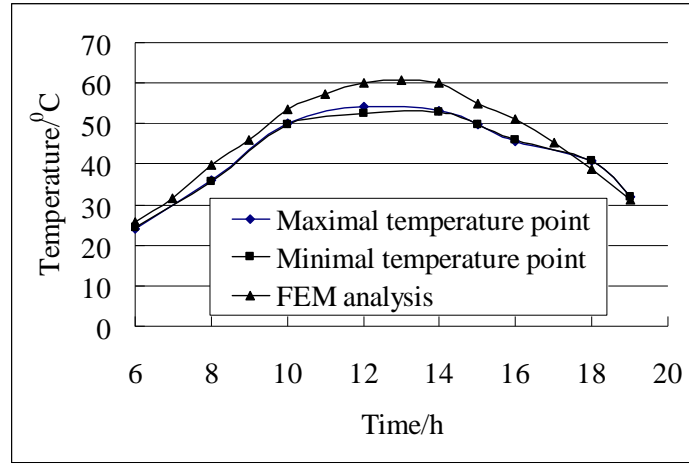

(a) Specimen PT1

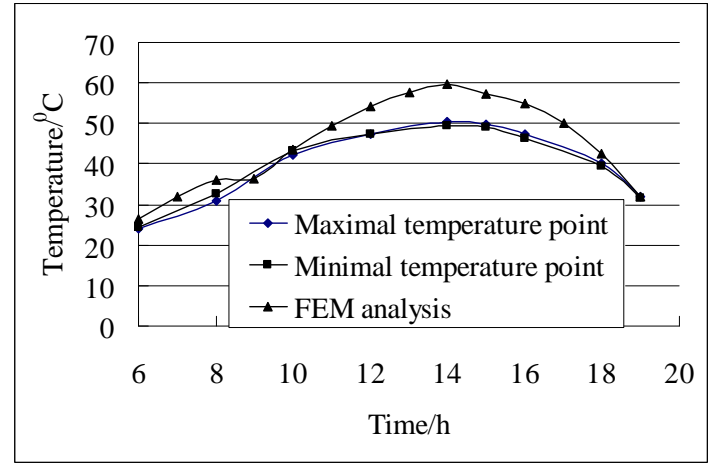

(c) Specimen PT3

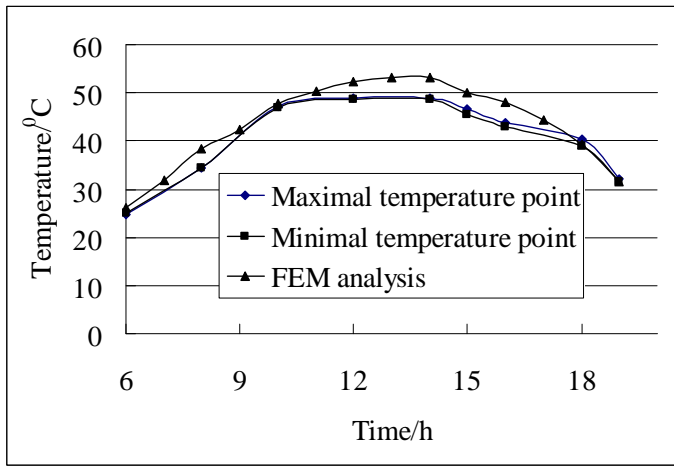

(e) Specimen PT5

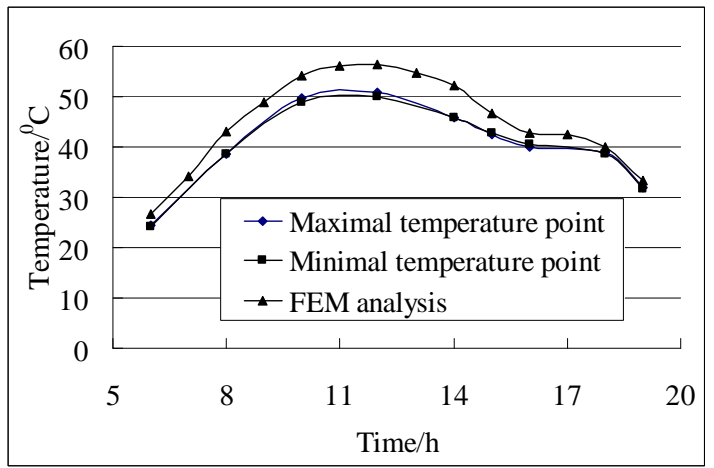

(g) Specimen PT7

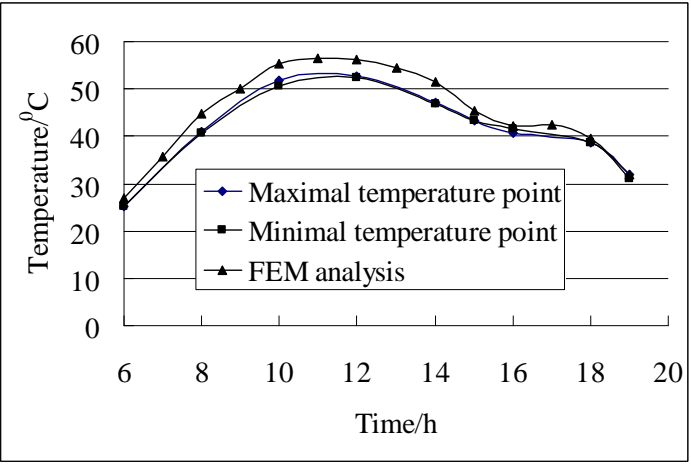

(b) Specimen PT2

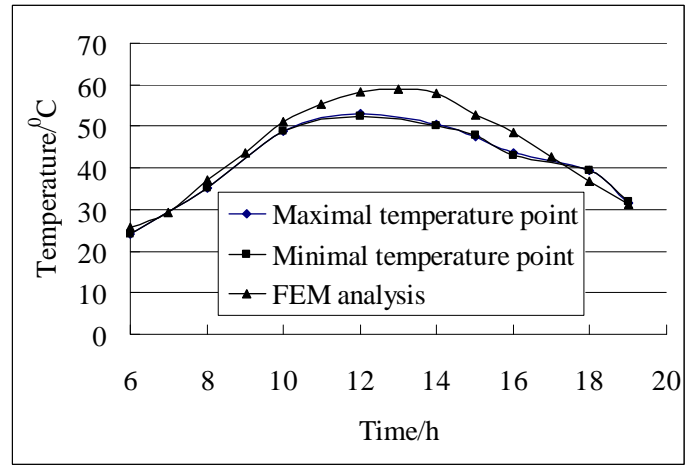

(d) Specimen PT4

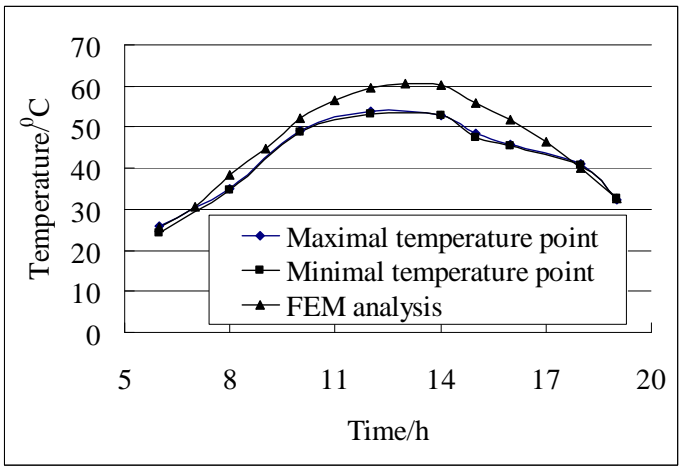

(f) Specimen PT6

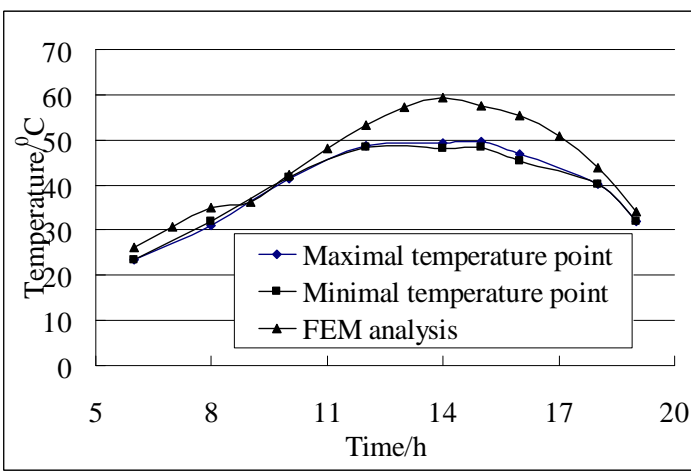

(h) Specimen PT8 


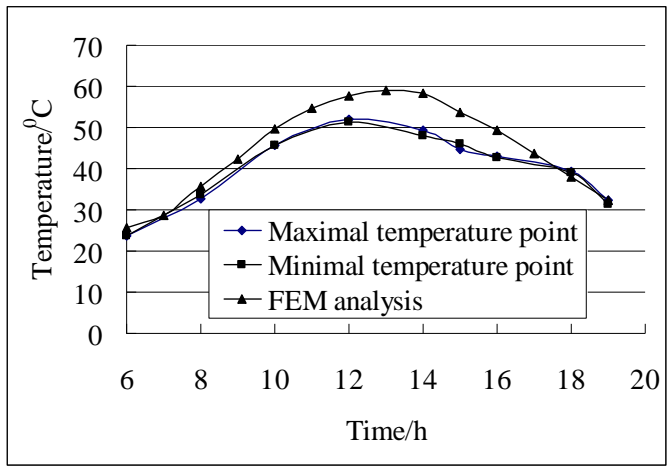

(i) Specimen PT9

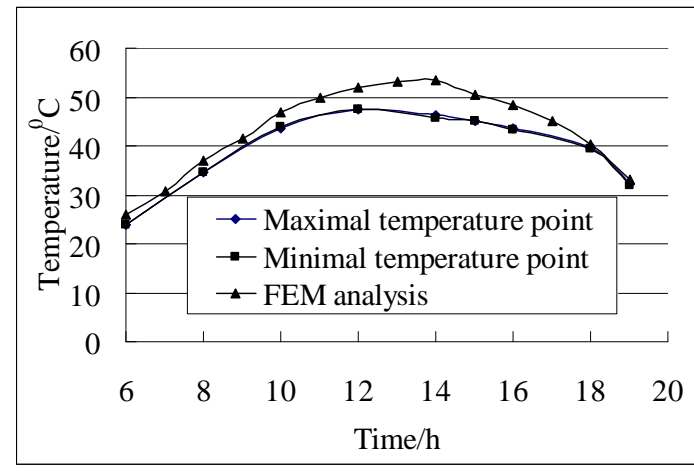

(j) Specimen PT10

Figure 10. Time-temperature Curve of Steel Plate Specimens on 22th July

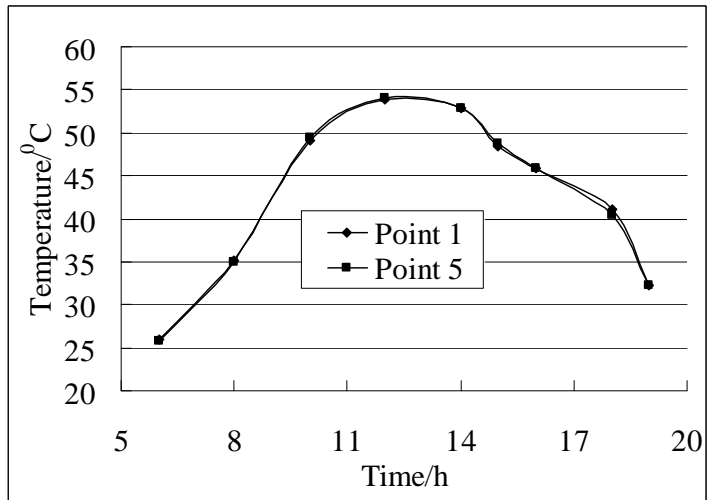

(a) Point temperature on Specimen 1

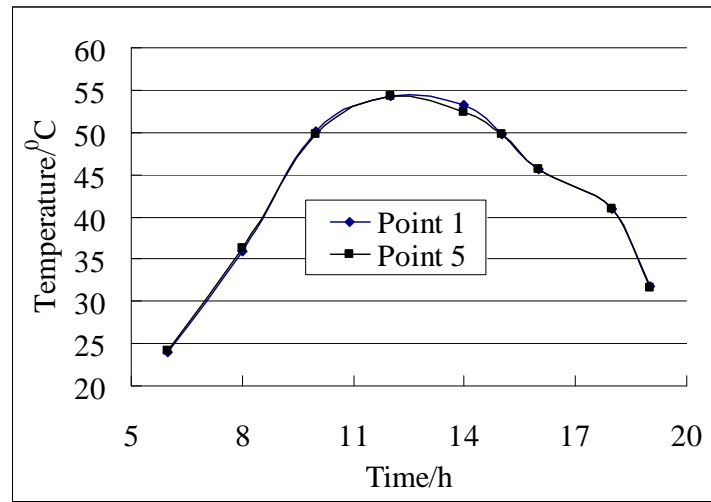

(b) Point temperature on Specimen 6

Figure 11. Time-temperature Curve of Point 1 and Point 5

Table 3. Temperature of 10 Specimens

\begin{tabular}{|c|c|c|c|c|c|}
\hline NUM & PT1 & PT2 & PT3 & PT4 & PT5 \\
\hline${\text { Temperature from test on } 22^{\text {th }} \text { July }}^{\text {th }}$ & 54.2 & 51.9 & 50.3 & 53.1 & 49 \\
\hline Temperature from test on 23 $^{\text {th }}$ July & 52.9 & 51.7 & 50.2 & 52.5 & 49.5 \\
\hline Temperature from FEM analysis & 60.77 & 56.39 & 59.7 & 59.02 & 53.29 \\
\hline Error1 & 0.1212 & 0.0865 & 0.1869 & 0.1115 & 0.0876 \\
\hline Error2 & 0.1488 & 0.0907 & 0.1892 & 0.1242 & 0.0766 \\
\hline NUM & PT6 & PT7 & PT8 & PT9 & PT10 \\
\hline Temperature from test on 22 $^{\text {th }}$ July & 53.9 & 50.8 & 49.2 & 52 & 47.5 \\
\hline Temperature from test on 23 $^{\text {th }}$ July & 53.2 & 49.7 & 49.6 & 51 & 48.8 \\
\hline Temperature from FEM analysis $^{\text {Error1 }}$ & 60.64 & 56.31 & 59.35 & 58.87 & 53.38 \\
\hline Error2 & 0.1250 & 0.1085 & 0.2063 & 0.1321 & 0.1238 \\
\hline & 0.1398 & 0.1330 & 0.1966 & 0.1543 & 0.0939 \\
\hline
\end{tabular}

It is clear that $\mathrm{T}_{\mathrm{FEL}}$ (results obtained from the transient analysis) was generally more than $\mathrm{T}_{\mathrm{T}}$ (results obtained from the tests) with a ratio of 1.0 to 1.2. Therefore, it is clear that the strength $\mathrm{T}_{\mathrm{FEL}}$ was generally consistent with the test results, with a maximum difference of $20.63 \%$. 
Reasons attributing to the discrepancies might be due to variance in the solar radiation model, variance in solar radiation absorption and ground reflectance, precision of infra-red temperature meter, etc. In the test process, the clouds may shelter against solar radiation, which resulted in a decrease of the steel plate specimen's temperature. In order to study the effect of solar radiation decrease on steel plate specimens, the temperature variation of specimen PT7 was obtained by the transient FE analysis under the condition that only solar radiation acted on it with strength of $200 \mathrm{w} / \mathrm{m}^{2}, 400 \mathrm{w} / \mathrm{m}^{2}, 600 \mathrm{w} / \mathrm{m}^{2}$ and $800 \mathrm{w} / \mathrm{m}^{2}$. From Figure 12, it is clear that the temperature increment per min is $0.37{ }^{\circ} \mathrm{C} 、 0.74{ }^{\circ} \mathrm{C} 、 1.11^{\circ} \mathrm{C} 、 1.49{ }^{\circ} \mathrm{C}$ under $200 \mathrm{w} / \mathrm{m}^{2}, 400 \mathrm{w} / \mathrm{m}^{2}, 600 \mathrm{w} / \mathrm{m}^{2}$ and $800 \mathrm{w} / \mathrm{m}^{2}$, respectively.

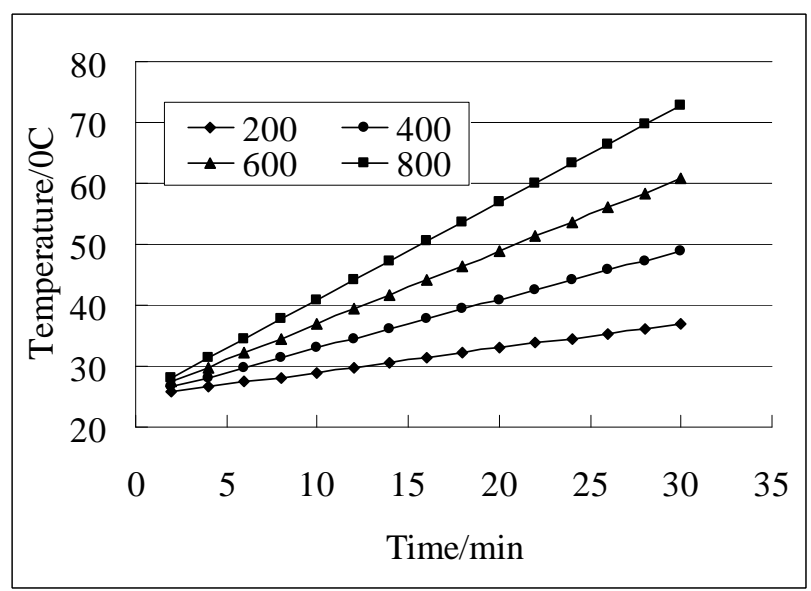

Figure 12. Effect of Solar Radiation on the Temperature of Steel Plate

To sum up the above arguments, the FE simulation results for the steel plate test specimens were generally considered to be precise. Based on the test and numerical results, the following conclusions were drawn on the curves of these figures:

1) For the measure points from Point 1 to Point 4, the temperature-time curves of the maximal temperature point were identical to those of the minimal temperature points. It indicated that the temperature of steel plate was uniformly distributed under solar radiation.

2) The temperature-time curves of all the points were similar to sine curve, and for all the specimens, the maximal temperatures usually occurred at 11:00 am 14:00 pm.

3) The maximal temperature obtained in this experiment was $54.2{ }^{\circ} \mathrm{C}$ with $20{ }^{\circ} \mathrm{C}$ higher than the corresponding ambient air temperature.

4) The temperature-time curves of Measure Point 4 of specimen PT1 and PT6 were identical to those of Measure Point 5. It showed that the temperature in thickness direction was also uniformly distributed.

5) For all the specimens, the maximal temperature was different from each other, and the maximal difference reached $6.7^{\circ} \mathrm{C}$. The temperature distribution of steel plates was affected by their orientation. 


\section{EXAMPLE ANALYSES}

\subsection{The Studied Model}

In order to study the temperature distribution and thermal behavior of steel spatial structures considering the solar radiation, a single-layer lattice shell was designed. This single-layer lattice shell was with a span of $92 \mathrm{~m}$ and a rise of $17 \mathrm{~m}$. steel pipes of $\phi 203 \mathrm{~mm} \times 6 \mathrm{~mm}, \phi 219 \mathrm{~mm} \times 7$ $\mathrm{mm}, \phi 245 \mathrm{~mm} \times 7 \mathrm{~mm}, \phi 273 \mathrm{~mm} \times 8 \mathrm{~mm}, \phi 299 \mathrm{~mm} \times 8 \mathrm{~mm}$ were used as the principal members. The single-layer lattice shell was supported by twenty-four concrete columns. In this study, the boundary conditions were assumed to be simply supported. The studied model was shown in Figure 13.

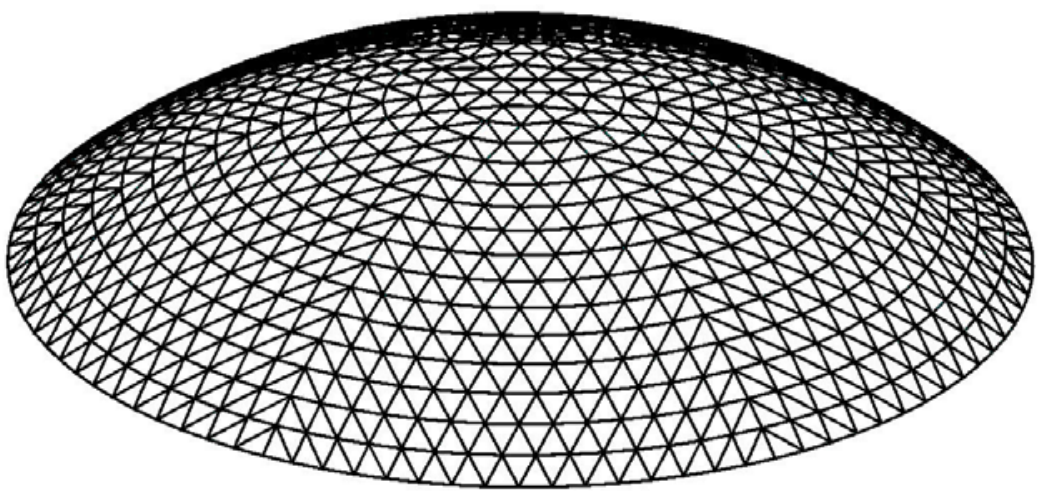

Figure 13. The Studied Model

The light steel roof was used as roof material above the structural members. The temperature of steel members in the single-layer lattice shell was assumed to be similar to the temperature of the above light steel roof.

\subsection{Temperature Distribution of Steel Roof}

Using the numerical simulation method presented in this paper, the temperature distribution of the studied dome model was analyzed. Because the solar radiation on June 21 is the strongest day, June 21 was chosen as the analysis time. The values of all parameters in the numerical simulation model were similar to those of the tested specimens.

The temperature distributions at typical time were shown in Figure 14 to Figure 16. The temperature-time curve of typical node (the center node) is shown in Figure 17. From these figures, it is clear that:

1) The temperature distribution is nearly uniform before sunrise or after sunset.

2) The temperature distribution is very no-uniform under solar radiation, especially around noon. Moreover, the temperature is very high around noon, up to $66^{\circ} \mathrm{C}$ and $31{ }^{\circ} \mathrm{C}$ higher than the corresponding ambient temperature.

3) The temperature-time curve for the steel roof is similar to sine curve. 


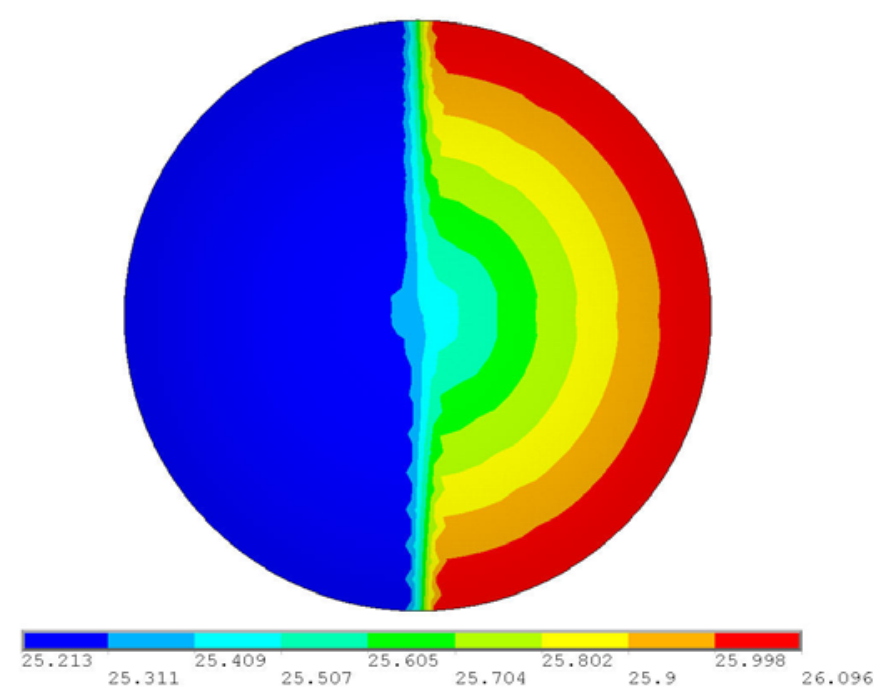

Figure 14. Temperature Distribution of Steel Roof at 6:00 on June 21

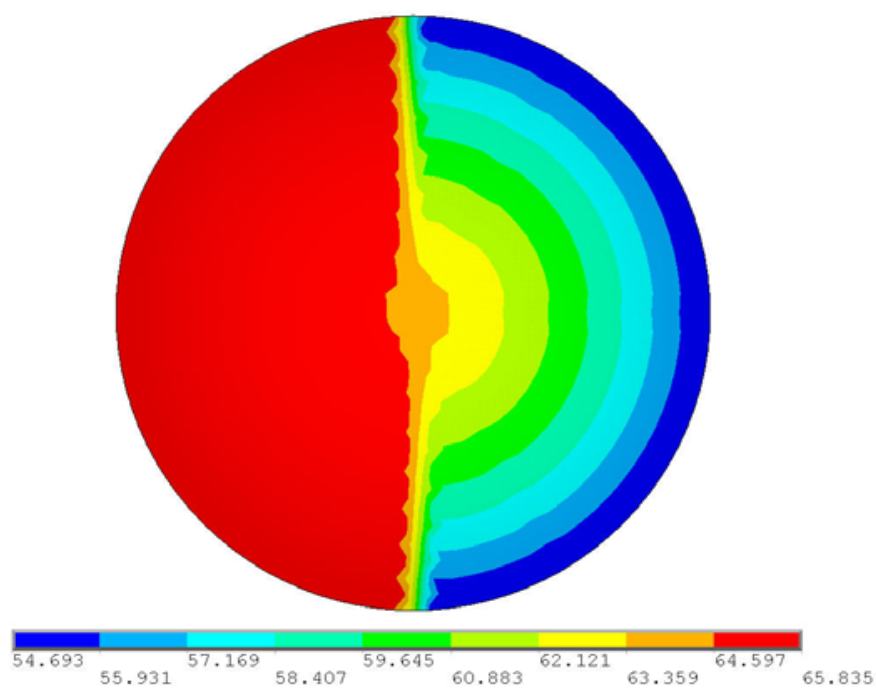

Figure 15. Temperature Distribution of Steel Roof at 14:00 on June 21

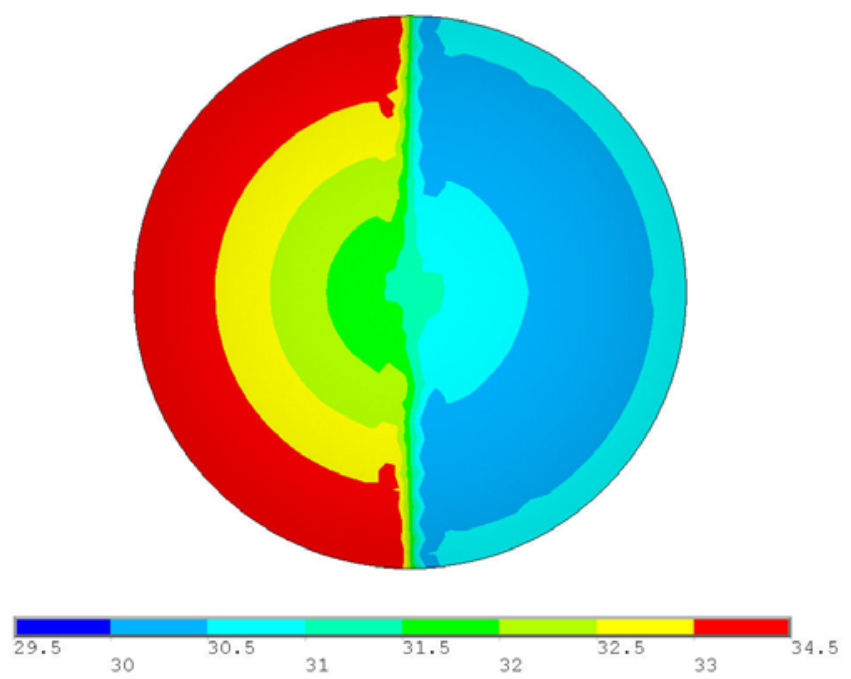

Figure 16. Temperature Distribution of Steel Roof at 19:00 on June 21 


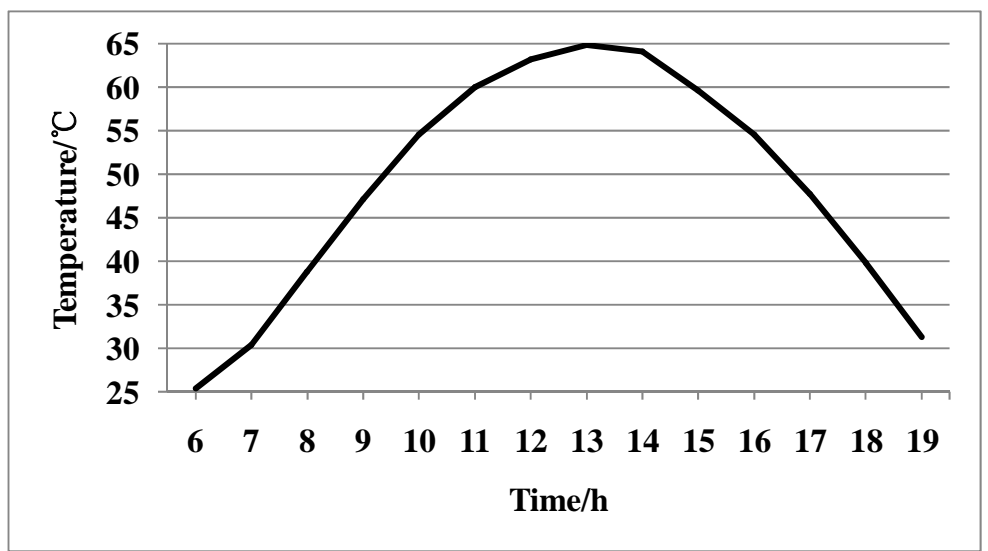

Figure 17. Temperature-time Curve of Typical Node (The Center Node)

\subsection{Thermal Behavior}

Using the temperature field obtained in the Section 4.1, the thermal behavior of the studied dome was analyzed by finite element method. In this paper, ANSYS software was adopted and the BEAM188 was used to simulate the members. The healing temperature for this studied model was assumed to be $10^{\circ} \mathrm{C}$. The maximal nodal displacement $\mathrm{D}$, the maximal member stress $\mathrm{S}$, the maximal reaction force Fx (at radial direction), the maximal reaction force Fy (at circumferential direction) and the maximal reaction force $\mathrm{Fz}$ (at vertical direction) induced by temperature change on June 21 were shown in Figure $18 \sim$ Figure 22. The maximal nodal displacement, the maximal member stress, the maximal reaction force Fx, the maximal reaction force Fy and the maximal reaction force $\mathrm{Fz}$ induced by dead load $\left(1 \mathrm{kN} / \mathrm{m}^{2}\right)$ were $9.5 \mathrm{~mm}, 45.1 \mathrm{Mpa}, 293.8 \mathrm{kN}, 44.9 \mathrm{kN}$ and $249.1 \mathrm{kN}$, respectively.

From these figures, following conclusions can be obtained:

1) The changing curves of D, S, Fx and Fz during a day is similar to the structural temperature changing curve.

2) The variation of D, S, Fx, Fy and Fz induced by temperature change during a day on June 21 were $37.4 \mathrm{~mm}, 123.3 \mathrm{Mpa}, 176.2 \mathrm{kN}, 156.1 \mathrm{kN}$ and $59.5 \mathrm{kN}$, respectively. They are $393.5 \%, 273.4 \%$, $60.0 \%, 347.6 \%$ and $23.9 \%$ of the corresponding value under dead load. Therefore, it is concluded that the solar radiation has a significant effect on the structural behavior of steel dome structures.

3) Due to the remarkable variation of member stress, it is necessary to study the fatigue behavior of steel dome structure under solar radiation. 


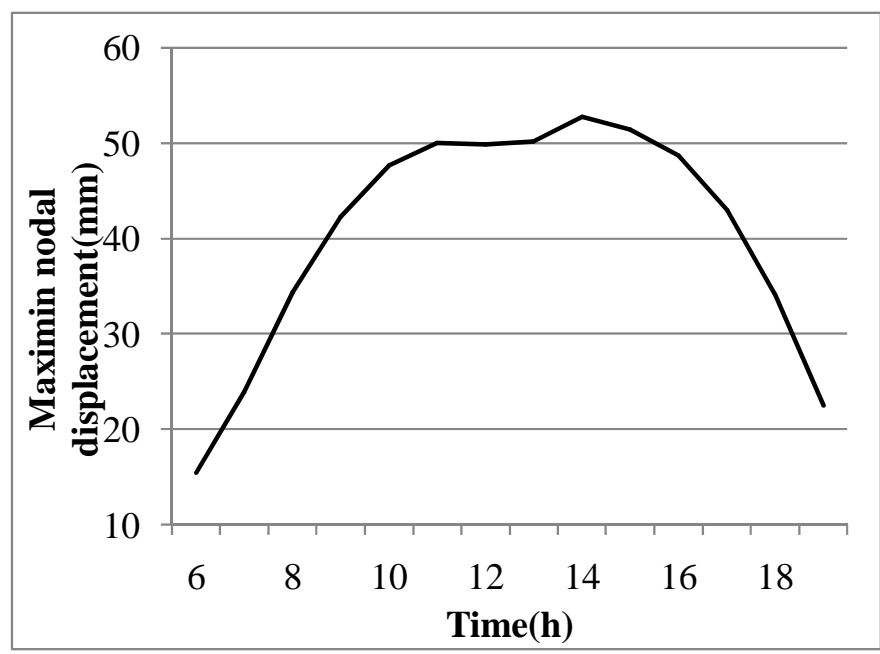

Figure 18. Maximal Nodal Displacement-time Curve Induced by Temperature Change

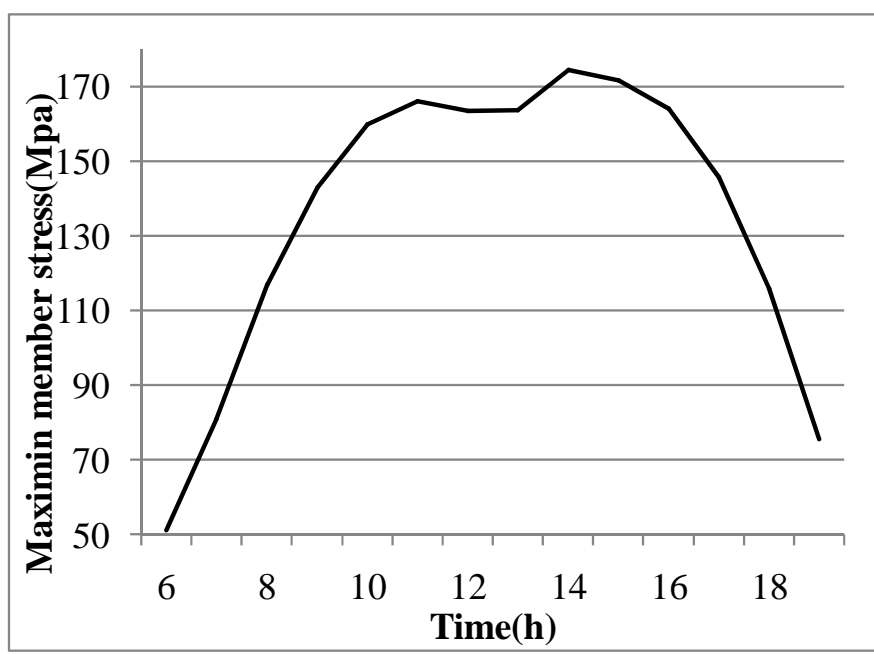

Figure 19. Maximal Member Stress-time Curve Induced by Temperature Change

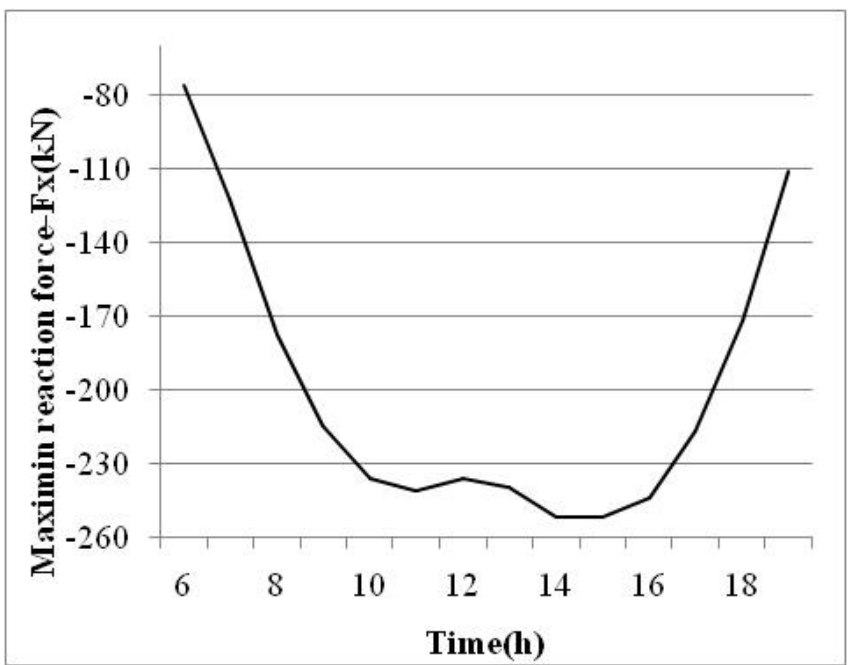

Figure 20. Maximal Reaction Force Fx-time Curve Induced by Temperature Change 


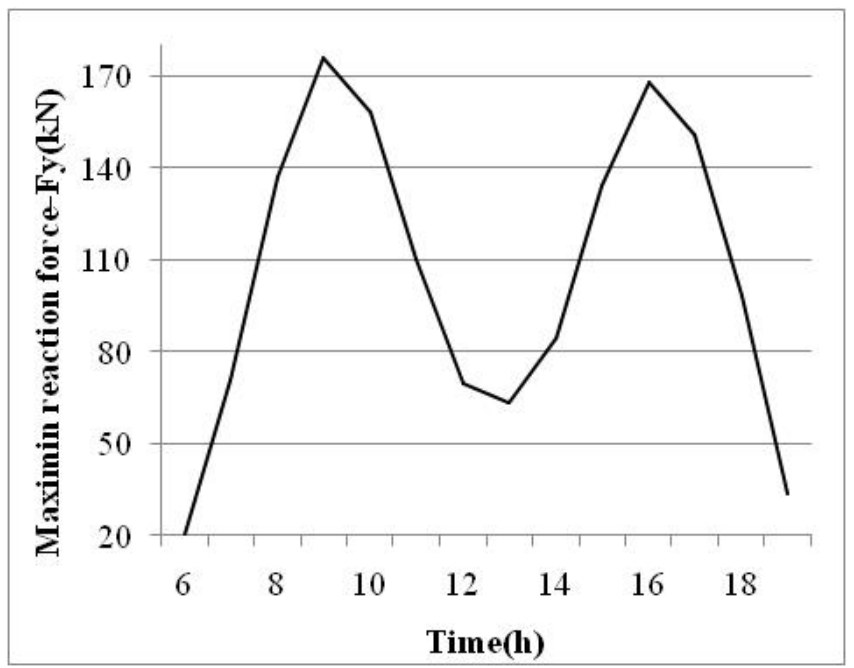

Figure 21. Maximal Reaction Force Fy-time Curve Induced by Temperature Change

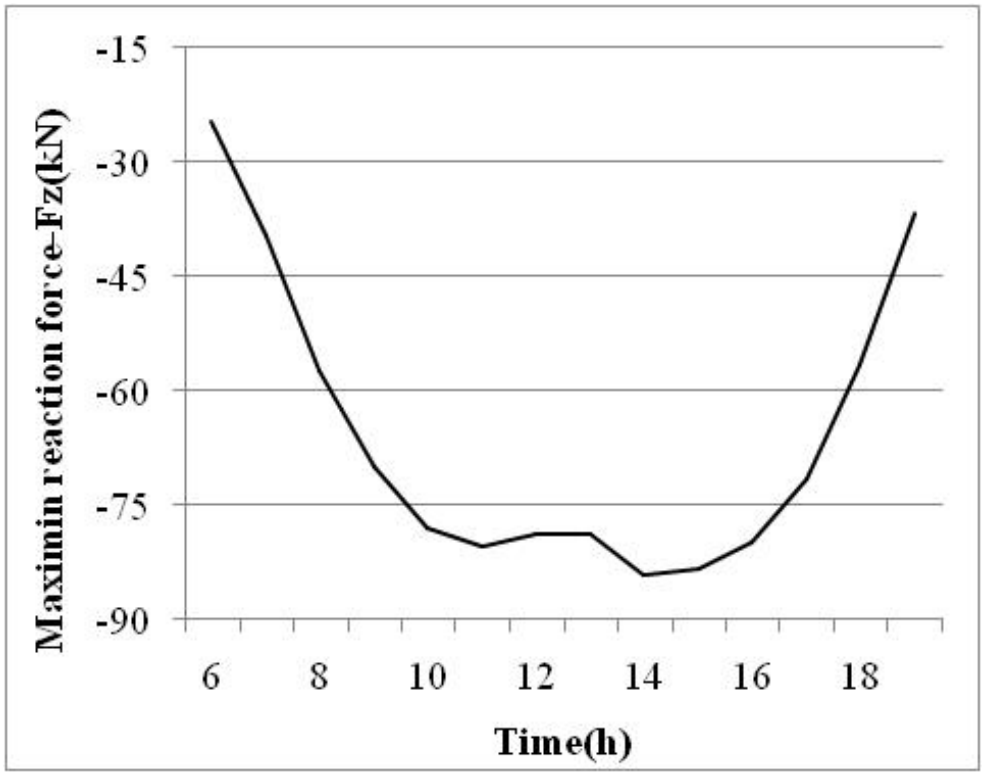

Figure 22. Maximal Reaction Force Fz-time Curve Induced by Temperature Change

\section{CONCLUSIONS}

1) A numerical model, based on a transient thermal FE analysis, was presented for evaluating the thermal performance of steel plates, and its precision is verified by the test data.

2) The daily temperature of ten steel plate specimens with different thickness and orientations were measured on $22^{\text {th }}$ July, 2010. From the test results, the following conclusions were obtained: a) the temperature of steel plates is uniform under solar radiation; b) the temperature-time curve for all point is similar to sine curve; c) The maximal temperature obtained in this experiment is $54.2^{\circ} \mathrm{C}$, and for all specimens, the maximal temperatures usually occurred at 11:00 14:00; d) the temperature in thickness direction is uniform; e) the temperature distribution of steel plates is affected by its orientation.

3) The solar radiation has a remarkable effect on the member stress, nodal displacement and reaction force of steel lattice shell. 


\section{ACKNOWLEDGEMENTS}

This work was supported by the National Natural Science Foundation of China(No. 51208355), China Postdoctoral Science Foundation funded project(No. 2012M510751) and the Independent innovation foundation of Tianjin University(No. 1102, No. 1104).

\section{REFERENCES}

[1] Alinia, M.M. and Kashizadeh, S., "Effect of Flexibility of Substructures upon Thermal Behaviour of Spherical Double Layer Space Truss Domes, Part I: Uniform Thermal Loading”, Journal of Constructional Steel Research, 2006, Vol. 62, No. 4, pp. 359-368.

[2] Alinia, M.M. and Kashizadeh, S., "Effect of Flexibility of Substructures upon Thermal Behaviour of Spherical Double Layer Space Truss Domes, Part II: Gradient \& Partial Loading”, Journal of Constructional Steel Research, 2006, Vol. 62, No. 7, pp. 675-681.

[3] Alinia, M.M. and Kashizadeh, S., "Effects of Support Positioning on the Thermal Behaviour of Double Layer Space Truss Domes”, Journal of Constructional Steel Research, 2007, Vol. 63, No. 3, pp. 375-382.

[4] Yong, D., “A Practical Approach for Fire Risitance Design of Large Space Building Grid Structures [D]”, Shanghai, Tongji University, 2007.

[5] Li, G.Q. and Zhang, C., "Thermal Response to Fire of Uniformly Insulated Steel Members: Background and Verification of the Formulation Recommended by Chinese Code CECS200, Advanced Steel Construction, 2010, Vol. 6, No. 2, pp. 788-802.

[6] Fan, Z., Wang, Z. and Tian, J., "Analysis on Temperature Field and Determination of Temperature upon Healing of Large-span Steel Structure of the National Stadium”, Journal of Building Structures, 2007, Vol. 28, No. 2, pp. 32-40. (in Chinese)

[7] Pei, Y.Z., Bai, Y., Shi, Y.J., Zhu, D. and Wang, Y.Q., "Temperature Distribution in a Long-span Aircraft Hanger [J], Tsinghua Science and Technology, 2008, Vol. 13, No. 2, pp. 184-190.

[8] Xiao, J.C., Xu, H., Liu, J.K. and Ma, K.J., “The Influence of Intense Solar Radiation on Long-span Spatial Steel Structures [J]”, Chinese Journal of Solid Mechanics, 2010, Vol. 31, pp. 275-280.

[9] Wang, Y.Q., Lin, C.C. and Shi, Y.J., "Experimental Study on the Temperature of Steel Members in Sunshine [J]”, Journal of Building Structures, 2010, Supplementary Issue Vol. 1, pp. 140-147.

[10] Jin, X.F., Fan, F. and Shen, S.Z., "Effect of Non-uniform Temperature Field under Sunshine on the Structure Supporting the Reflector of a Large Radio Telescope-FAST [J]", China Civil Engineering Journal, 2008, Vol. 41, No. 11, pp. 71-77.

[11] Brisn, K., Diefenderfer, Imad L. and Al-Qadi Stacey, D. Diefenderfer., "Model to Predict Pavement Temperature Profile: Development and Validation”, Journal of Transportation Engineering, 2006, Vol. 132, No. 2, pp. 162-167.

[12] Andrew, D. Chiasson, Cenk, Yavuzturk and Khaled, Ksaibati, "Linearized Approach for Predicting Thermal Stresses in Asphalt Pavements due to Environmental Conditions", Journal of Materials in Civil Engineering, 2008, Vol. 20, No. 2, pp. 118-127.

[13] Tong, M., Tham, L.G. and Au, F.T.K., "Numerical Modeling for Temperature Distribution in Steel Bridges”, Computers and Structures, 2001, Vol. 79, No. 6, pp. 583-593.

[14] Kim, S.-H., Cho, K.-I., Won, J.-H. and Kim, J.-H., "A Study on Thermal Behavior of Curved Steel Box Girder Bridges Considering Solar Radiation”, Archives of Civil and Mechanical Engineering, 2009, Vol. 9, No. 3, pp: 59-76. 
[15] Xu, Y.L., Chen, B., Ng, C.L., Wong, K.Y. and Chan, W.Y., “Monitoring Temperature Effect on a Long Suspension Bridge”, Structural Control and Health Monitoring, 2010, Vol. 17, No. 6, pp. 632-653

[16] Jin, F., Chen, Z., Wang, J.T., Yang, J., "Practical Procedure for Predicting Non-uniform Temperature on the Exposed Face of Arch Dams”, Applied Thermal Engineering, 2010, Vol. 30, No. 14-15, pp. 2146-2156.

[17] Faye, C. McQuiston, Jerald, D. Parker and Jeffrey, D. Spitler, "Heating, Ventilating, and Air Conditioning Analysis and Design, USA, John Wiley and Sons, 2005.

[18] Li, J.P. and Song, A.G., "Compare of Clear Day Solar Radiation Model of Beijing and ASHRAE”, Journal of Capital Normal University, 1998, Vol. 19, No. 1, pp. 35-38. (in Chinese) 


\title{
EVALUATION OF WELDED FLANGE PLATE CONNECTIONS BETWEEN STEEL BEAMS AND BOX COLUMNS
}

\author{
M. Gholami, M. Tehranizadeh* and A. Deylami \\ Department of Civil and Environmental Engineering, Amirkabir University of Technology, Tehran, Iran \\ *(Corresponding author: E-mail: Dtehz@yahoo.com)
}

Received: 23 November 2011; Revised: 10 December 2011; Accepted: 20 February 2012

\begin{abstract}
This study elucidates the behavior of flange plate connection between a steel beam and a welded box column. Four finite element models simulating an exterior connection were prepared and analyzed. On the basis of finite element results, two flange plate connection details which are the reinforcing plate length and plate-to-flange fillet weld geometry were improved. Then, two full-scale specimens with flange plate connections were tested using a standard connection requalification test protocol. The flange plate connections of test specimens achieved the AISC seismic provision requirements for special moment frames.
\end{abstract}

Keywords: Connections, Flange plate, Box columns, Steel beam, Experimental program, Finite element analysis

\section{INTRODUCTION}

Box columns are frequently employed in areas of high seismic risk because they have an excellent capacity to resist biaxial bending. Cold-formed hollow sections are often used for low and medium rise buildings and built-up sections made up of four plates welded together are used for high rise buildings [1]. Extensive studies have been carried out and several new connection details have been proposed for the connection of I-beams to wide flange columns since the 1994 Northridge earthquake[2-7], but limited research for the connection of I-beams to box-columns has been conducted[8].

Kim et al. [9, 10] tested two full-scale moment connections to US box columns fabricated using pre-Northridge connection details. Test results revealed that both specimens failed by brittle fracture of complete joint penetration (CJP) welds between the beam flange and the column during a story drift angle of less than $1 \% \mathrm{rad}$, which resulted in no plastic rotation in the connections.

Chen et al. [8] tested six large scale specimens of steel beam-to-box column connections. One of the test specimens was the unreinforced connection using pre-Northridge details, and other test specimens were the reinforced connections using rib plates or wing plates. The unreinforced connection was failed by fracture in the heat affected zone (HAZ) of the beam bottom flange during $2.3 \%$ story drift angel cycle.

In the present study the behavior of a moment resisting connection, shown in Figure 1, has been investigated. This type of connection is mainly fabricated on site similar to a welded flange plate (WFP), which is considered as a prequalified connection in accordance with FEMA [11].The shapes of the top and bottom flange plates are different due to the field construction of the connection at the site. The geometry of these plates is considered in a manner that site welding in a horizontal position is possible for connecting flange plates to beam and column. The WFP connections using rectangular and trapezoidal shapes of flange plates connecting to the $\mathrm{H}$ shape columns have already been tested $[12,13]$. 
A special welding sequence should be followed to join the continuity plates to the box column plate. As shown in Figure 2, after groove welds are performed to join the continuity plates to three plates of box column, the fourth plate should cuts into three segments. As shown in Figure 2, first, middle segment put into the place and CJP groove welds of continuity plates to this segment will be done. Finally, three segments will weld to each other.

This study analytically and experimentally investigates the behavior of the WFP connections. On the base of finite element results, an improved WFP connection was proposed. Then, two full-scale specimens with flange plate connections were tested using a standard connection prequalification test protocol. The results of the specimen's hysteretic behavior were obtained and compared to the AISC seismic provision requirements in order to qualify the improved flange plate connection.

\section{NONLINEAR FINITE-ELEMENT ANALYSIS}

Finite-element analysis can provide considerable insight into behavior of complex connections even though the analysis cannot readily address material imperfections, geometric imperfections, residual stresses and strains, and defects.

\subsection{Specimens}

Four models were prepared to simulate an exterior T-shaped joint subassembly. The general configuration of the exterior joint subassembly is shown in Figure 3. All models consisted of a $\mathrm{H}$-shaped steel beam with the dimensions of $\mathrm{H}-380 \times 200 \times 8 \times 12(\mathrm{~mm})$ connected to a box column with the measurements of B-400 $\times 400 \times 20 \times 20(\mathrm{~mm})$. The width-thickness ratios of the beam flange and the web are 8.33 and 44.5 , respectively, and the beam section categorizes to a compact section, which is capable of developing the fully plastic stress distribution.

Summary information on models is presented in Table 1. Model UN represents an unreinforced connection. Connection details of model UN is presented in the Figure 4. In the remaining three models, the joint from the steel beam to the box column was a WFP moment connection. Figure 5 shows connection details of model LF30. In the model LF30, flange plates were joined to the beam flanges with longitudinal fillet welds only. Model LF30-T was identical to LF30 except for the addition of the transverse fillet weld at the nose of the flange plate; the size of the LF30-T fillet welds was smaller than that of LF30 to preserve the total volume of fillet weld material. Figure 6 is a plan view of the fillet welds of LF30 and LF30-T. Model LF50-T was most similar to model LF30-T except that the flange-plate length was arbitrarily increased from 300 to $500 \mathrm{~mm}$.

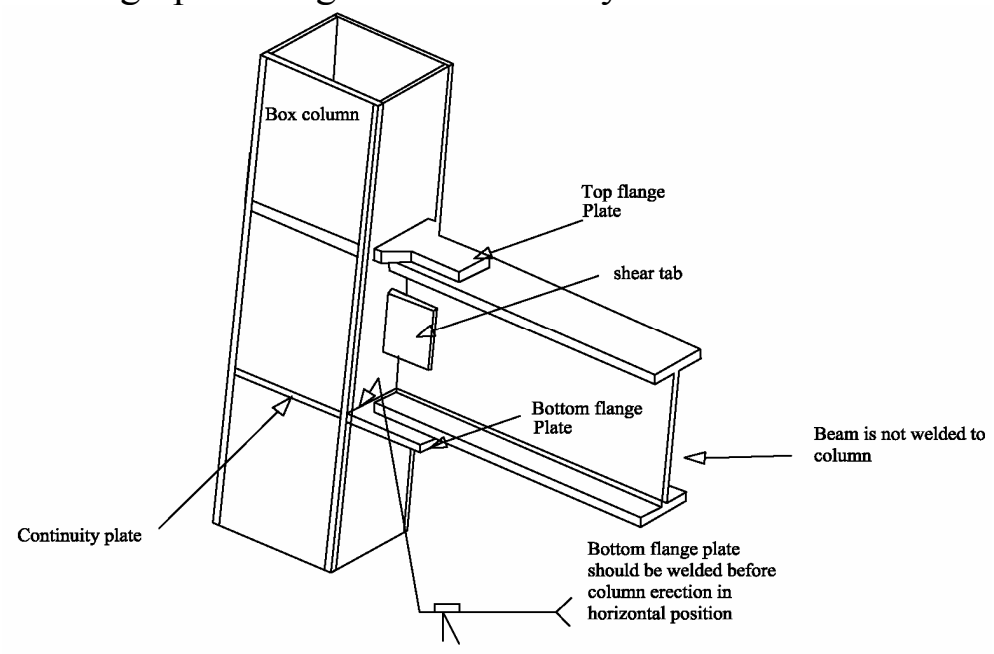

Figure 1. Field Welded Moment Connection 


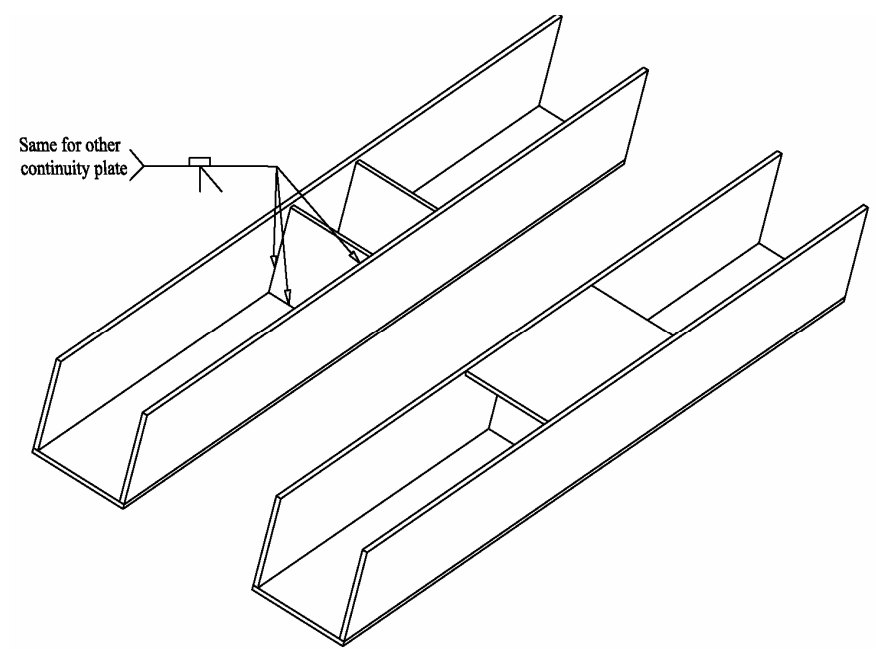

Figure 2. Welding of Continuity Plates to the Box Column Plates

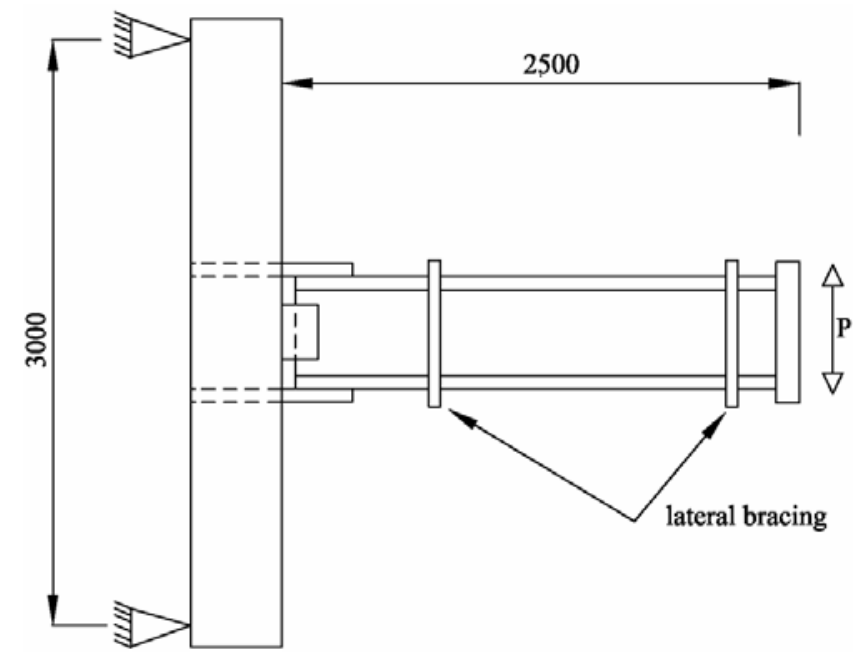

Figure 3. Configuration of the Exterior Joint Subassembly

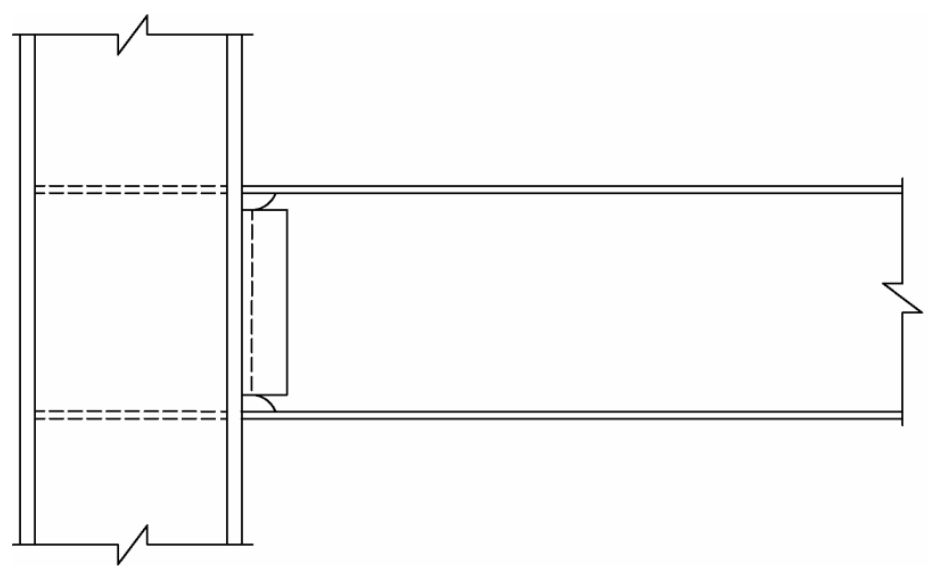

Figure 4. Connection Details of Model UN 

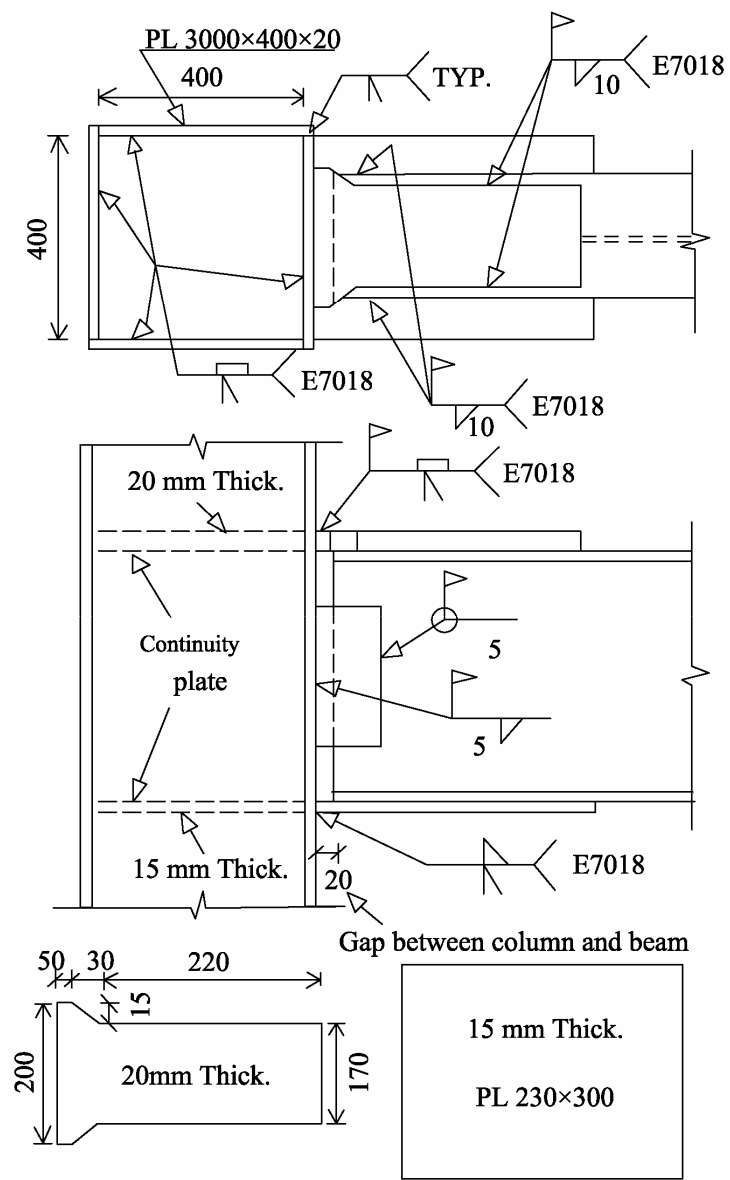

$\underline{\text { Top reinforcing flange plate Bottom reinforcing flange plate }}$

Figure 5. Connection Details of Model LF30

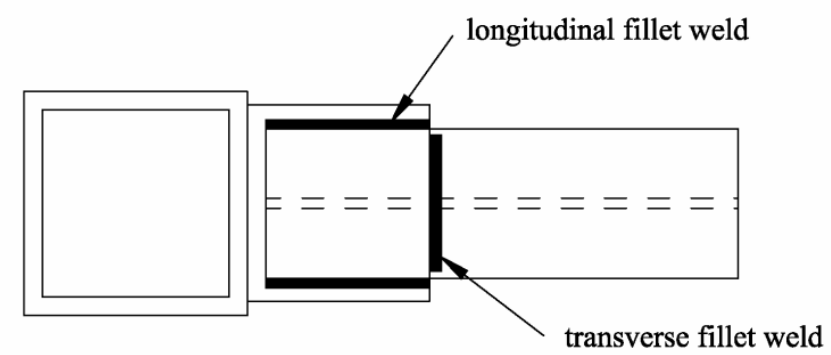

a)

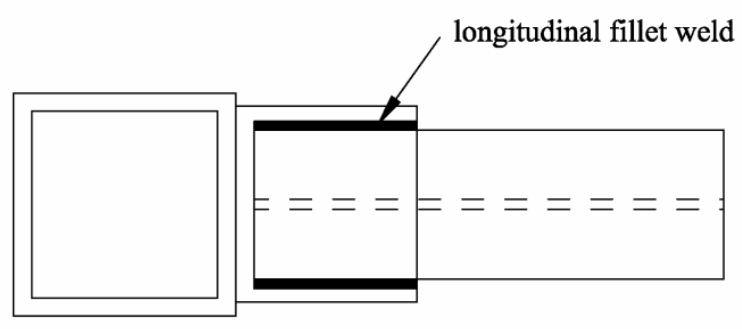

b)

Figure 6. Fillet Weld Geometry: (a) LF30-T and (b) LF30 
Table 1. Summary Information on Models

\begin{tabular}{|c|l|c|c|c|c|c|}
\hline Model & $\begin{array}{l}\text { Connection } \\
\text { type }\end{array}$ & $\begin{array}{c}\text { Flange-plate } \\
\text { length }\end{array}$ & $\begin{array}{c}\text { Top } \\
\text { flange-plate } \\
\text { thickness }\end{array}$ & $\begin{array}{c}\text { Bottom } \\
\text { flange-plate } \\
\text { thickness }\end{array}$ & $\begin{array}{c}\text { Longitudinal } \\
\text { fillet weld }\end{array}$ & $\begin{array}{c}\text { Transverse } \\
\text { fillet weld }\end{array}$ \\
\hline UN & Unreinforced & ------ & ------ & ------ & ------ & ------ \\
LF30 & Flange plate & 300 & 20 & 15 & 10 & ----- \\
LF30-T & Flange plate & 300 & 20 & 15 & 8 & 8 \\
LF50-T & Flange plate & 500 & 25 & 20 & 8 & \\
& & & & & & \\
\hline
\end{tabular}

Note: All dimensions in $\mathrm{mm}$.

\section{$2.2 \quad$ Finite Element Modeling}

ABAQUS models of UN, LF30, LF30-T and LF50-T were prepared. As shown in Figure 7, groove welds that join flange plates to column flange and fillet welds that join flange plates and shear tabs to the beam were modeled. The beam, column, plates, CJP groove welds and fillet welds in the models were discretized using three-dimensional solid (brick) elements.

The size of the finite-element mesh varied over the length and height of the specimen as can be seen in Figure 7. A fine- mesh was used near the connection of the beam to the column and the beam flange to the reinforcing plate. A coarser mesh was used elsewhere. Most of the solid elements were right-angle prisms. Hinged boundary conditions were used to support the column top and bottom. The load was applied by imposing incremental vertical displacements at the beam tip during the analysis.

A bilinear stress-strain relationship was considered for each of materials. Figure 8 shows the assumed bilinear stress-strain relationship. Table 2 presents the material properties used for the analytical models. Data from test of coupon extracted from the beam of test specimen LF30-T were used to establish the stress-strain relationship for the steel material. The weld material was modeled using the test data of Kaufmann [14]. The Poisson's ratio was taken as 0.3 for all materials throughout the analyses. To account for material nonlinearities, the von mises yield criterion was employed.

\subsection{Rupture Index}

To compare between the behavior of the different configurations analyzed in this research, a rupture index was used and computed for different cases; this same methodology and approach was used by others $[13,15-18]$. The rupture index $(\mathrm{RI})$ is defined as:

$$
R I=\frac{P E E Q}{\exp \left(-1.5 \frac{\sigma_{m}}{\bar{\sigma}}\right)}
$$

Where, $\sigma_{\mathrm{m}}$ and $\bar{\sigma}$ are, respectively, the equivalent plastic strain, hydrostatic stress, and von mises stress. The rupture index was introduced by Hancock and Mackenzie [19]. Locations in a connection with higher values of RI have a greater potential for ductile fracture. 


\section{$2.4 \quad$ Analytical Results}

The rupture index was computed at three locations, the top surface of the beam flange at the column face, at the nose of the reinforcing plate and the top surface of the reinforcing plate at the face of the column. The maximum values of stress and strain along these lines were not necessarily the maximum values in the components, but these lines were chosen to facilitate a comparison of results for different specimens. A story drift angle of $4 \%$ rad was used to compare the connection behaviors under highly strained states because a special moment-resisting frame is assumed to be capable of sustaining a story drift angle of at least $4 \% \operatorname{rad}[20]$.
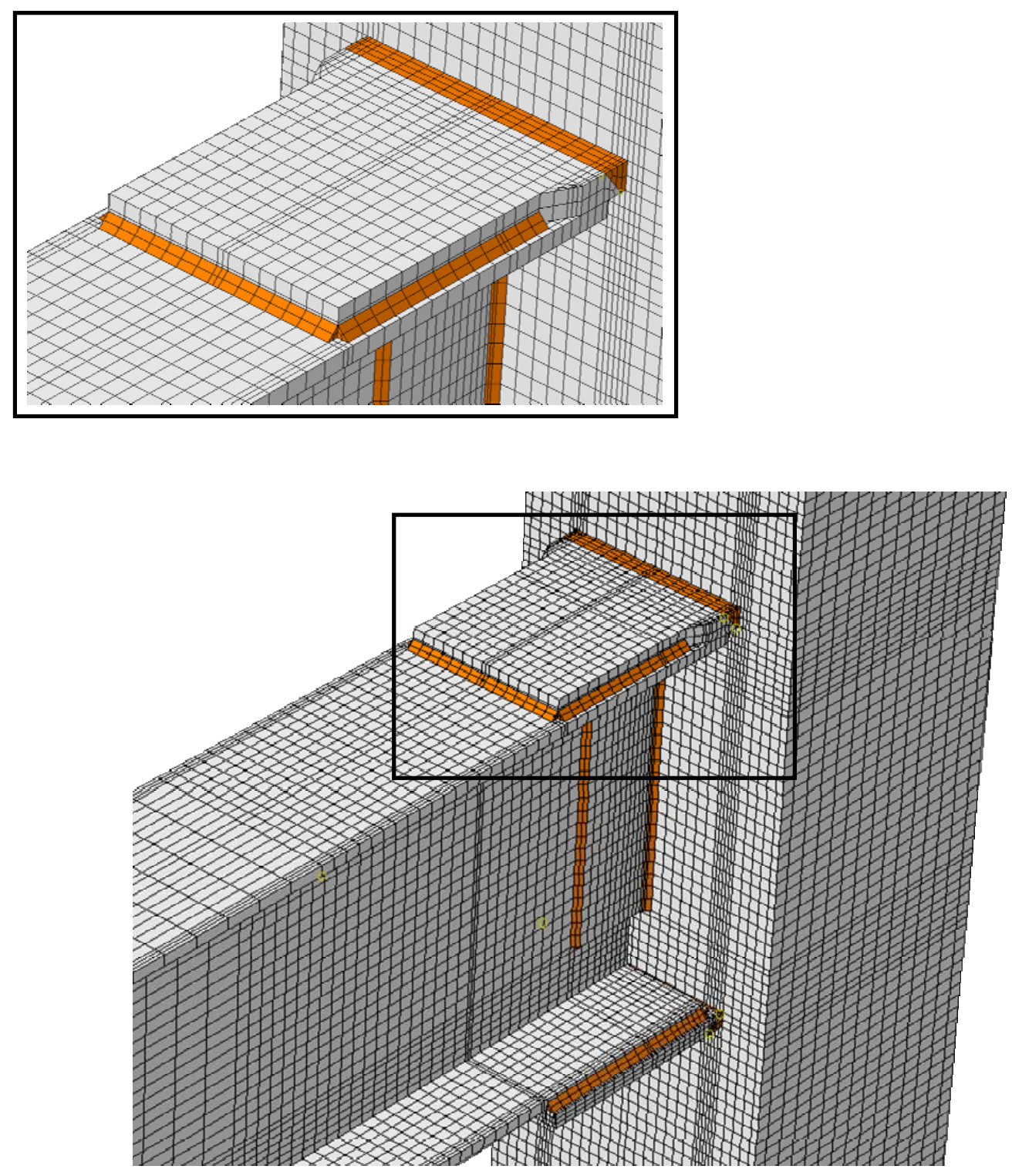

Figure 7. Finite Element Model 
Table 2. Material Properties used for the Analytical Models

\begin{tabular}{|c|c|c|c|c|c|c|}
\hline \multirow[b]{2}{*}{ Material } & \multirow[b]{2}{*}{$\begin{array}{l}\text { Young } \\
\text { modulus(Mpa) }\end{array}$} & \multirow[b]{2}{*}{$\begin{array}{l}\text { Strain hardening } \\
\text { modulus(Mpa) }\end{array}$} & \multicolumn{2}{|l|}{ Yield point } & \multicolumn{2}{|c|}{ Ultimate point } \\
\hline & & & $\begin{array}{l}\text { Stress(Mpa) } \\
\sigma_{\mathbf{y}}\end{array}$ & $\begin{array}{l}\text { Strain }(\%) \\
\varepsilon_{y}\end{array}$ & $\begin{array}{l}\text { Stress(Mpa) } \\
\sigma_{\mathrm{u}}\end{array}$ & $\begin{array}{l}\text { Strain }(\%) \\
\varepsilon_{\mathrm{u}}\end{array}$ \\
\hline Steel & 200000 & 6000 & 300 & 0.15 & 4200 & 18 \\
\hline Weld & 200000 & 3000 & 520 & 0.26 & 560 & 12 \\
\hline
\end{tabular}

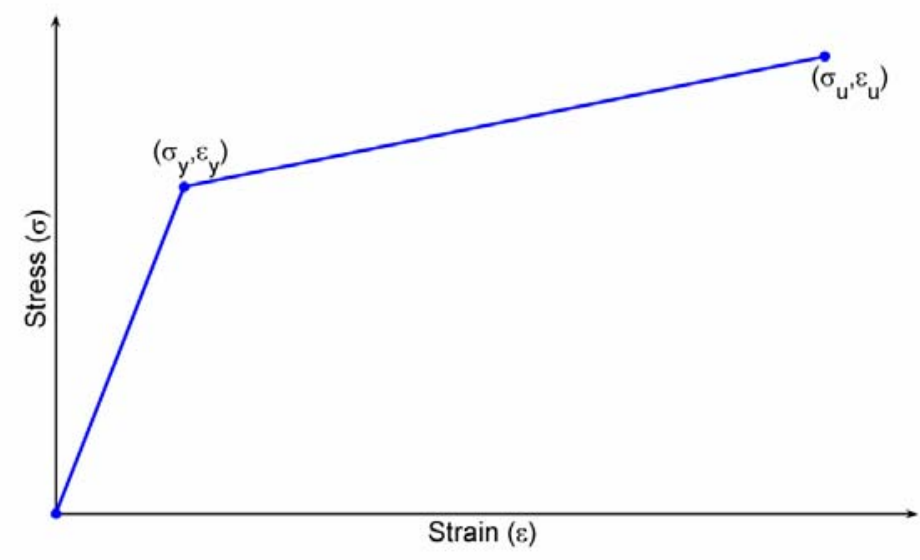

Figure 8. Assumed Bilinear Stress-strain Relationship for ABAQUS Models

\subsubsection{Comparison between the Behavior of Unreinforced and Flange Plate Connections}

To compare between the behavior of unreinforced and reinforced connections, the finite element models of LF30-T and UN were studied.

Figure 9 presents information on the distributions of the RI for models UN and LF30-T at the face of the column. The maximum value of the RI of UN is approximately 0.22 and is recorded at the edge of the beam flange. The largest value of RI is approximately 0.05 for LF30-T. The maximum value of the RI of UN is approximately four times greater than that of LF30-T. This indicates that the use of the flange plate connection will reduce the likelihood of ductile fracture of steel moment-resisting connections as compared to the unreinforced connection.

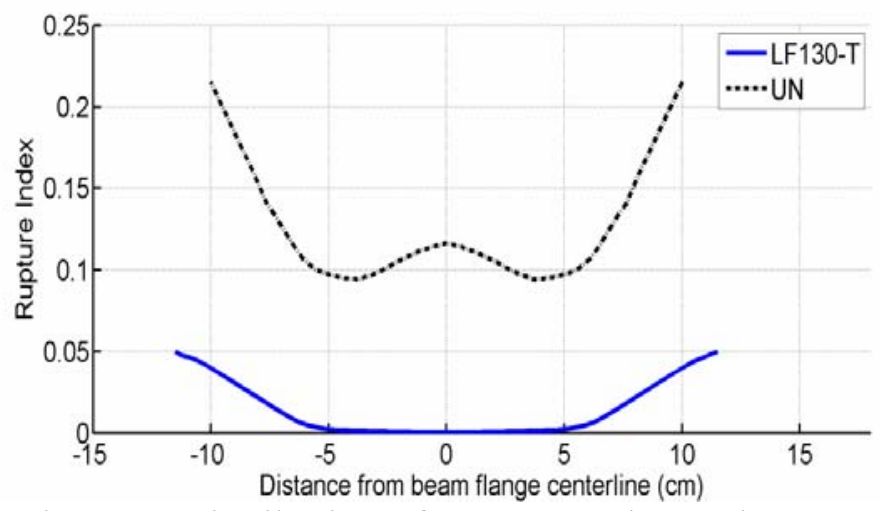

Figure 9. Distribution of Rupture Index at the Face of the Column for Models UN and Model LF30-T 


\subsubsection{Influence of Connection Details on the Response of Connection}

\section{- Fillet Weld Profiles}

Two fillet weld (two-sided and three-sided) profiles were studied in this research. To compare the fillet weld profiles, the responses of two specimens LF30 (L-L fillet weld), LF30-T (L-L-T fillet weld), are compared below.

Figure 10 shows the distributions of the RI for LF30 and LF30-T on the beam bottom flange at the nose of the bottom reinforcing plate. As can be seen in the Figure 10, the maximum value of the RI is recorded at the end of the longitudinal fillet weld of LF30. The maximum value of the RI is 0.45 for LF30, whereas its value is merely 0.2 for LF30-T. This reveals that addition of the transverse fillet weld at the nose of the flange plate substantially reduces the maximum value of the RI . There is a possible explanation for this phenomenon:

Consider the 2-sided fillet weld (longitudinal fillet welds only) and the end of the fillet weld at the nose of the reinforcing plate. The gap between the beam flange and the reinforcing plate at the bottom of the vertical leg of the fillet weld acts as an initial defect. The resulting stress concentrations and a state of triaxial tension at the end of the longitudinal fillet weld substantially increase the RI values. The addition of a transverse fillet weld eliminates the defect at the base of the vertical leg of the longitudinal fillet weld and reduces the stresses and triaxial tension at the end of the longitudinal fillet weld. Construction-related issues aside and based on the ABAQUS analysis data only, the 3-sided fillet weld (2 longitudinal welds and 1 transverse weld) is superior to the 2-sided fillet weld (2 longitudinal welds).

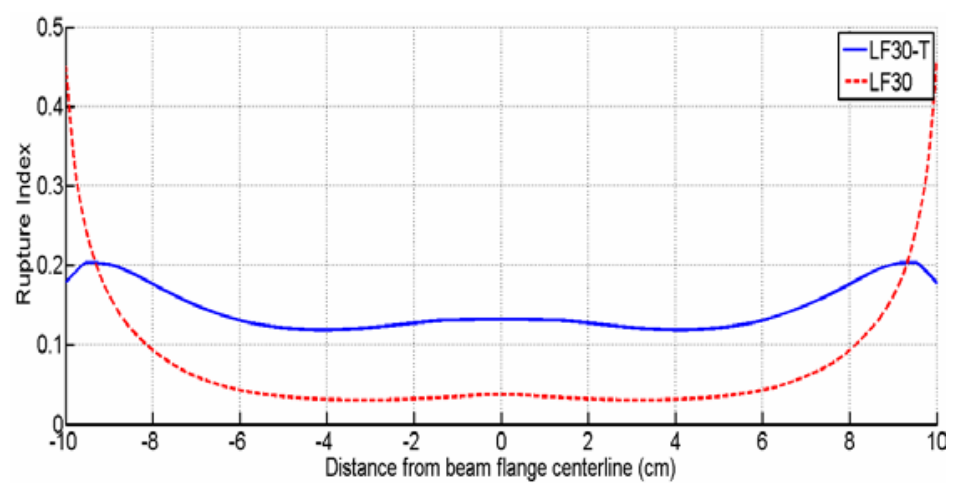

Figure 10. Distribution of Rupture Indices on Beam Flange at the Nose of Reinforcing Plate

- Length of the Flange Plate

The effect of flange plate length on the response of reinforced connections was investigated in this research. To assess the effect of flange plate length on the behavior of connections, the responses of two specimens LF30-T and LF50-T are compared below.

The distributions of the RI for LF30-T and LF50-T on the beam bottom flange at the nose of the reinforcing plate are shown in Figure 11. The maximum RI value of LF50-T is approximately $15 \%$ larger than that of LF30-T. This indicates that a longer flange plate increases values of RI at the nose of the reinforcing plate. There is a possible explanation for this phenomenon: 


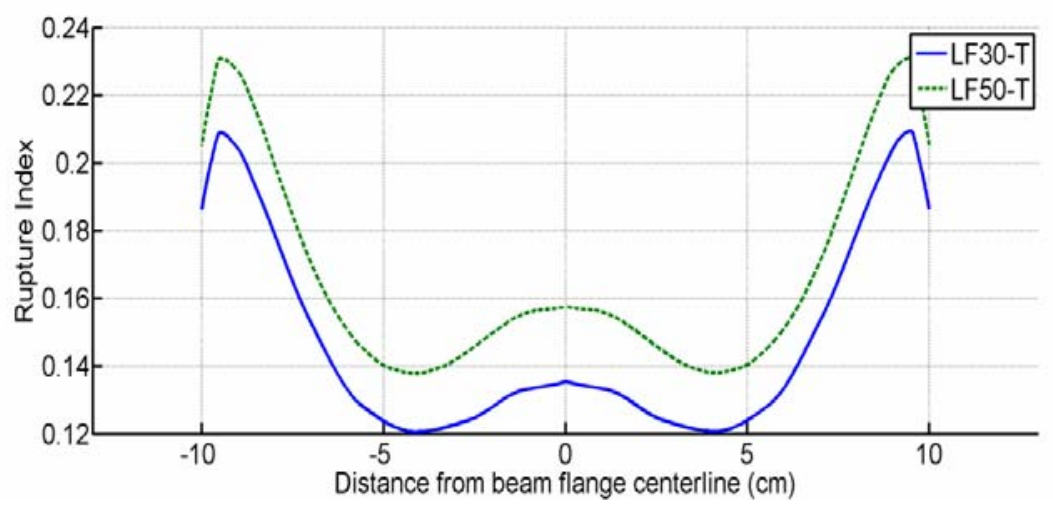

Figure 11. Distribution of Rupture Indices on Beam Flange at the Nose of Reinforcing Plate

A longer flange plate results in a higher plastic strain at the nose of reinforcing plate due to an increase in the beam plastic rotation. Eq. 1 shows that the higher plastic strain can results in higher RI value.

\subsubsection{Global Response of Flange Plate Connections}

In this section, the global behavior of models LF30 and LF30-T was evaluated before experimental studies. A displacement-control loading in the beam tip was induced in compliance with AISC seismic provisions loading history, which is shown in Figure 12. Equivalent plastic strain contours for models LF30 and LF30-T are presented in Figure 13. The key observations from Figure 13 are (1) the maximum plastic strain occurs at the end of the longitudinal fillet weld of model LF30 and (2) in models LF30 and LF30-T, plastic hinge forms away from the column flange into the beam beyond the nose of flange plates.

The moment at the column face versus story drift angle $(\theta)$ relationship for model LF30-T is shown in Figure 14. Story drift angle is computed by dividing the total beam tip displacement by the distance from the beam tip to the column centerline. The hysteretic curve for model LF30 was identical to model LF30-T.

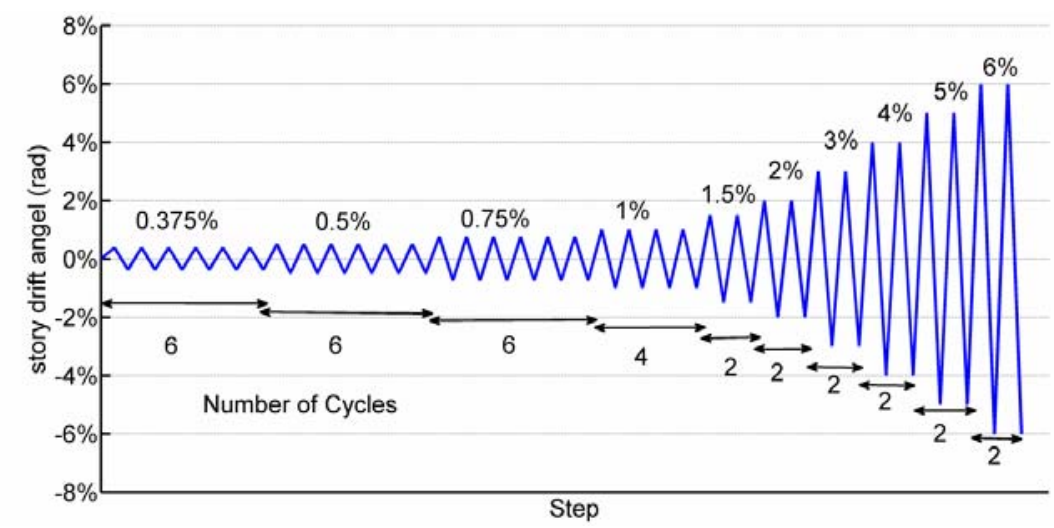

Figure 12. Cyclic Loading History 


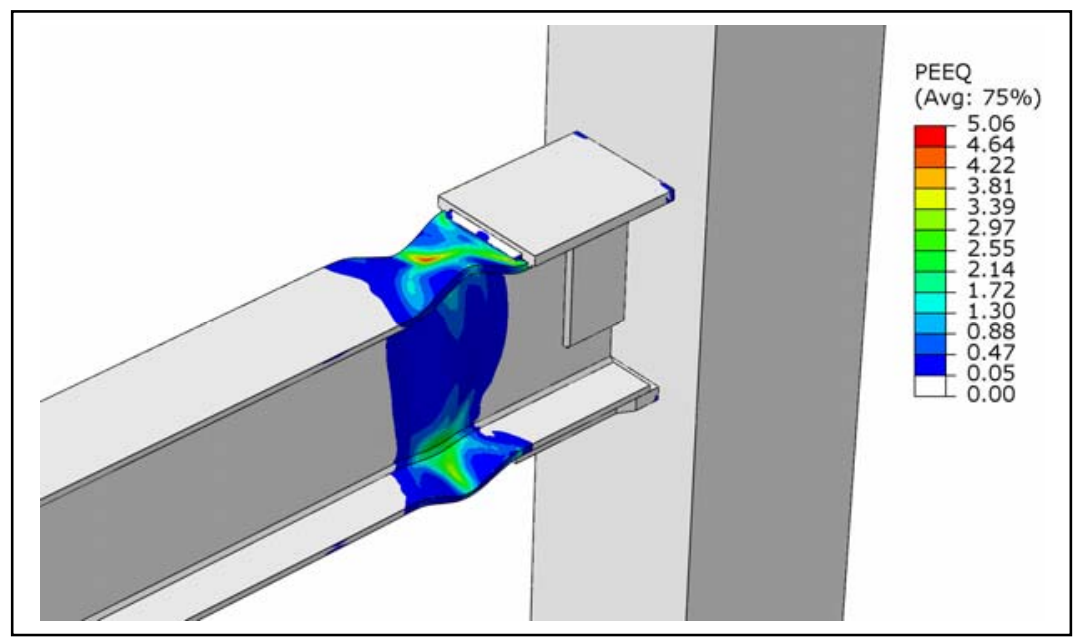

a)

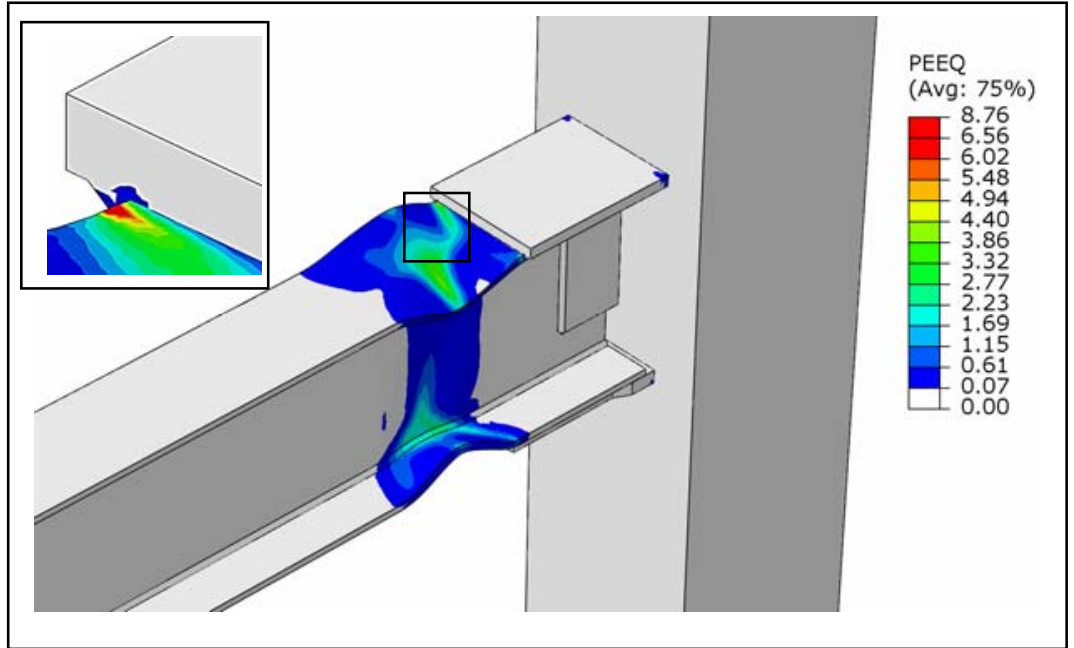

b)

Figure 13. Equivalent Plastic Strain Contours for Models a)LF30 and b)LF30-T

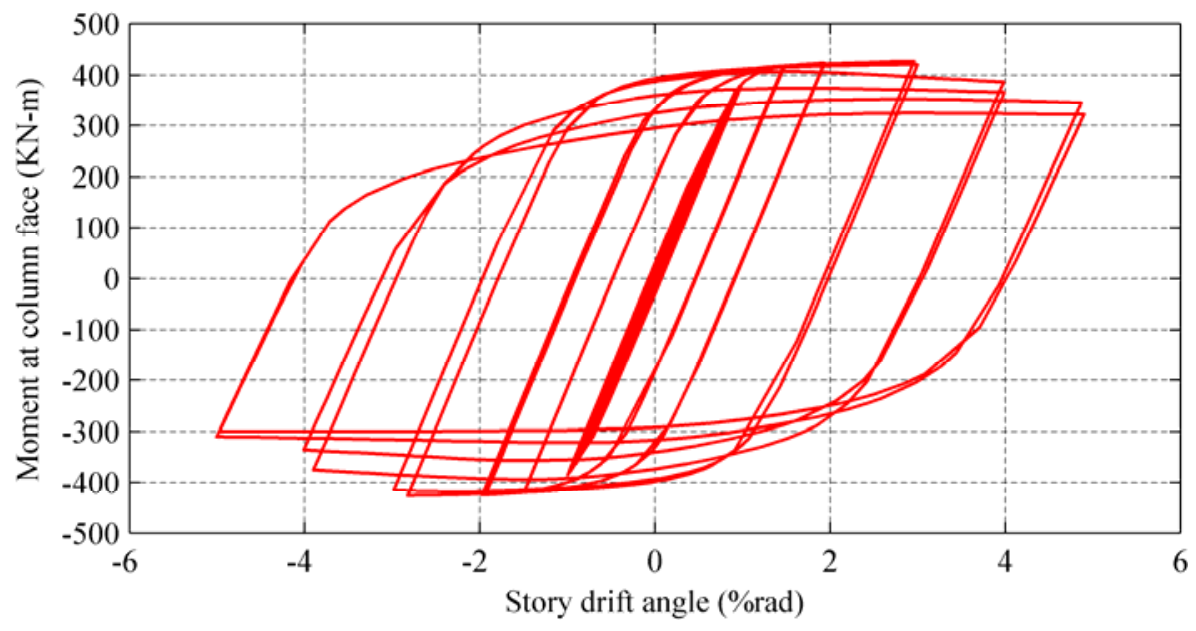

Figure 14. Cyclic Response of Model LF30-T 


\section{EXPERIMENTAL PROGRAM}

Two full scale test specimens with the same dimensions and connection details of models LF30-T and LF30 were fabricated and were subjected to cyclic loading. Figure 15 depicts the welding details for the test specimen LF30-T. The testing procedure and test results for global and local seismic behavior of the test specimens are discussed in the following sections.

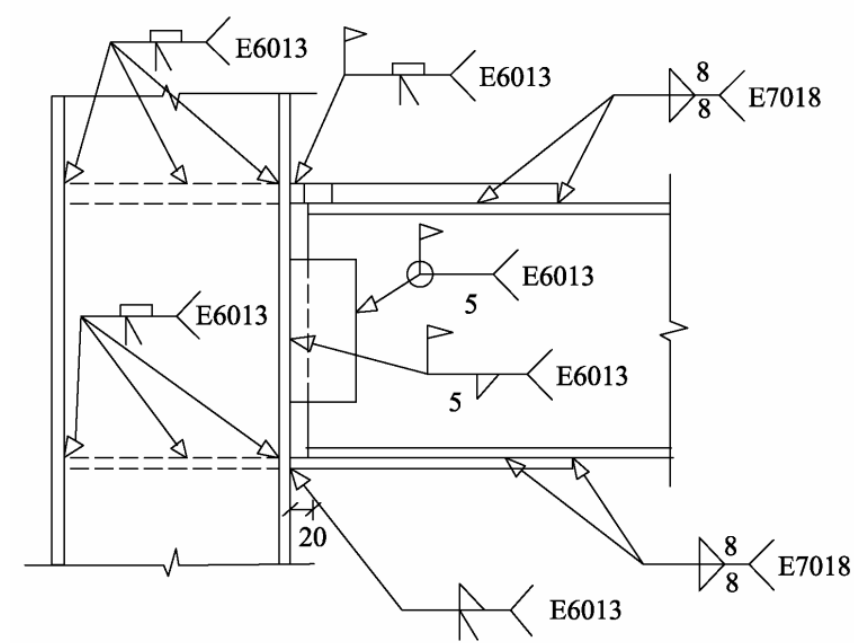

Figure 15. Welding Details for the Test Specimen LF30-T

\subsection{Test Setup and Instrumentation}

According to the shape of the specimen, a test setup was prepared to simulate the boundary conditions of the exterior joint subassembly in a laterally loaded moment frame. The column top and bottom was supported by real hinges. The beam was laterally braced in the vicinity of the plastic hinge and also near the beam end. The general configuration of the test setup and test specimen is shown in Figure 16.

The cyclic displacement was applied at the tip of the beam by a hydraulic actuator. The hydraulic loading system, mounted between the reaction frame and the beam tip, consisted of a $1000 \mathrm{KN}$ hydraulic actuator with $150 \mathrm{~mm}$ equal stroke for both forward and backward directions and also a load cell placed on the tip of a hydraulic actuator to record the applied loads. The actuator displacement is measured via both an internal displacement transducer of the actuator and an external LVDT. The specimen was cleaned and strain gauges were pasted at several locations. Whitewash was also painted on specimens in order to monitor the inelastic deformation during the test.

\subsection{Loading History}

The specimens were subjected to the loading sequence proposed by AISC seismic provisions for testing of beam-to-column moment connections [20]. Cyclic loading history is shown in Figure 12. The test was stopped at 5\% rad story drift to avoid damage to the hydraulic actuator. 


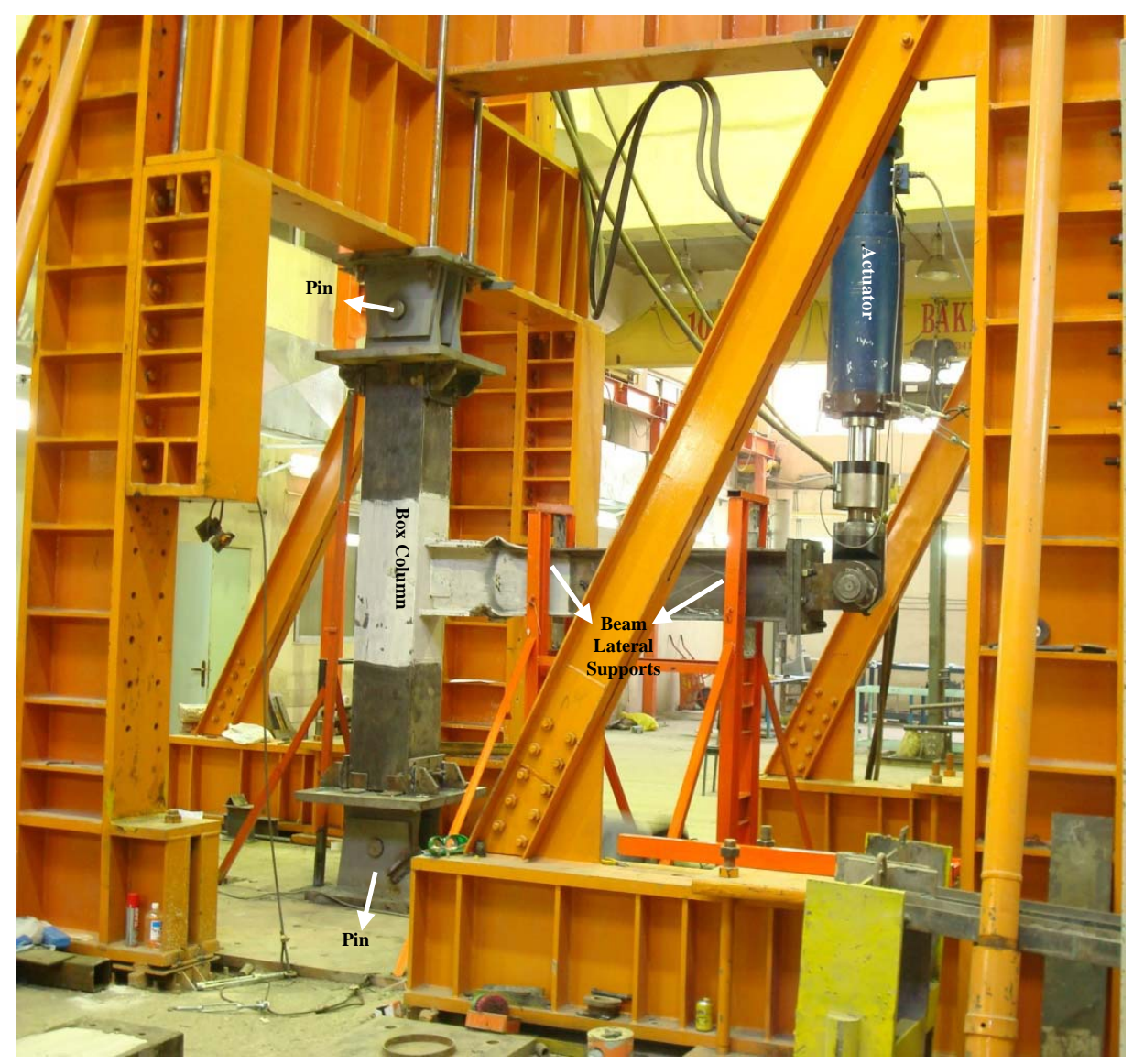

Figure 16. Test Setup Configuration

\subsection{General Test Observations}

\subsubsection{Specimen LF30-T}

The yielding of the specimen LF30-T was initiated in beam flanges during the first cycle of $1.5 \%$ story drift and during 3\% story drift, yielding extended into the beam web and spread about 300 $\mathrm{mm}$ along the beam flanges. Local buckling of the beam flanges was noticed in the cycles with $4 \%$ rad story drift angle. In the cycles of 5\% rad story drift angle, amplitude of beam local buckling was increased. At the end of the test, no signs of fracturing were observed except that minor cracking was noticed at the k-line of the beam bottom flange during the second cycle of $5 \% \mathrm{rad}$ story drift angle, as shown Figure 17. Figure 18 shows that the plastic hinge formed away from the face of the column in the beam beyond the nose of the reinforcing plate.

\subsubsection{Specimen $\mathrm{LF30}$}

Just one difference between behavior of specimens LF30 and LF30-T was observed:

In the specimens LF30, the beam flange buckles penetrated beyond the nose of the flange plate toward the face of the column and tore the end of the longitudinal fillet weld. Figure 19 shows this tearing. But the transverse fillet welds joining the LF30-T flange plates to the beam flanges prevented the buckle penetration observed in LF30 and no tearing of the LF30-T fillet welds was observed. 


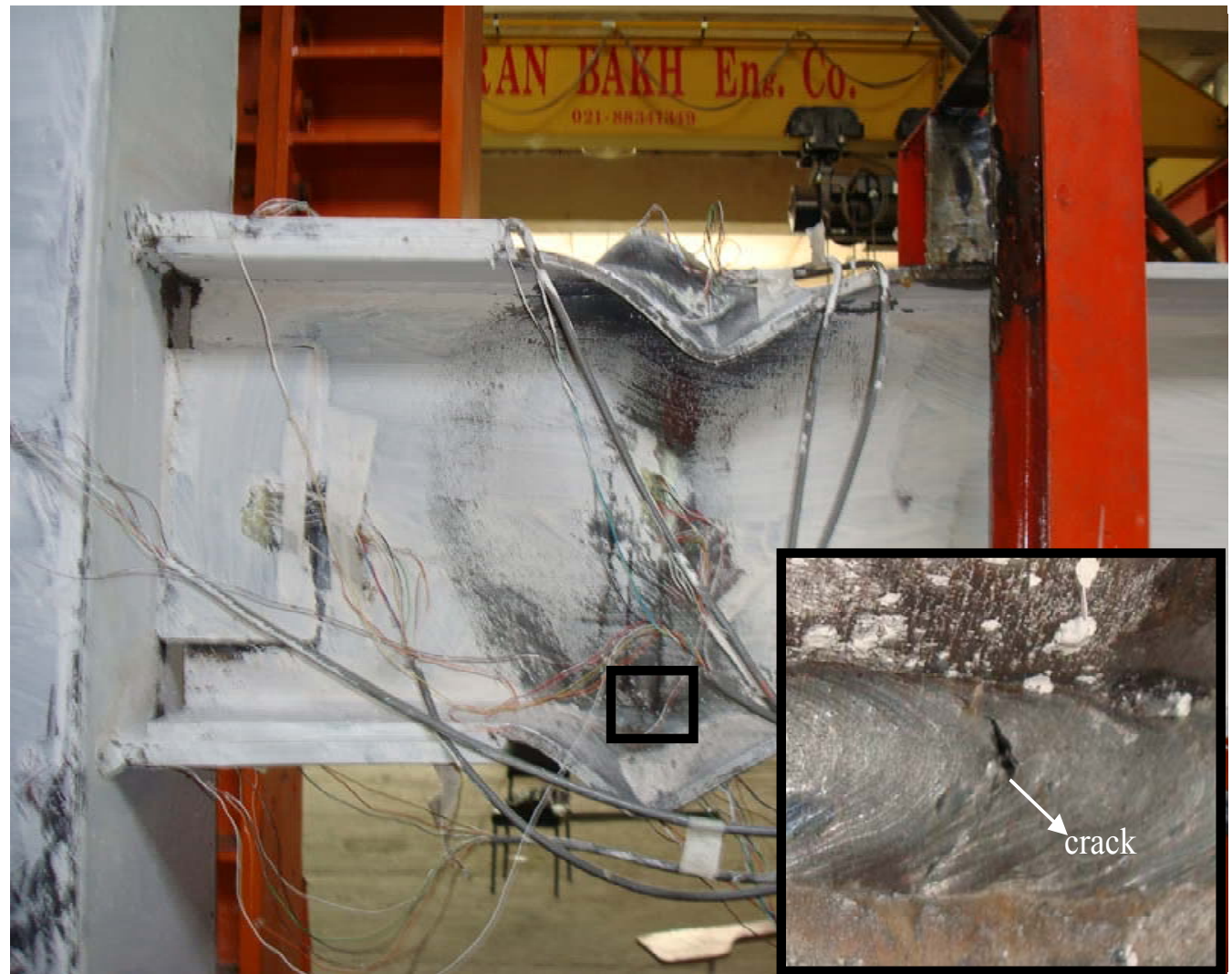

Figure 17. Minor Cracking at the k-line of the

Beam Bottom Flange at 5\% Rad in Specimen LF30-T

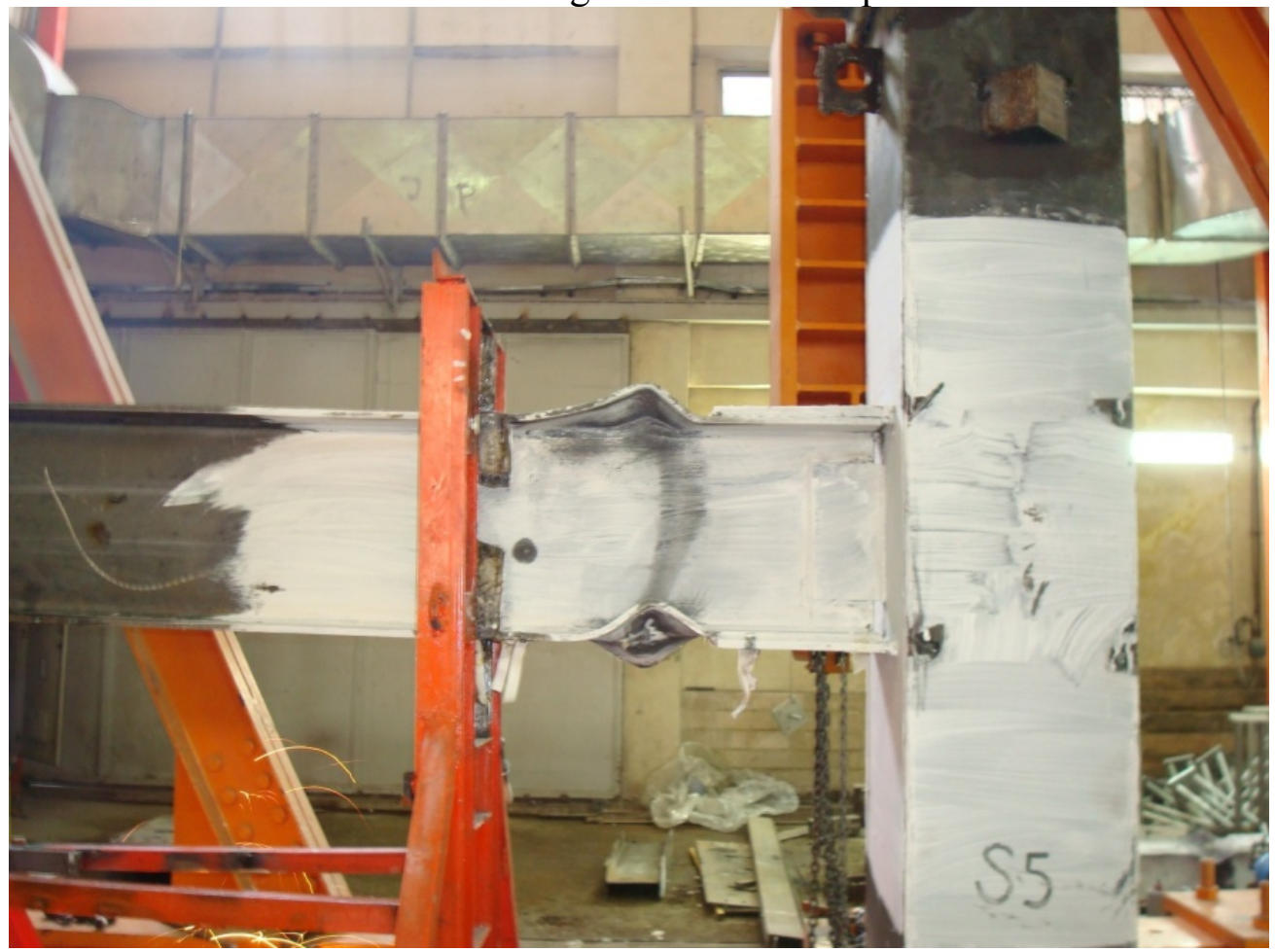

Figure 18. Specimen LF30-T at the End of the Test 


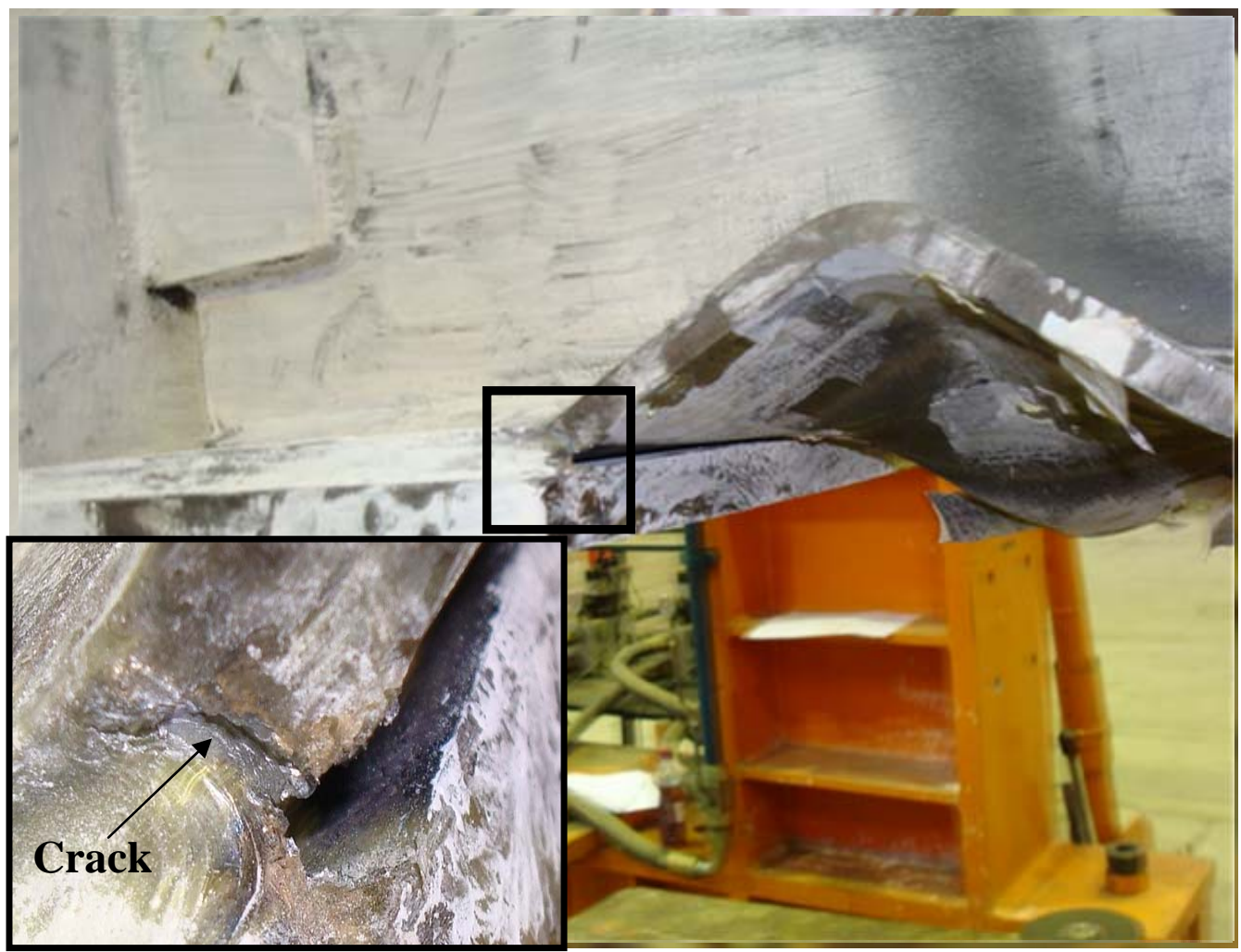

Figure 19. Crack in the Beam Flange at the End of the Longitudinal Fillet Weld of Specimen LF30

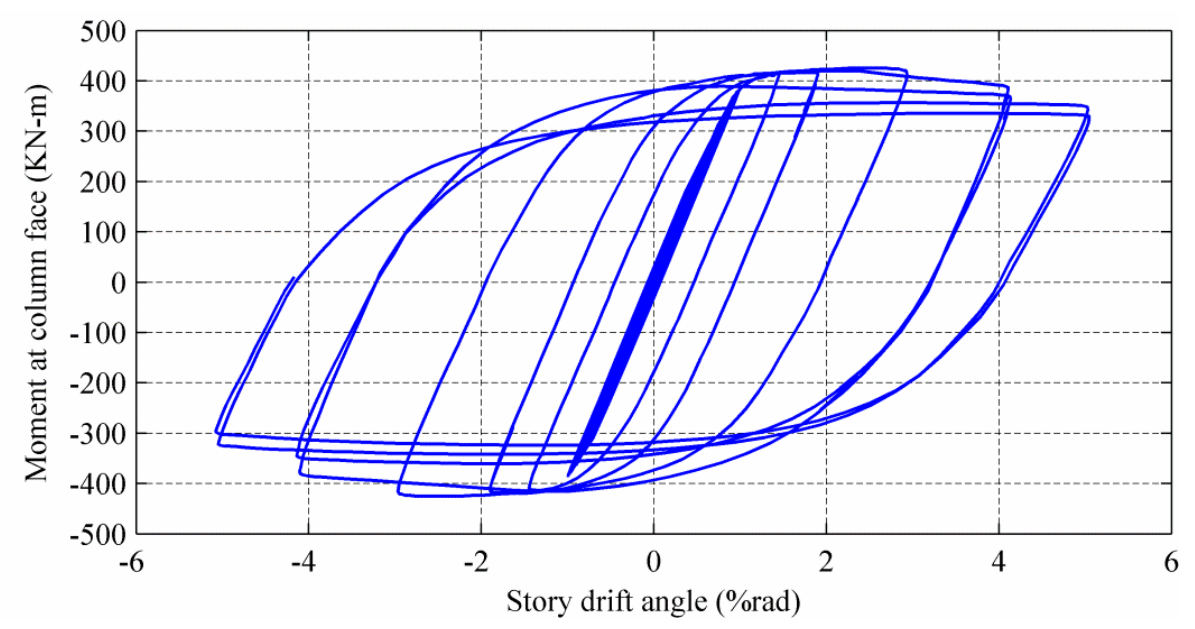

Figure 20. Moment at the Column Face Versus Story Drift Angel Relationship

\subsection{General Evaluation of the Connection Behavior}

The moment at the column face versus story drift angle $(\theta)$ relationship for the test specimen LF30-T is shown in Figure 20. The cyclic response of test specimen LF30 was identical to LF30-T. The results showed fair agreement between both experimental (Figure 20) and analytical (Figure 14) responses. In order to have a good comparison between analytical and experimental results a combined plot is illustrated in Figure 21. 
According to the AISC seismic provision [20] Beam-to-column connections used in special moment frames shall satisfy the following requirement:The measured flexural resistance of the connection, determined at the column face, shall equal at least $0.80 \mathrm{Mp}$ of the connected beam at an inter story drift angle of 0.04 radians. Figure 20 indicates that Moment resistances of test specimens were more than $80 \%$ plastic moment of beam at $4 \%$ total story drift. Therefore flange plate connections of test specimens achieved the AISC seismic provision requirements for special moment frames. It should be noted that the strength degradation of the specimens resulted from ductile local and global buckles during the cyclic loading and no significant fracture was occurred in the specimen.

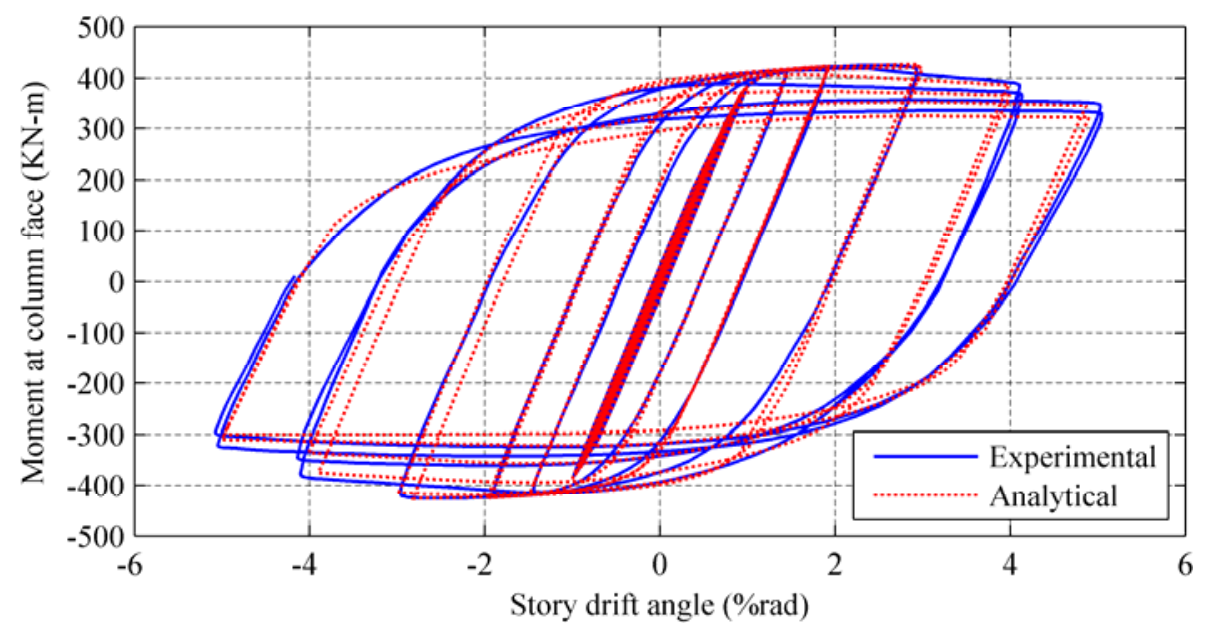

Figure 21. Comparison of the Experimental and Analytical Results

\subsection{Strains in Flange Plate and Beam Flange}

Figure 22 presents the relationship between axial strain and the story drift angle in the bottom flange plate and beam flange for specimen LF30. The maximum axial strain was recorded at the end of the longitudinal fillet weld joining the flange plate to the beam flange: the crack initiation site for specimen LF30. The maximum measured axial strain on the top surface of the flange plates in LF30, $50 \mathrm{~mm}$ from the column face, was approximately 5 times the yield strain. Such inelastic strains had no apparent deleterious effect on the response of either specimen. Beyond the $5 \%$ story drift, the strains in the flange e plates reduced slightly because of local buckling in the beam flange $\mathrm{s}$ and web and the consequent loss of strength in the beam. 

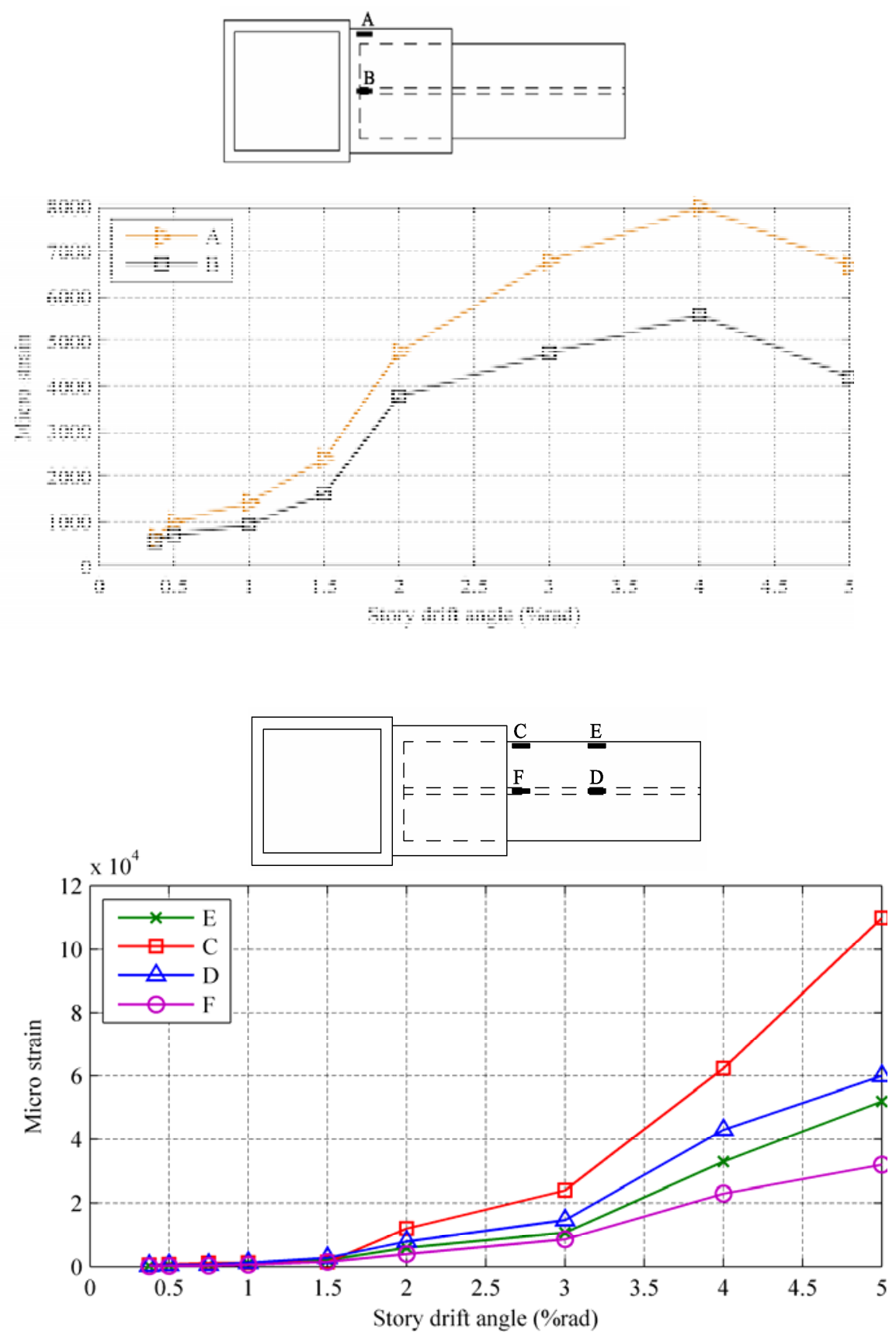

Figure 22.The relationship between axial strain and the story drift angle in the bottom flange plate and beam flange for specimen LF30

\section{CONCLUSIONS}

Two full-size specimens with flange plat connections were tested. Each specimen composed of a $\mathrm{H}$-shaped steel beam with the dimensions of $\mathrm{H}-380 \times 200 \times 8 \times 12(\mathrm{~mm})$ connected to a box column with the measurements of B- $400 \times 400 \times 20 \times 20(\mathrm{~mm})$. In the one of specimens, flange plates were joined to the beam flanges with longitudinal fillet welds only. The flange plates of other specimen were joined to the beam flanges with longitudinal and transverse fillet welds. Flange plate connections of test specimens achieved the AISC seismic provision requirements for special moment frames. 
The key conclusions drawn from the analytical studies and the associated experimental results are:

1. In the test specimens, no damage was observed at the groove welds joining flange plates to column flange. Because use of flange plate reduces potential for fracture at column face.

2. Analytical analysis indicated that use of transverse fillet weld at the nose of flange plate will reduce potential for fracture at the end of longitudinal fillet welds. This result was confirmed by the tests conducted for two full-scale specimens. .

3. It is better that the required flange plate length be limited to shortest possible length using weld of higher strength and increasing weld thickness to the maximum allowable limit.

\section{REFERENCES}

[1] Nakashima, M., Roeder, C.W. and Maruoka, Y., "Steel Moment Frames for Earthquakes in United States and Japan”, J. Struct. Eng., ASCE 2000, Vol. 126, No. 8, pp. 861-8.

[2] Del Savio, A.A, Nethercot, D.A., Vellasco, P.C., de Lima L.R.O., Andrade, S.A.L. and Martha, L.F., " An Assessment of Beam-to-Column Endplate and Baseplate Joints Including the Axial-Moment Interaction", Advanced Steel Construction, 2010, Vol. 6, No. 1, pp. 548-566.

[3] Arul Jayachandran, S., Marimuthu, V., Prabha, P., Seetharaman, S. and Pandian, N., "Investigations on the Behaviour of Semi-Rigid Endplate Connections", Advanced Steel Construction, 2009, Vol. 5, No. 4, pp. 432-451.

[4] Tabar, A.M. and Deylami, A., "Instability of Beams with Reduced Beam Section Moment Connections Emphasizing the Effect of Column Panel Zone Ductility", Journal of Constructional Steel Research, 2005, Vol. 61, No. 11, pp. 1475-1491.

[5] Tabar, A.M. and Deylami, A., "Investigation of Major Parameters Affecting Instability of Steel Beams with RBS Moment Connections”, Steel and Composite Structures, Vol. 6, No. 3, pp. 1475-1491.

[6] Shiravand, M.R. and Deylami, A., "Application of Full Depth Side Plate to Moment Connection of I-Beam to Double-I Column", Advances in Structural Engineering, 2010, Vol. 13, No. 6, pp. 1047-1062.

[7] Adeli, M., Banazadeh, M. and Deylami, A., "Bayesian Approach for Determination of Drift Hazard Curves for Generic Steel Moment-resisting Frames in Territory of Tehran", International Journal of Civil Engineering, 2011, Vol. 9, No. 3, pp. 145-154.

[8] Chen, C.C., Lin, C.C. and Tsai, C.L.," Evaluation of Reinforced Connections between Steel Beams and Box Columns", Engineering Structures, 2004; Vol. 13, pp.1089-1092.

[9] Kim, T., Stojadinovic, B. and Whittaker, A.S., "Seismic Performance of US Steel Box Column Connections", Proceedings, 13th World Conference on Earthquake Engineering, Canada, 2004, Paper No. 981.

[10] Kim, T., "Experimental and Analytical Performance Evaluation of Welded Steel Moment Connections to Box or Deep W-shape Columns", PhD Dissertation, University of California, Berkeley, CA, 2003.

[11] FEMA. Recommended Seismic Design Criteria for New Steel Moment Frame Buildings, Report No. FEMA-350, Federal Emergency Management Agency, 2000.

[12] Kim, T., Whittaker, A.S., Gilani, A.S.J., Bertero, V.V. and Takhirov, S.M., "Experimental Evaluation of Plate-reinforced Steel Moment-resisting Connections", Journal of Structural Engineering, ASCE 2002, Vol. 128, No. 4, pp. 483-491. 
[13] Kim, T., Whittaker, A.S., Gilani, A.S.J., Bertero, V.V. and Takhirov, S.M.," Cover-plate and Fange-plate Steel Moment-resisting Connections", Journal of Structural Engineering, ASCE 2002;128(4):474-482.

[14] Kaufmann, E.J., "Dynamic Tension Tests of Simulated Moment Resisting Frame Weld Joints", Chicago", Steel Tips, Structural Steel Education Council, American Institute of Steel Construction, 1997.

[15] Mao, C., Ricles, J.M., Lu, L.W., Fisher, J.W., "Effect of Local Details on Ductility of Welded Moment Connections", Journal of Structural Engineering, ASCE, 2001, Vol. 127, No. 9, pp. 1036-1044.

[16] Ricles, J.M., Fisher, J.W., Lu, L.W. and Kaufmann, E.J.," Development of Improved Welded Moment Connections for Earthquake-resistant Design", Journal of Constructional Steel Research 2002, Vol. 58, pp. 565-604.

[17] Ricles, J.M., Mao, C., Lu, L.W. and Fisher, J.W.," Ductile Details for Welded Unreinforced Moment Connections Subject to Iinelastic Cyclic Loading”, Engineering Structures 2003, Vol. 25, pp. 667-680.

[18] El-Tawil, S., Mikesell, T., Vidarsson, E. and Kunnath, S.," Strength and Ductility of FR Welded-bolted Connections", Report No. SAC/BD-98/01, SAC Joint Venture, Sacramento, CA, 1998.

[19] Hancock, J.W. and Mackenzie, A.C.," On the Mechanisms of Ductile Failure in High Strength Steels Subjected to Multi-axial Stress States", Journal of the Mechanics and Physics of Solids, 1976, Vol. 24, pp. 147-169.

[20] AISC, Seismic Provisions for Structural Steel Buildings, Chicago (IL) American Institute of Steel Construction; 2002. 


\title{
SYSTEM RELIABILITY ASSESSMENT OF 3D STEEL FRAMES DESIGNED PER AISC LRFD SPECIFICATIONS
}

\author{
S. Zhang ${ }^{1}$ and W. Zhou ${ }^{2, *}$ \\ ${ }^{1}$ PhD candidate, Civil and Environmental Engineering, Western University, London, Ontario, Canada N6A 5B9 \\ ${ }^{2}$ Assistant Professor, Civil and Environmental Engineering, \\ Western University, London, Ontario, Canada N6A 5B9 \\ *(Corresponding author: E-mail: wzhou@eng.uwo.ca)
}

Received: 5 October 2012; Revised: 23 October 2012; Accepted: 20 November 2012

\begin{abstract}
This paper presents the system reliability analysis of a three-dimensional steel frame designed per AISC LRFD with respect to the collapse limit state under the dead and live loads. The system reliability is evaluated using the first-order reliability method (FORM)-based adaptive response surface approach. The uncertainties in the material properties, geometric properties of frame members, initial geometric imperfection of the structure, dead load and live load as well as the spatial variability of the live load are accounted for in the reliability analysis. The analysis results suggest that the system reliability of the example frame is similar to that of the planar steel frames designed per AISC LRFD and evaluated in a previous study. It is observed that the spatial variability of the live load leads to a decreased system reliability. Results of the sensitivity analysis indicate that the failure probability of the example frame increases by almost one order of magnitude if the coefficient of variation of the steel yield strength increases from 0.06 to 0.1 . Furthermore, the system reliability decreases drastically if the upper bound of the magnitude of initial geometric imperfection is greater than $0.4 \%$ of the overall height of the example frame.
\end{abstract}

Keywords: Three-dimensional steel frame, System reliability, Response surface approach, FORM, Advanced analysis

\section{INTRODUCTION}

The limit states design or load and resistance factors design (LRFD) codes for building structures, e.g. AISC LRFD [1-2] and CSA S16-09 [3], are generally developed by considering the reliability of individual members in a structure. However, failure of an individual member in a structure does not necessarily lead to the failure of the entire structural system due to the structure redundancy or the force redistribution after the member failure. Therefore, the reliability of a structural system is typically higher than that of individual members in the structure (Ellingwood [4-5]; Zhou and Hong [6]). With the advances in numerical computation and increased acceptance of the performance-based design, knowledge about the reliability levels of structural systems becomes more accessible as well as important for both researchers and practitioners (Ellingwood [5]; Li and Li [7]).

The system reliability of steel frame structures has been investigated in the past (e.g. Zhou and Hong [6]; Buonopane et al. [8-9]). Zhou and Hong [6] evaluated the member and system reliability of four planar steel frames designed per AISC LRFD [1] by considering the uncertainties in the dead load, live load and steel yield strength. The member reliability was evaluated based on the load effects obtained from a first-order elastic analysis and equations that indirectly take into account the second-order effects; whereas the system reliability of the structure was evaluated based on the collapse load factor-based limit state function, in which the collapse load factor was calculated by using the refined second-order elastic-plastic hinge method (Chen et al. [10]). The Monte Carlo techniques and first-order reliability method (FORM) were employed to evaluate the member and system reliability. They reported that the probabilities of collapse of the steel frames considered are approximately one order of magnitude lower than the failure probabilities of the most critical members in the frames. 
Buonopane et al. [8] evaluated the reliability of two-story two-bay planar steel frames designed according to two design methods, namely the AISC LRFD [2] and the so-called advanced analysis approach that evaluates the load capacity (i.e. collapse load) of the entire structural system by directly accounting for the second-order effects (both $P-\Delta$ and $P-\delta$ effects), plastic hinging, residual stress and geometric imperfection in the analysis. The uncertainties in the load (both dead load and live load) and steel yield strength were considered in the reliability analysis. The reliability was evaluated with respect to the limit states associated with collapse as well as occurrence of the first plastic hinge in the structure. The analysis results revealed that the structures designed per AISC LRFD generally have higher system reliability than those designed using the advanced analysis approach.

Buonopane et al. [9] investigated the probabilistic characteristics of the collapse load and system reliability of two planar steel frames that were designed using the first-order elastic analysis, modified by the effective length factors and magnification factors to approximately account for the second-order effects. The uncertainties in the yield strength, Young's modulus, geometric imperfection and peak compressive residual stress were taken into account in their investigation. The system reliability of planar steel portal frames with tapered beams and columns has been reported in the literature ( $\mathrm{Li}$ and $\mathrm{Li}$ [7]), where a second-order plastic analysis was used to evaluate the collapse load of the structure. Huh et al. [11] studied the reliability of planar steel frames with or without shear walls using the nonlinear finite element method and FORM. Hadianfard and Razani [12] evaluated the reliability of semi-rigid planar steel frames. Note that the above-mentioned previous studies on the system reliability of steel frames are all focused on two-dimensional frames.

Recently, system reliability assessments of three-dimensional (3D) steel scaffold systems were reported in the literature (Zhang et al. [13-15]). In these investigations, the ultimate load capacity of the scaffold system was predicted using the advanced analysis approach by taking into account the material and geometry nonlinearity, initial geometric imperfections, joint details, and residual stresses. The model uncertainty was characterized by comparing the experimentally determined ultimate load capacities with those predicted using the advanced analysis approach for fifteen full-scale scaffold specimens (Zhang et al. [14]). The probabilistic characteristics of the ultimate load capacity were obtained from Monte Carlo simulation considering the model uncertainty as well as the uncertainties associated with material properties, initial geometric imperfections, load eccentricity and joint stiffness. Given the statistics of the resistance and applied loads, the system reliability was estimated using the FORM. Note that the steel scaffold systems are relatively simple 3D structures compared with 3D building structures. To the best knowledge of the authors of this paper, system reliability analysis of 3D steel building frames has not been reported in the literature.

The objective of the study reported in this paper was to carry out system reliability analyses of 3D steel frame structures. To this end, a realistic 3D steel frame example designed per AISC LRFD [1] was considered. The reliability was evaluated with respect to the collapse limit state, with the collapse load of the structure evaluated using the advanced analysis implemented in the finite element software SAP2000 [16]. The analysis methodologies and results are described in the following sections. 


\section{METHODOLOGY FOR SYSTEM RELIABILITY EVALUATION}

\subsection{Limit State Function}

Without loss of generality, consider a structure subjected to the gravity loads only. Let $R(\boldsymbol{X})$ and $S(\boldsymbol{Y})$ denote the random variables representing the collapse load (i.e. resistance) of the structure and total external loads applied on the structure, respectively. The notation $R(\boldsymbol{X})$ was used to emphasize that the resistance, $R$, is a function of a set of random variables, $\boldsymbol{X}$, such as the material properties (e.g. yield strength and Young's modulus) of steel, cross-sectional properties (e.g. cross-sectional area and moment of inertia) of individual members in the structure, initial geometric imperfections and model uncertainty, whereas $S(\boldsymbol{Y})$ is a function of a vector of random variables, $\boldsymbol{Y}$, such as the dead load, live load, as well as geometric properties of the structure. Let $r(\boldsymbol{x})$ and $s(\boldsymbol{y})$ denote the realizations of $R(\boldsymbol{X})$ and $S(\boldsymbol{Y})$, respectively. The limit state function corresponding to the collapse of the structure can be written as

$g(r(\boldsymbol{x}), s(\boldsymbol{y}))=r(\boldsymbol{x})-s(\boldsymbol{y})$

Therefore, $g \leq 0$ indicates that the structure with a resistance of $r(x)$ will collapse under the external loads $s(\boldsymbol{y})$, whereas $g>0$ indicates that the structure is safe.

The total external loads $s(y)$ can be easily calculated given the load condition and geometric properties of the structure. In most cases, analytical solutions are however not available to evaluate the resistance $r(\boldsymbol{x})$; therefore, numerical approaches such as the finite element method are needed to evaluate $r(\boldsymbol{x})$.

\subsection{Evaluation of the Collapse Load}

The advanced analysis as implemented in SAP2000 was used to evaluate the collapse load of the $3 \mathrm{D}$ steel frame in this investigation. The main assumptions involved in the advanced analysis approach in SAP2000 are: 1) the material (steel) is elastic-perfectly plastic; 2) geometric nonlinearities including the $P-\Delta$ and large displacement effect are considered; 3 ) all joints are rigid and each floor is characterized as a rigid diaphragm; 4) all beams are subjected to zero axial force and unidirectional bending about either the strong or weak axis, and all columns are subjected to non-zero axial forces and bi-directional bending about both the strong and weak axes; 4) no composite action between the steel beam and concrete floor; 5) all beams and columns have compact cross sections, i.e. local buckling not considered; 6) no lateral-torsional buckling failure for beams or columns; 7) the capacity of a beam-column is represented by the axial force-bending moment interaction equations specified in AISC LRFD 2005 with the resistance factors set to unity; 8) once a plastic hinge has formed, the cross-sectional forces at the plastic hinge move on the axial and moment interaction surface as the load further increases, and 9) the external load is applied proportionally and incrementally.

The interaction equation for a beam-column subjected to axial force and bi-directional bending moments is given by (AISC [2])

$$
\begin{aligned}
& \frac{P}{P_{r}}+\frac{8}{9}\left(\frac{M_{x}}{M_{p x}}+\frac{M_{y}}{M_{p y}}\right) \leq 1.0 \quad \frac{P}{P_{r}} \geq 0.2 \\
& \frac{P}{2 P_{r}}+\left(\frac{M_{x}}{M_{p x}}+\frac{M_{y}}{M_{p y}}\right) \leq 1.0, \frac{P}{P_{r}}<0.2
\end{aligned}
$$


where $P$ is the applied axial force; $P_{r}$ is the axial tensile or compressive strengths; $M_{x}$ and $M_{y}$ are the applied bending moments with respect to the strong $(x)$ axis and weak $(y)$ axis, respectively, and $M_{p x}$ and $M_{p y}$ are the flexural strengths with respect to the strong and weak axes.

The flexural strengths can be calculated as $M_{p x}=f_{y} Z_{x}$ and $M_{p y}=f_{y} Z_{y}$, respectively, where $Z_{x}$ and $Z_{y}$ correspond to the plastic section moduli about the $x$-axis and $y$-axis, and $f_{y}$ is the steel yield strength. The axial tensile strength of a beam-column is calculated assuming gross section yielding, i.e. $P_{r}=$ $f_{y} A_{g}$, where $A_{g}$ is the gross cross-sectional area. The axial compressive strength of the member is given by

$$
P_{r}=\left\{\begin{array}{cc}
f_{y} A_{g}\left(0.658^{\frac{f_{y}}{F_{e}}}\right) & F_{e} \geq 0.44 f_{y} \\
0.877 F_{e} A_{g} & F_{e}<0.44 f_{y}
\end{array}\right.
$$

where $F_{e}$ is the elastic critical buckling stress determined by $F_{e}=\pi^{2} E /(K L / r)^{2}$, where $K$ is the effective length factor of the column; $L$ is the column length; $r$ is the radius of gyration about the axis of buckling, and $E$ is Young's modulus for steel.

The advanced analysis allows the development of the relationship between the applied load and displacement at a given point on the structure (e.g. the horizontal displacement at the top of the structure). The collapse load of the structure is then obtained as the total load corresponding to the peak point on the load-displacement curve. Because initial geometric imperfection of columns (an out-of-straightness of the span length over 1,500 at midspan) and residual stresses have been implicitly accounted for in the AISC interaction equation given by Eq. 2 (Chen et al. [10]), their impact on the collapse load is implicitly taken into account in the analysis.

\subsection{System Reliability Evaluation}

The system failure probability of a 3D steel frame can be expressed as the following multidimensional integral over the failure domain $\mathrm{g}(r(\boldsymbol{x}), s(\boldsymbol{y})) \leq 0$ :

$P_{f}=\operatorname{Pr}(g(r(\boldsymbol{x}), s(\boldsymbol{y})) \leq 0)=\int_{g(r(\boldsymbol{x}), s(\boldsymbol{y})) \leq 0} f_{Z}(\boldsymbol{z}) d \boldsymbol{z}$

where $\boldsymbol{Z}=\boldsymbol{X} \cup \boldsymbol{Y}$ (" $\cup$ " indicates the union operation) is a vector of basic random variables on which the structural resistance and total load are dependent, and $f_{\boldsymbol{Z}}(\boldsymbol{z})$ is the joint probability density function of $\boldsymbol{Z}$.

It is usually not feasible to obtain an analytical solution of the failure probability defined by Eq. 4 . The Monte Carlo simulation is an accurate and robust technique to evaluate this integration; however, this method is time-consuming for the cases that have low failure probabilities. Approximate approaches such as the first- and second-order reliability methods (FORM and SORM) (Rackwitz and Fissler [17]; Low and Tang [18]; Breitung [19]; Der Kiureghian [20]) can be used to evaluate the integral in Eq. 4. However, incorporating the finite element method required to evaluate the collapse load into the FORM/SORM may give rise to numerical difficulties in the reliability analysis, as reported by Zhou and Hong [6]. 
A reasonable trade-off between efficiency, accuracy and robustness in the reliability analysis can be achieved through the response surface approach. The application of response surface approach in the system reliability evaluation has been reported in the literature. For example, this method was used by Huh and Haldar [21] to calculate non-linear seismic reliability of planar frames. Zhao and Ono [22] also used the response surface approach to investigate the system reliability of planar framed structures using the collapse load factor-based limit state function.

In this study, a so-called FORM-based adaptive response surface approach was used to evaluate the system reliability of 3D steel frames. The method involves constructing a sequence of response surfaces to approximate the collapse load (i.e. resistance) of 3D steel frames. For each response surface, the collapse load, $R$, is approximated by a second-order polynomial (Bucher and Bourgund [23]) as follows:

$$
R(X) \approx a_{0}+\sum_{i=1}^{n} b_{i} X_{i}+\sum_{i=1}^{n} c_{i} X_{i}^{2}
$$

where $\boldsymbol{X}=\left(X_{1}, X_{2}, \ldots, X_{n}\right)$ denotes the vector of random variables on which the resistance is dependent; the mean and standard deviation of $X_{i}(i=1,2, \ldots, n)$ are denoted by $m_{i}$ and $\sigma_{i} ; a_{0}, b_{i}$ and $c_{i}$, are the $2 n+1$ unknown coefficients to be determined, and $n$ is the total number of random variables. In order to determine the $2 n+1$ coefficients in Eq. 5, the collapse load needs to be determined using the advanced analysis corresponding to at least $2 n+1$ sets of sampling points. These sampling points are adaptively selected as described in the following calculation steps.

1) Evaluate the resistance $R(\boldsymbol{X})$ at the mean value point $\left(m_{1}, m_{2}, \ldots, m_{i}, \ldots, m_{n}\right)$ and the $2 n$ points each at $\left(m_{1}, m_{2}, \ldots, m_{i} \pm h \sigma_{i}, \ldots, m_{n}\right)$ through the advanced analysis; the value of $h$ was selected to equal 3 (Bucher and Bourgund [23]);

2) Use the $2 n+1$ sets of sampling points and corresponding values of $R(\boldsymbol{X})$ from Step 1) to solve Eq. 5 for the coefficients $a_{0}, b_{i}$ and $c_{i}$, which leads to a tentative response surface for the resistance;

3) Carry out the FORM to obtain the reliability index based on the tentative response surface obtained in Step 2) and the corresponding design point $\boldsymbol{x}^{*}$;

4) Construct a new tentative response surface for the resistance based on sampling points corresponding to the tentative design point $\boldsymbol{x}^{*}$ and the $2 n$ points each at $\left(x_{1}{ }^{*}, x_{2}{ }^{*}, \ldots, x_{i}{ }^{*} \pm h \sigma_{i}, \ldots, x_{n}{ }^{*}\right)$ $(i=1,2, \ldots, n)$; carry out the FORM to obtain a new reliability index and an updated tentative design point;

5) Repeat Step 4) until the calculated reliability index has converged, i.e. the absolute difference between the reliability indices corresponding to two consecutive tentative response surfaces being less than a pre-defined tolerance. The failure probability, $P_{f}$, can then be approximated by

$P_{f} \approx \Phi(-\beta)$

where $\Phi(\bullet)$ denotes the standard normal cumulative distribution function and $\beta$ is the converged reliability index obtained from the FORM-based adaptive response surface approach. 


\section{NUMERICAL EXAMPLE}

\subsection{Example Description}

In this study, the system reliability of a 3D unbraced steel framed structure (see Figure 1) designed by Ziemian [24]; Ziemian et al. [25] per ASCI LRFD [1] was evaluated using the methodology described in Section 2. The plan of the frame is shown in Figure 2, and the two elevations of the frame are shown in Figures 3(a) and (b), respectively. The dashed lines in Figure 2 represent simply supported beams (ignored in the numerical analysis) on typical floors. Therefore, the distribution of the gravity loading is approximated by uniformly distributed loads on interior girders spanning in the N-S direction and as concentrated loads at the mid-spans of the E-W girders. The frame consists of three similar bents spanning in the E-W direction and nine bents spanning in the N-S direction. The bents in the N-S direction are either six column exterior bents or three column interior bents as shown in Figure 2. All beam webs are in the vertical plane and all column webs are in the N-S plane. Furthermore, in the finite element model for the advance analysis, all columns are fully fixed at the base and their effective length factors were automatically calculated by SAP2000. To expedite the analysis, each beam or column was represented by one beam element, and plastic hinges were assumed to only take place at the two ends of the member.

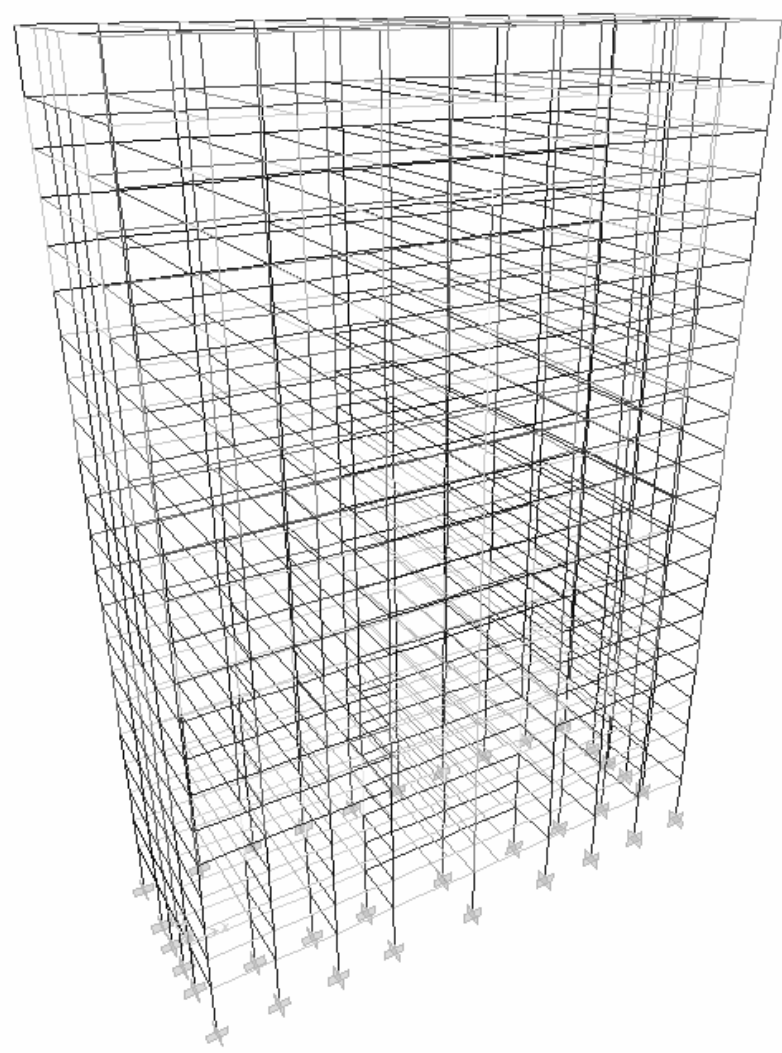

Figure 1.3D Model of the Example Frame 


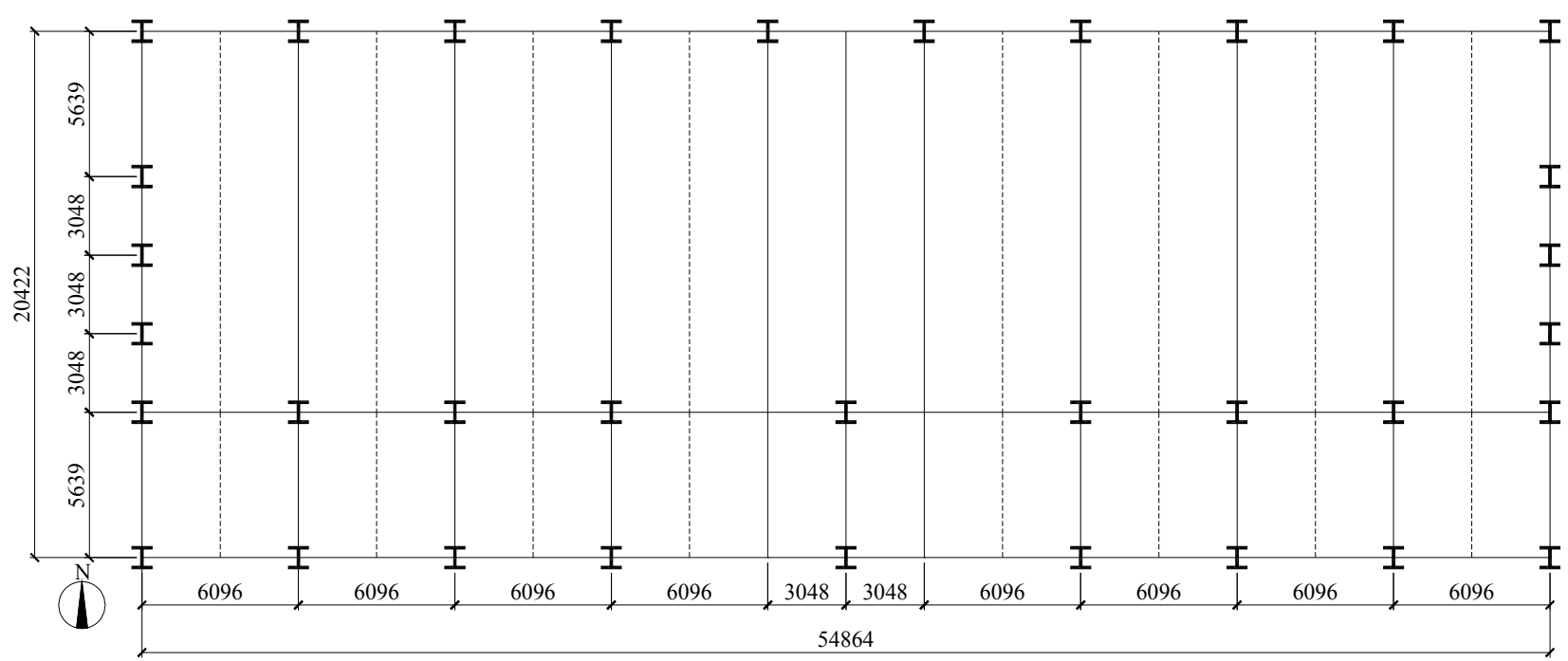

Figure 2. Plan of the Example Frame (Unit: $\mathrm{mm}$ )

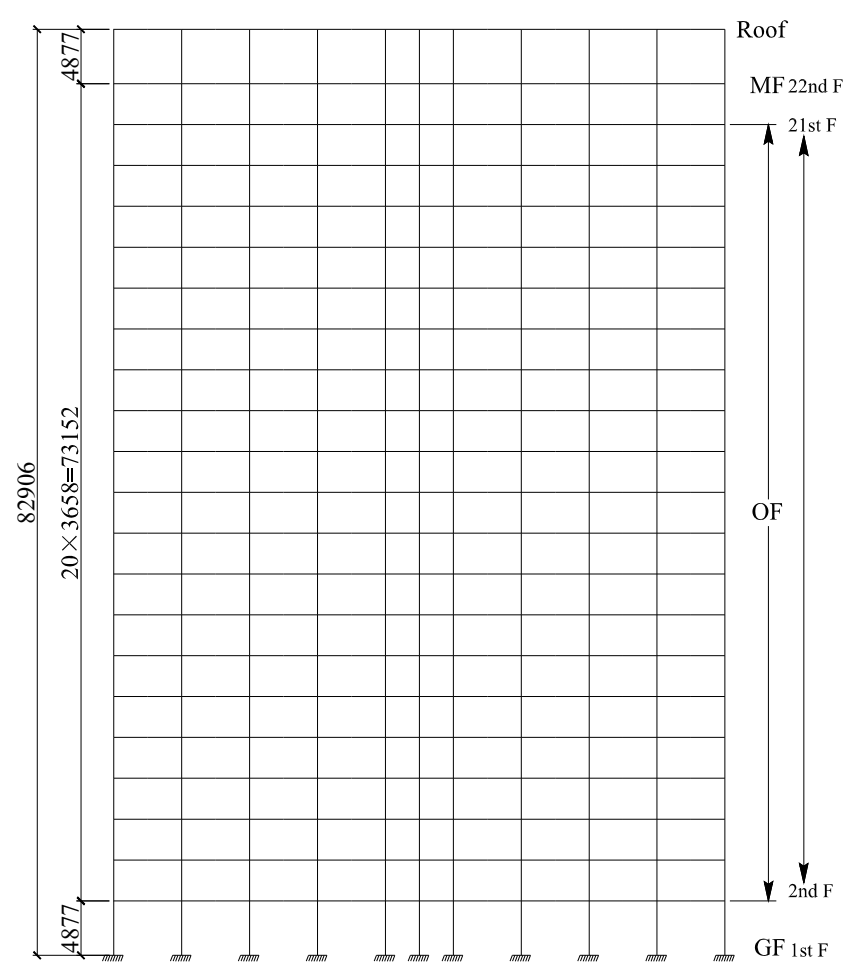

(a)

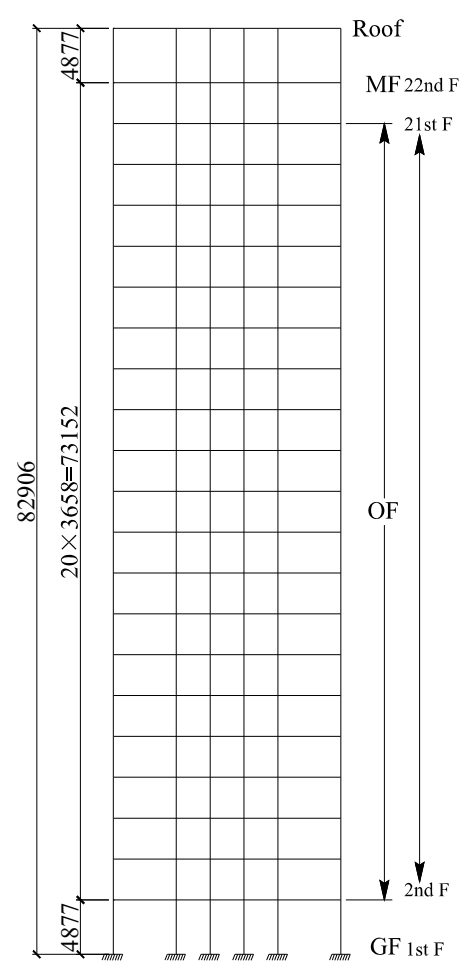

(b)

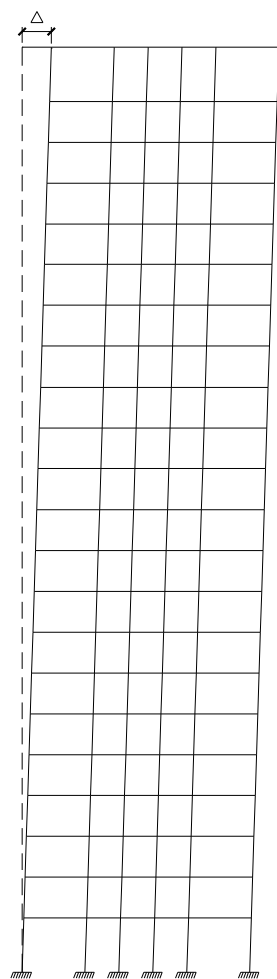

(c)

Figure 3. (a) N-S Elevation (b) W-E Elevation (c) Initial Geometric Imperfection Distribution (Unit: $\mathrm{mm}$ )

GF: Ground Floor OF: Office Floor MF: Mechanical Floor

The building has an overall height $(H)$ of $82.906 \mathrm{~m}$ ( 272 feet) and consists of 22 stories, including 20 office levels (from the $2^{\text {nd }}$ floor to the $21^{\text {st }}$ floor) with the same floor-height of $3.658 \mathrm{~m}$ (12 feet), one mechanical level occupying the $22^{\text {nd }}$ floor and one ground floor (see Figures 3(a) and 3(b)). Both the mechanical and ground floors are $4.877 \mathrm{~m}$ (16 feet) high. All members are designed using A36 steel with a specified yield strength of $248 \mathrm{MPa}$ and a nominal Young's modulus of 200,000 MPa (Ziemian [24]). Only the dead and live loads were included in the reliability analysis because Ziemian [24] indicated that the combination of the factored dead load (D) and live load (L) (1.2D+1.6L) governs the LRFD design of this structure. The nominal dead load on all the floors equals $3.6 \mathrm{kN} / \mathrm{m}^{2}$. In addition, the nominal dead load of the building facade equals 2.2 $\mathrm{kN} / \mathrm{m}^{2}$ (distributed over the four vertical surfaces of the building). Three different nominal live 
loads are assumed for the building, namely $2.4 \mathrm{kN} / \mathrm{m}^{2}$ on the office floor (i.e. $2^{\text {nd }}$ to $21^{\text {st }}$ floors), 12 $\mathrm{kN} / \mathrm{m}^{2}$ on the mechanical floor (i.e. $22^{\text {nd }}$ floor), and $1.2 \mathrm{kN} / \mathrm{m}^{2}$ on the roof.

\subsection{Statistic Properties of Random Variables}

The random variables considered in the reliability analysis included the steel yield strength, Young's modulus, cross-sectional area and moment of inertia of individual members, initial geometric imperfection, dead and live loads. Due to a lack of information, the model uncertainty associated with the collapse load was ignored. To simplify the analysis, the yield strength, Young's modulus, cross-sectional area and moment of inertia of different members were assumed to be fully correlated. The ratios between the cross-sectional areas (or moments of inertia) of different members were assumed to be the same as those between the corresponding nominal properties. The same dead load was assumed to apply on all the floors; that is, the dead loads on all the floors are identical and fully correlated. Furthermore, the floor dead load and facade dead load were assumed to be fully correlated, with the ratio between the two loads equal to that between the corresponding nominal loads.

Table 1. Statistic Parameters of Random Variables

\begin{tabular}{|c|c|c|c|c|c|c|}
\hline Property & Random variables & Nominal value & Mean/Nominal & $\mathrm{COV}$ & $\begin{array}{l}\text { Probability } \\
\text { Distribution }\end{array}$ & Source \\
\hline \multirow{2}{*}{$\begin{array}{c}\text { Material } \\
\text { property } \\
\text { (MPa) }\end{array}$} & Yield strength & 248 & 1.1 & 0.06 & Normal & \multirow{2}{*}{$\begin{array}{c}\text { Bartlett et al. } \\
{[26]}\end{array}$} \\
\hline & Young's modulus & 200,000 & 0.993 & 0.034 & Normal & \\
\hline \multirow{2}{*}{$\begin{array}{l}\text { Geometric } \\
\text { property }\end{array}$} & Cross-sectional area & varies & 1.0 & 0.05 & Lognormal & \multirow{2}{*}{$\begin{array}{c}\text { Huh et al. } \\
\text { [11] }\end{array}$} \\
\hline & Moment of inertia & varies & 1.0 & 0.05 & Lognormal & \\
\hline $\begin{array}{c}\text { Initial } \\
\text { geometric } \\
\text { imperfection }\end{array}$ & $\begin{array}{l}\text { Maximum lateral } \\
\operatorname{sway}(\Delta) \text { at the top }\end{array}$ & N/A & $H / 1,000^{\mathrm{a}}$ & 0.577 & Uniform & $\begin{array}{c}\text { Buonopane et al. } \\
\text { [9] }\end{array}$ \\
\hline \multirow{2}{*}{ Load $\left(\mathrm{kN} / \mathrm{m}^{2}\right)$} & Dead load & $3.6(2.2)^{\mathrm{b}}$ & 1.05 & 0.1 & Normal & \multirow{2}{*}{$\begin{array}{c}\text { Ellingwood et al. } \\
{[27]}\end{array}$} \\
\hline & Live load & $2.4(12,1.2)^{\mathrm{c}}$ & 1.0 & 0.25 & Gumbel & \\
\hline \multirow{2}{*}{ Live load ratio ${ }^{\mathrm{d}}$} & $K_{1}$ & 5 & 1.057 & 0.346 & Gumbel & \multirow{2}{*}{ Fitted distribution } \\
\hline & $K_{2}$ & 0.5 & 1.062 & 0.345 & Gumbel & \\
\hline
\end{tabular}

${ }^{\mathrm{a}} \mathrm{H} / 1,000$ is the mean value of the maximum lateral sway at the top of structure.

b $3.6 \mathrm{kN} / \mathrm{m}^{2}$ is the interior load of the building and $2.2 \mathrm{kN} / \mathrm{m}^{2}$ is the exterior façade load of the building.

${ }^{c} 2.4 \mathrm{kN} / \mathrm{m}^{2}, 12 \mathrm{kN} / \mathrm{m}^{2}$ and $1.2 \mathrm{kN} / \mathrm{m}^{2}$ are the nominal uniformly distributed live loads on the office floors, mechanical floor and roof, respectively.

d The nominal values of $K_{1}$ and $\mathrm{K}_{2}$ were calculated based on the nominal uniform live loads on office floors, mechanical floor and roof; their probabilistic characteristics (mean and standard deviation) were calculated using simulation and distribution type was determined through fitting methodology.

Two cases were considered regarding the correlation between the live loads on different floors. The first case assumes that the live loads on all the floors are fully correlated; that is, the same live load is applied on all the office floors (i.e. $2^{\text {nd }}$ to $21^{\text {st }}$ floors), whereas the ratio between the live loads on the office floor and mechanical floor (or roof) equals that between the corresponding nominal live loads. The second case assumes that the same live load is applied on all the office floors and that the live loads on the roof, mechanical floor and office floor are independent of each other. Let $K_{1}$ denote the ratio of the live load on the mechanical floor to that on the office floor, and let $K_{2}$ denote the ratio of the live load on the roof to that on the office floor. It follows that $K_{1}$ and $K_{2}$ are independent random variables in the second case. Furthermore, the resistance of the 
steel frame depends on $K_{1}$ and $K_{2}$, i.e. the relative magnitudes between the live loads on different floors. Therefore, the response surface for the resistance is a function of $K_{1}$ and $K_{2}$, in addition to the material and geometric properties in the second case. The Monte Carlo simulation was carried out to derive the probabilistic characteristics of $K_{1}$ and $K_{2}$ based on the probabilistic characteristics of the live loads on the roof, mechanical floor and office floor.

The initial geometric imperfection of the frame was assumed to be in the form of lateral sway linearly distributed along the height of the structure with zero sway at the base and the maximum sway $(\Delta)$ at the top (see Figure 3(c)) (Buonopane et al. [9]). It is further assumed that the initial imperfection exists in the N-S direction only. The probabilistic characteristics of the random variables considered in this study are summarized in Table 1. All the random variables were assumed to be independent of each other in the analysis.

\subsection{Analysis Results}

The reliability indices calculated from the FORM and the corresponding sensitivity factors associated with the random variables involved in the analysis are summarized in Table 2 . The table shows that the reliability index, $\beta_{1}$, for Case 1 (i.e. the live loads on all the floors are fully correlated) equals 3.59 and that the reliability index, $\beta_{2}$, for Case 2 (i.e. the live loads on the roof, mechanical floor and office floor are independent of each other) equals 3.54. These reliability index values are similar to those of the planar steel frames designed per AISC LRFD [1] and evaluated by Zhou and Hong [6]. Note that $\beta_{1}$ is slightly higher than $\beta_{2}$. This suggests that the spatial variability of the live load reduces the system reliability of the example frame. The impact of the spatial variability is however small for this example, because the live loads on the majority of the floors (i.e. office floors) were assumed to be fully correlated in Case 2.

The sensitivity factors for the moment of inertia and cross-sectional areas shown in Table 2 are almost zero, which suggests that the system reliability is insensitive to the inaccuracies in these two parameters. The sensitivity factors associated with the material properties indicate that the impact of the yield strength on the system reliability is, as expected, much higher than that of Young's modulus. Furthermore, the system reliability is somewhat sensitive to the inaccuracy in the magnitude of initial geometric imperfection. The live load has the most significant impact on the system reliability in that it is associated with the highest sensitivity factor, which equals approximately 0.75 for both Cases 1 and 2. Finally, the results for Case 2 indicate that the system reliability index is sensitive to $K_{1}$, i.e. the ratio between the live load on the mechanical floor and that on the office floor.

Sensitivity analyses were carried out to investigate the impact of the variability of the yield strength and magnitude of the initial geometric imperfection on the system reliability of the 3D frame example. The live loads on all the floors were assumed to be fully correlated in the sensitivity analysis. To expedite the analysis, the response surface for the resistance, $R$, was not adaptively constructed in the sensitivity analysis, but instead approximated by the response surface corresponding to the converged reliability index (i.e. $\beta_{1}$ ) obtained for Case 1 shown in Table 2. The sensitivity analysis results are shown in Figures 4 and 5. 
Table 2 Reliability Index, Failure Probability and the Sensitivity Factors

\begin{tabular}{|c|c|c|c|}
\hline \multicolumn{2}{|c|}{ Results } & Case 1 & Case 2 \\
\hline \multicolumn{2}{|c|}{ Reliability index } & 3.59 & 3.54 \\
\hline \multicolumn{2}{|c|}{ Failure probability } & $1.65 \times 10^{-4}$ & $2 \times 10^{-4}$ \\
\hline \multirow{9}{*}{$\begin{array}{l}\text { Sensitivity } \\
\text { factor }\end{array}$} & Yield strength & -0.5277 & -0.4608 \\
\hline & Young's modulus & -0.0251 & 0.0378 \\
\hline & Cross-sectional area & -0.00028 & 0.00025 \\
\hline & Inertial moment & $-1.18 \times 10^{-6}$ & $6.97 \times 10^{-6}$ \\
\hline & $\begin{array}{l}\text { Initial geometric } \\
\text { imperfection }\end{array}$ & 0.0955 & 0.0633 \\
\hline & Dead load & 0.3687 & 0.3462 \\
\hline & Live load & 0.7588 & 0.7438 \\
\hline & $K_{1}$ & - & 0.3244 \\
\hline & $K_{2}$ & - & -0.0620 \\
\hline
\end{tabular}

Figure 4 depicts the system reliability indices and corresponding failure probabilities versus the coefficients of variation (COV) of the yield strength with values ranging from 0.01 to 0.1 . The figure shows that the system reliability decreases as the COV of the yield strength increases. For example, the reliability index equals 3.59 and 2.97 corresponding to the COV values of 0.06 and 0.1 respectively. In other words, the system failure probability increases by almost one order of magnitude as the COV of the yield strength increases from 0.06 to 0.1 . This suggests that good quality control in the steel manufacturing process has a significant contribution to the system reliability of steel frames.

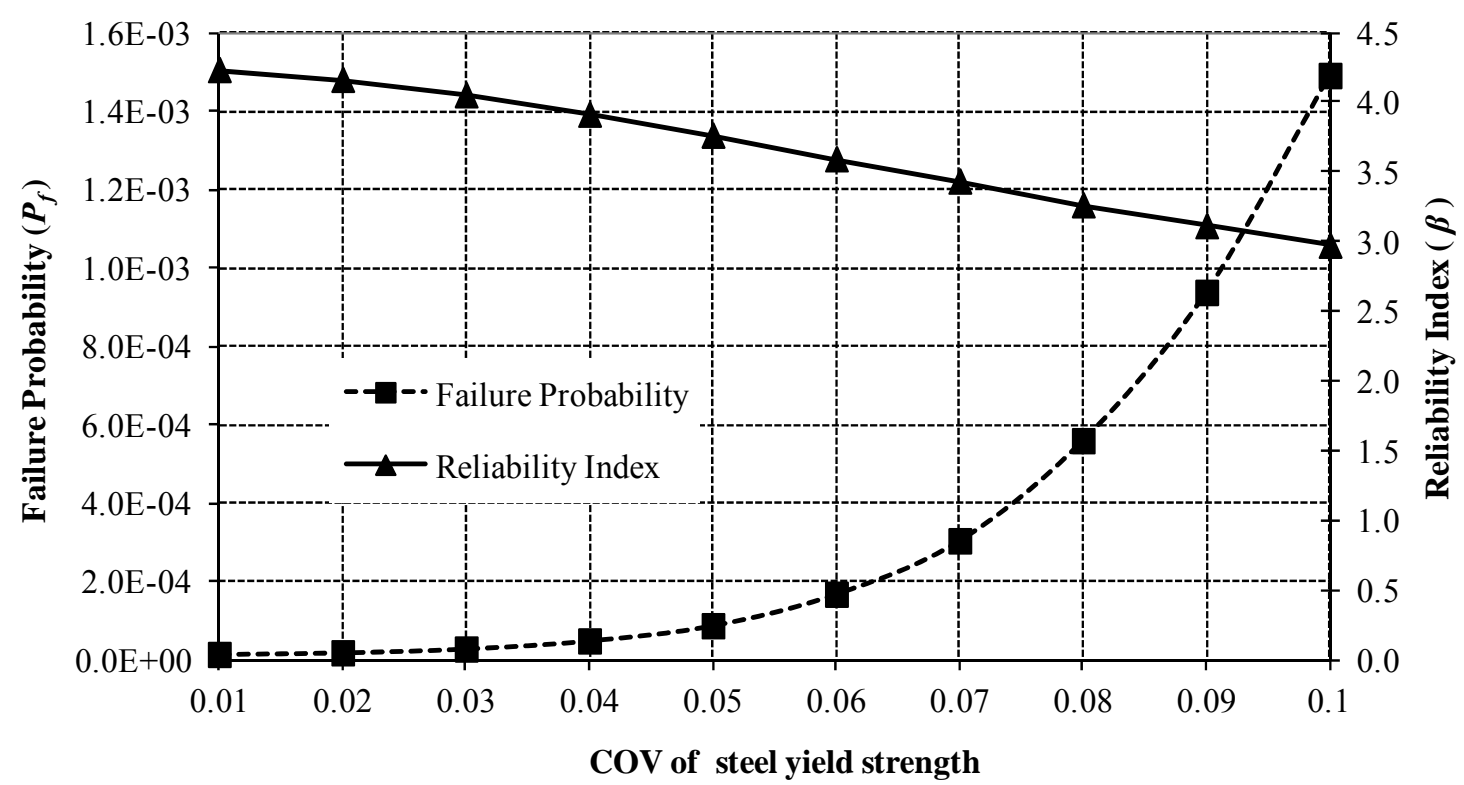

Figure 4. System Reliability Versus COV of Steel Yield Strength

Figure 5 depicts the system reliability as a function of the magnitude of the initial geometric 
imperfection characterized by the upper bound value of the maximum lateral sway that is assumed to be uniformly distributed with a lower bound of zero. The results indicate that the system reliability is relatively insensitive to the upper bound value of the maximum lateral sway as long as it is less than or equal to $H / 300$. For example, the system reliability index equals 3.62 corresponding to an upper bound of the maximum lateral sway of $H / 600$, and decreases to 3.40 if the upper bound increases to $H / 300$. However, the system reliability decreases drastically if the upper bound of the maximum lateral sway is greater than $H / 250$ : the reliability index declines from 3.22 to 2.02 if the upper bound of the maximum lateral sway increases from $H / 250$ to $H / 150$. It can be inferred that the system reliability for the example structure is markedly reduced if the upper bound of the maximum lateral sway is greater than twice the maximum allowable erection tolerance $(H / 500)$ specified by AISC [2] assuming that the maximum lateral sway is uniformly distributed with a lower bound of zero.

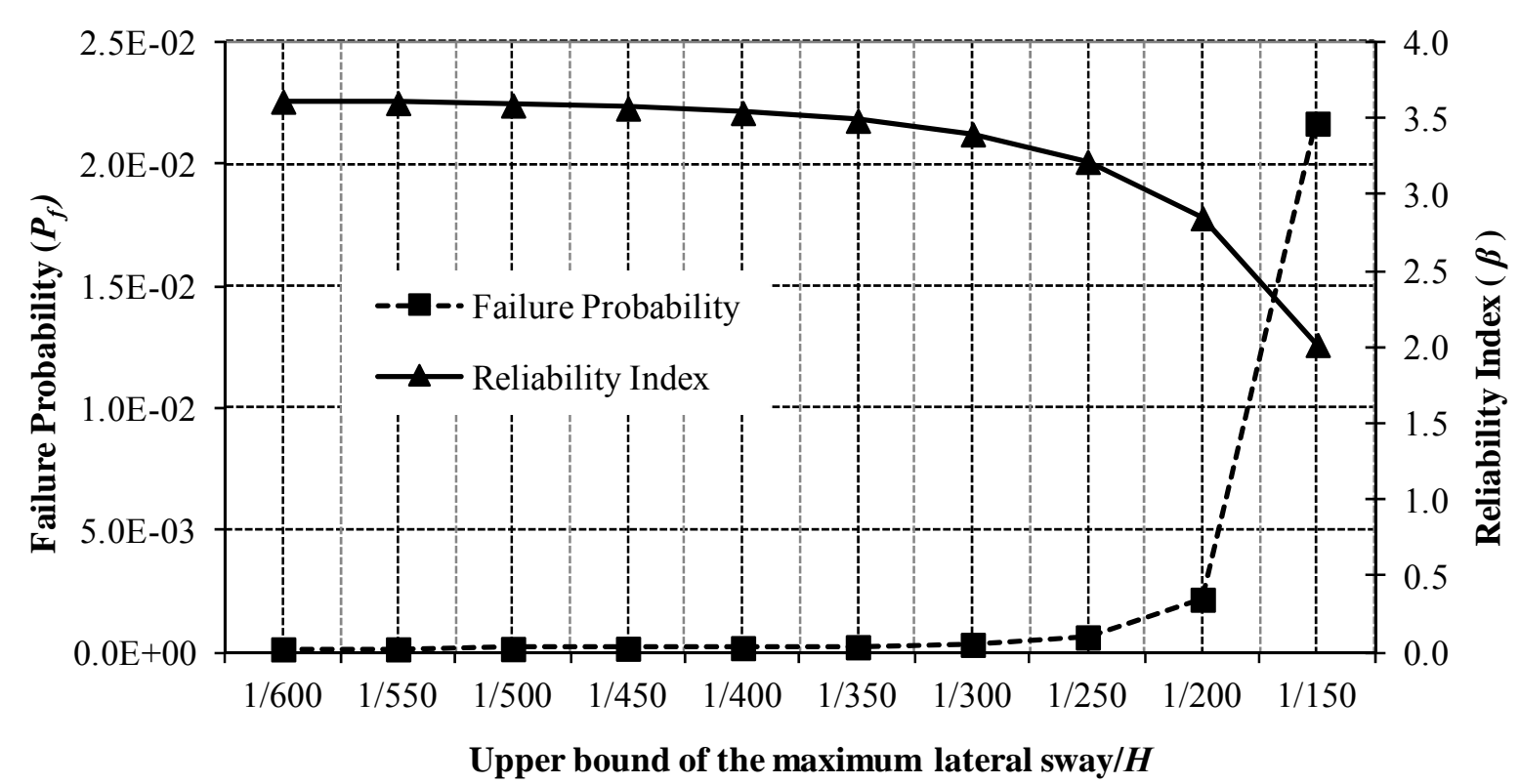

Figure 5. System Reliability Versus the Magnitude of Initial Geometric Imperfection

\section{CONCLUSIONS}

The system reliability of a 3D steel frame with respect to the collapse limit state under the dead and live loads was evaluated using the FORM-based adaptive response surface approach in this study. The structure considered is a typical high-rising office building designed by Ziemian [24] per AISC LRFD [2]. The advanced analysis approach as implemented in SAP2000 that accounts for the $P-\Delta$ and large displacement effect as well as the nonlinear material property was employed to obtain the resistance, i.e. collapse load, of the structure. In the reliability analysis, the uncertainties in the steel yield strength, Young's modulus, cross-sectional area and moment of inertia of the frame members, initial geometric imperfections of the frame, dead load and live load as well as the spatial variability of the live load were taken into account. To achieve a trade-off between computational efficiency and robustness, the resistance of the frame was approximated using the response surface approach based on the collapse loads evaluated from the advanced analysis at sampling points that are adaptively selected during the reliability analysis. The system reliability of the frame was calculated using the FORM based on the adaptively evaluated response surfaces for the resistance.

The system reliability of the frame was evaluated for two cases, namely ignoring and considering 
the spatial variability of the live load. For the former case, the live loads on all the floors in the frame were assumed to be fully correlated. For the latter case, the live loads on the office floors were assumed to be fully correlated; however, the live loads on the office floor, mechanical floor and roof were assumed to be independent of each other. The analysis results indicate that the spatial variability of the live load reduces the system reliability. The impact of such spatial variability on the reliability of the example frame is small due to the fact that the live loads on the majority of the floors were assumed to be fully correlated for Case 2 .

The calculated system reliability of the example 3D steel frame is similar to that of the planar steel frames designed per AISC LRFD [1] and reported in the literature (Hong and Zhou [6]). Sensitivity analyses were carried out to investigate the impact of the variability of the steel yield strength and magnitude of the initial geometric imperfection on the system reliability of the example frame. The analysis results indicate that the system failure probability of the frame increases by almost one order of magnitude if the COV of the yield strength increases from 0.06 to 0.1 . This suggests that quality control of the steel manufacturing process has a large impact on the system reliability of steel frames. The sensitivity analysis results also indicate that the system reliability of the example frame decreases drastically if the upper bound of the uniformly distributed maximum later sway that characterizes the initial geometric imperfection is greater than $H / 250$, which is twice the maximum allowable erection tolerance specified by AISC [2]. Finally, it should be emphasized that the analysis results obtained in this paper are with respect to the particular example considered. However, the methodology for evaluating the system reliability of 3D steel frames presented here can be applied to other types of $3 \mathrm{D}$ steel frame structures, for example, the braced steel frames.

\section{ACKNOWLEDGEMENTS}

The financial support for this research is provided by the Faculty of Engineering at Western University and Natural Sciences and Engineering Research Council of Canada (NSERC) Discovery Grant. Their support is gratefully acknowledged. The constructive comments provided by the anonymous reviewer are gratefully appreciated.

\section{REFERENCES}

[1] American Institute of Steel Construction (AISC), "Load and Resistance Factor Design Specification for Structural Steel Buildings", AISC, Chicago, 1986.

[2] American Institute of Steel Construction (AISC), "Specification for Structural Steel Buildings", AISC, Chicago, 2005.

[3] Canadian Standards Association (CSA), "Design of Steel Structures", CSA S16-09. CSA, Mississauga, Canada, 2009.

[4] Ellingwood, B.R., "Probability-based Codified Design: Past Accomplishments and Future Challenges", Structural Safety, 1994, Vol. 13, No. 3, pp. 159-176.

[5] Ellingwood, B.R., "LRFD: Implementing Structural Reliability in Professional Practice", Engineering Structures, 2000, Vol. 22, No. 2, pp. 106-115.

[6] Zhou, W. and Hong, H.P., "System and Member Reliability of Steel Frames", Steel and Composite Structures, 2004, Vol. 4, No. 6, pp. 419-435.

[7] Li, J. and Li, G., "Reliability-based Integrated Design of Steel Portal Frames with Tapered Members", Structural Safety, 2004, Vol. 26, No. 2, pp. 221-239.

[8] Buonopane, S.G. and Schafer, B.W., "Reliability of Steel Frames Designed with Advanced Analysis”, Journal of Structural Engineering, ASCE, 2006, Vol. 132, No. 2, pp. 267-276. 
[9] Buonopane, S.G., "Strength and Reliability of Steel Frames with Random Properties", Journal of Structural Engineering, ASCE, 2008, Vol. 134, No. 2, pp. 337-344.

[10] Chen, W.F., Goto, Y. and Liew, J.Y.R., "Stability Design of Semi-rigid Frames", John Wiley \& Sons, Inc., New York, 1996.

[11] Huh, J.W., Lee, S.Y. and Haldar, A., "Reliability Evaluation Using Finite Element Method", Proceedings of the $4^{\text {th }}$ International Symposium on Uncertainty Modeling and Analysis, College Park, Maryland, 2003

[12] Hadianfard, M.A. and Razani, R., "Effects of Semi-rigid Behavior of Connections in the Reliability of Steel Frames", Structural Safety, 2003, Vol. 25, No. 2, pp. 123-138.

[13] Zhang, H., Chandrangsu, T. and Rasmussen, K.J.R., "Probabilistic Assessment of the Strength of Steel Scaffold Systems Using Advanced Analysis", Proceedings of the $10^{\text {th }}$ International Conference on Structural Safety and Reliability, Osaka, Japan, 2009.

[14] Zhang, H., Chandrangsu, T. and Rasmussen, K.J.R., "Probabilistic Study of the Strength of Steel Scaffold Systems", Structural Safety, 2010, Vol. 32, No. 6, pp. 393-401.

[15] Zhang, H., Rasmussen, K.J.R. and Ellingwood, B.R., "Reliability Analysis of Steel Scaffold Shoring Structures", Proceedings of the $11^{\text {th }}$ International Conference on Applications of Statistics and Probability in Civil Engineering, Zurich, Switzerland, 2011.

[16] Computer and Structures Inc. (CSI), "SAP2000 Analysis Reference Manual”, CSI, Berkeley, CA, 2008.

[17] Rackwitz, R. and Fissler, B., "Structural Reliability under Combined Random Load Sequences", Computers \& Structures, 1978, Vol. 9, No. 5, pp. 489-494.

[18] Low, B.K. and Tang, W.H., "Efficient Spreadsheet Algorithm for First-order Reliability Method", Journal of Engineering Mechanics, ASCE, 2007, Vol. 133, No. 12, pp. 1378-1387.

[19] Breitung, K., “Asymptotic Approximation for Multinormal Integrals", Journal of Engineering Mechanics, ASCE, 1984, Vol. 110, No. 3, pp. 357-366.

[20] Der Kiureghian, A., Lin, H.Z. and Hwang, S.J., "Second-order Reliability Approximations", Journal of Engineering Mechanics, ASCE, 1987, Vol. 113, No. 8, pp. 1208-1225.

[21] Huh, J. and Haldar, A., "Seismic Reliability of Non-linear Frames with PR Connections Using Systematic RSM", Probabilistic Engineering Mechanics, 2002, Vol. 17, No. 2, pp. 177-190.

[22] Zhao, Y.G. and Ono, T., "System Reliability Evaluation of Ductile Frame Structures", Journal of Structural Engineering, 1998, Vol. 124, No. 6, pp. 678-685.

[23] Bucher, C.G. and Bourgund, U., "A Fast and Efficient Response Surface Approach for Structural Reliability Problems”, Structural Safety, 1990, Vol. 7, No. 1, pp. 57-66.

[24] Ziemian, R.D., "Advanced Methods of Inelastic Analysis in the Limit States Design of Steel Structures", PhD dissertation, Cornell Univ., Ithaca, N.Y., 1990.

[25] Ziemian, R.D., McGuire, W. and Deierlein, G.G., "Inelastic Limit States Design. Part II: Three-dimensional Frame Study", Journal of Structural Engineering, 1992, Vol. 118, No. 9, pp. 2550-2568.

[26] Bartlett, F.M., Dexter, R.J., Graeser, M.D., Jelinek, J.J., Schmidt, B.J. and Galambos, T.V., "Updating Standard Shape Material Properties Database for Design and Reliability", Engineering Journal, AISC, 2003, Vol. 40, No. 1, pp. 2-14.

[27] Ellingwood, B.R., Galambos, T.V., MacGregor, J.G. and Cornell, C.A., "Development of Probability Based Load Criterion for American National Standard A58", National Bureau of Standard Special Publication 577, Faithersburg, Md, 1980. 